\title{
Sedating and stimulating antihistamines: old problems and new insights
}

Citation for published version (APA):

Theunissen, E. L. (2005). Sedating and stimulating antihistamines: old problems and new insights.

[Doctoral Thesis, Maastricht University]. Maastricht University. https://doi.org/10.26481/dis.20051208et

Document status and date:

Published: 01/01/2005

DOI:

10.26481/dis.20051208et

Document Version:

Publisher's PDF, also known as Version of record

\section{Please check the document version of this publication:}

- A submitted manuscript is the version of the article upon submission and before peer-review. There can be important differences between the submitted version and the official published version of record.

People interested in the research are advised to contact the author for the final version of the publication, or visit the DOI to the publisher's website.

- The final author version and the galley proof are versions of the publication after peer review.

- The final published version features the final layout of the paper including the volume, issue and page numbers.

Link to publication

\footnotetext{
General rights rights.

- You may freely distribute the URL identifying the publication in the public portal. please follow below link for the End User Agreement:

www.umlib.nl/taverne-license

Take down policy

If you believe that this document breaches copyright please contact us at:

repository@maastrichtuniversity.nl

providing details and we will investigate your claim.
}

Copyright and moral rights for the publications made accessible in the public portal are retained by the authors and/or other copyright owners and it is a condition of accessing publications that users recognise and abide by the legal requirements associated with these

- Users may download and print one copy of any publication from the public portal for the purpose of private study or research.

- You may not further distribute the material or use it for any profit-making activity or commercial gain

If the publication is distributed under the terms of Article $25 \mathrm{fa}$ of the Dutch Copyright Act, indicated by the "Taverne" license above, 


\section{SEDATING AND STIMULATING ANTIHISTAMINES; OLD PROBLEMS AND NEW INSIGHTS}

Eef Lien Theunissen 


\section{Colofon}

(C) E. Theunissen, Maastricht 2005

(c) Cover design: Theo Buiting

Layout : D\&L graphics:

John Derwall \& Eric Lemmens

Iris van Hezik

www.dlgraphics.n!

proefschrift@dlgraphics.nL

Printed by : Ponsen \& Looijen bv

ISBN-10 : 9085900077

ISBN-13 : 9789085900078 


\title{
SEDATING AND STIMULATING ANTIHISTAMINES; OLD PROBLEMS AND NEW INSIGHTS
}

\author{
Proefschrift \\ ter verkrijging van de graad van doctor aan de Universiteit Maastricht, \\ op gezag van de Rector Magnificus, Prof, mr. G.P.M.F. Mols \\ volgens het besluit van het College van Decanen, \\ in het openbaar te verdedigen \\ op donderdag 8 december 2005 om 14:00 uur
}

door

\section{Eef Lien Theunissen}

Geboren op 1 mei 1977

te Hasselt 


\section{Promotor}

Prof. dr. W. J. Riedel

\section{Copromotor}

Dr. J.G. Ramaekers

\section{Beoordelingscommissie}

Prof dr. J. Jolles (voorzitter)

Prof dr. R Goebel

Prof dr. EAL. Griez

Prof. dr. 1. Hindmarch (University of Surrey)

Prof. dr. B. Leonard (National University of Ireland)

The research described in this thesis was conducted at the Brain \& Behavior Institute, the department of Neurocognition, University of Maastricht. The studies described in this thesis were funded by Pierre Fabre Medicaments, France (ch 2, 3).

Financial support for the publication of this thesis from the Dutch Ministry of Transport and NV Organon Nederland is greatly appreciated. 


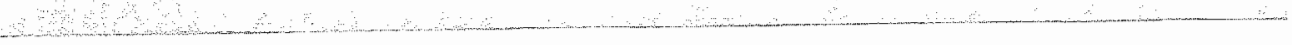


CONTENTS

Chapter 1 General introduction

Chapter 2 A dose ranging study of the effects of mequitazine on actual driving, memory and psychomotor performance as compared to dexchlorpheniramine, cetirizine and placebo

Chapter 3 Repeated-dose effects of mequitazine, cetirizine and dexchlorpheniramine on driving and psychomotor performance

Chapter 4 Stimulating effects of H1-antagonists

Chapter 5 Stimulating effects of fexofenadine under high workload conditions. A combined neurophysiological and behavioral approach

Chapter 6 Effects of a high dose of fexofenadine on cognitive function and motor impulsivity

Chapter 7 Fexofenadine's potential to inhibit dopamine reuptake in healthy volunteers: a SPECT study

Chapter $8 \quad$ General discussion

Summary

Samenvatting

Dankwoord

Curriculum Vitae

Publications 


\section{General introduction}

\section{ChAPTER 1}


Chapter 1 
As much as $20 \%$ to $30 \%$ of the population is estimated to suffer from allergic conditions such as allergic rhinitis, hay fever or urticaria (Nathan, Meltzer, Selner, \& Storms, 1997; Steerenberg et al., 2000). Allergic conditions do not only affect the patients" heatth but also thave a derrimental impact on a patient's qualiry of life (Meltzer, Nathan, Selner, \& Storms, 1997; Kremer, den Hartog, \& Jolles; 2002). Allergy patients may experience impairment in their work, their sleep, and their social life (Meltzer et al., 1997; Craig, McCann, Gurevich, \& Davies, 2004). Due to their condition, allergy patients also pay more visits to physicians and use more medication, which creates an extra financial load. An American survey estimated the mean cost per patient per year to be $\$ 56$ for prescription medication, and another $\$ 56$ for nonprescription medication (Storms, Meltzer, Nathan, \& Selner, 1997). Oral antihistamines are the first-line medications for treating allergic conditions and in 2002, 2.5 million prescriptions for oral antihistamines were processed by pharmacists in The Netherlands, with a total turnover of 50 million euros (Stichring Farmaceurische Kengetallen, 2003). The impact of this condition on the health cate system and society is consequently significant (Blaiss, 2000; Burton, Conti, Chen, Schultz, \& Edington, 2001; Weiss, Haus, \& likura, 2004). The toral cost of allergies for society does not only include the direct costs of treatment, but also indirect costs due to loss of work productivity and absenteeism.

The most important concern of parients with allergies is to get quick relief from annoying symptoms, such as itching, sneezing, teary eyes or a running nose, without experiencing undesirable side effects. Antihistamines or $\mathrm{H} 1$-antagonists are highly effective and act fast in relieving the symptoms in most patients. However, the majority of patients report side effects when using these antihistamines. The most frequently reported side effects include gastro-intestinal complaints, dry mouth but most importantly drowsiness. This drowsiness can be so serious that it affects patients' daily activities, like studying, working or car driving. So, although there is a relief of symptoms, the inconvenience of adverse effects may be more troubling than suffering from the untreated condition and eventually patients may prefer to stop the treatment because of the discomfort.

It has been repeatedly demonstrated that there is a clear relationship berween antihistamines and sedation or drowsiness. However, it has also been demonstrated that large differences exist between individual antihistamines; some causing excessive sedation, some causing no sedation at all and some even producing acrivation. The present thesis focuses on pharmacodynamic differences between sedating antihistamines and tries to asses the pharmacological mechanism which distinguishes stimulating antihistamines from sedating antihistamines.

The present chapter gives an introduction on how antihistamines bring about their therapeutic action and how they act in the brain, as well as the peripheral and central function of histamine. Furthermore, this chapter will introduce and evaluate the classification of antihistamines into first and second generation antihistamines. At the end, the aims and outlines of this dissertation are outlined.

\section{HISTAMINE}

Histamine is an endogenous substance which is relleased when an allergic person comes into contact with an allergen. The first exposure of an allergen to the inmune system causes $\lg$ antibodies to be secreted and these attach to the cell surface of mast cells. Mast cells occur 
in all body tissues but particularly in areas which are typical sites of allergic reactions, such as the skin, nose, throat, llungs, and the gastrointestinal tract. Ar a second encounter with the allergen, the allergen binds to the $\operatorname{lgE}$ antibodies, causing the mast cells to release histamine and other chemicals. Mast cells contain large amounts of histamine, and when released this causes the typical symptoms of allergies like rashes, a runny nose and teary eyes (Feldman, Meyer, \& Quenzer, 1997; van Wijk \& Vaessen, 2003).

Histamine also acts as a neurotransmitter in the CNS and is involved in several central processes such as arousal, cognition and homeostatic systems (Brown, Stevens, \& Haas, 2001). Histamine-releasing neurons are located exclusively in the tuberomamillary nucleus of the posterior hypothalamus, a region which has repeatedly been demonstrated to be important in wakefulness (Lin, 2000; Saper, Chou, \& Scammell, 2001). Histaminergic neurons project to almost all regions of the brain, especially to areas involved in sleep-wake control, i.e. the cortex, thalamus, preoptic/anterior hypothalamus (Panula, Yang, \& Costa, 1984; Lin, 2000). Impairing neuronal histamine transmission causes increases in sleep while enhancement of histaminergic neurotransmission increases wakefulness (Monti et al.. 1991; Lin, 2000). Other monoamine neurotransmitters, such as serotonin and noradrenaline are also important factors in the control of sleep and wakefulness. Together with histamine neurons, these neurons have been found to fire actively during wakefulness and stop firing during REM sleep (Saper et al., 2001).

At present, there are three types of histamine receptors identified; $\mathrm{H} 1, \mathrm{H} 2$ and $\mathrm{H} 3$. All three receptors have been found in the brain and periphery (Hill et al., 1997). H1-receptors are the main target for treatment of allergies and are found in several peripheral tissues, including the smooth muscle from the airways and the gastrointestinal tract. Peripheral H2receptors are mainly found in gastric cells and have a potent effect on gastric acid secretion. The recently discovered $\mathrm{H} 3$-receptor has also been found peripherally where it influences peripheral neurotransmission (e.g. in the gastrointestinal tract and the cardiovascular system). The central $\mathrm{H} 3$-receptor is an auto- and heteroreceptor, in that it influences its own neurotransmission as well as that of other neurotransmitter. By blocking the $\mathrm{H} 3$ receptor, $\mathrm{H} 3$-antagonists cause an increase in histamine levels and this has been related to improvements in cognitive functions such as learning and memory in animals (Prast, Argyriou, \& Philippu, 1996; Ligneau et all., 1998).

\section{ANTIHISTAMINES}

Antihistamines' main target for achieving their therapeutic effect is the peripheral Hl histamine receptor. Most antihistamines are selective for the H1-receptors and have little effect on the $\mathrm{H} 2$ or $\mathrm{H} 3$ histamine receptors. Besides $\mathrm{H} 1$-receptor blockade, nearly all antihistamines produce weak to pronounced blockade of cholinergic, serotonergic and adrenergic neurotransmission (Snyder \& Snowman, 1987; Simons, 1989).

The group of antihistamines includes chemically different compounds which all share the pharmacological capacity to prevent histamine from binding at its receptor and consequently diminish the symproms of allergies. Most antihistamines are rapidly absorbed after oral administration and generally give relief of symptoms within 1 to 2 hours. The elimination half-life of antihistamines varies considerably, ranging from a couple of hours to a few days (Simons, Simons, Chung, \& Yeh, 1987; Gonzalez \& Estes, 1998; Slater, Zechnich, \& Haxby, 1999; Golightly \& Greos, 2005). 
A distinction between first and second generation antihistamines is generally made. This division was intially made to distinguish sedating from non-sedating antilistamines.

\section{THE FIRST GENERATION}

First generation antihistamines readily cross the blood brain barrier and bind to $\mathrm{H} 1$ receptors in the CNS (Quach, Duchemin, Rose, \& Schwart, 1979; Nicholson at al., 1991). As a result, these drugs cause somnolence and various studies demonstrated a correlation between the amount of H1-occupancy and the sedative properties of antihistamines (Rose, Quach, Llorens, \& Schwartz, 1982; Tagawa et al., 2001; Tashiro et al., 2002). The sedating effect of first generation antihistamines is such that some of them are even prescribed as sleeping aids. But of course, when used as a treatment for allergies, the sedative side effects are unwanted, especially when they interfere with parient's daily funcrioning. Over the years, it has become evident that the use of first generation antihistamines is related to a decrease in work productivity (Burton et al., 2001), increased absenteeism from work or school (McLoughlin et al., 1983; McMenamin, 1994) and also with an increased risk at traffic accidents (Cimbura, Lucas, Bennet, Warren, \& Simpson, 1982; Ray, Foughr, \& Decker, 1992; Leveille et al., 1994) and occupational injuries (Gilmore, Alexander, Mueller, \& Rivara, 1996).

First generation anthistamines include drugs such as diphenhydramine, clemastine, chlorpheniramine and triprolidine, and are in most countries available without a prescription (over the counter). Because they are freely available and usually inexpensive, there are still a lot of patients who use these sedating drugs, even though less sedating antihistamines are now available.

\section{THE SECOND GENERATION}

In the 1980's, new antihistamines were developed, which were less sedating. These second generation antihistamines are as effective as the first generation in treating allergic rhinitis. It has been suggested that these drugs are less sedating because they do not cross the blood brain barrier as easily (Passalacqua et al, 1996; Tashiro et al., 2002). They are often called 'non-sedating" antihistamines, but several studies have demonstrated that this tem is not fully justified. Although they are clearly less sedating than firt generation antihistamines, patients occasionally report sedative side effects when treated with second generation antihistamines, especially when the therapeutic dose is exceded (Mann, Pearce, Dunn, $\&$ Shakir, 2000; Casale et al., 2003). Experimental sudies have also demonstrated that this generation of antihistamines has the potential to impair subjects" performance on several tasks such as cognitive, attention and driving tasks (O'Hanlon \& Ramaekers, 1995; Bender, Berning, Dudden, Milgrom, \& Tran, 2003).

There is a wide variety in the chemical structure of second generation antihistamines available, and every now and then, new drugs are developed and introduced on the market. One second generation antihistamine that is frequently used, and is discussed in this dissertation, is cetirizine. Cetirizine has been reported to be highly effective in reducing patients" symptoms. The reports on its sedative effects are often inconsistent, however. Patients report drowsiness after treatment with cetirizine in most studies (Meltzer, Weiler, \& Widlitz, 1996; Mann et al., 2000; Salmun et al., 2000) but not in others (Gengo, 
Dabronzo, Yuirchak, Love, \& Miller, 1987; Gengo \& Gabos, 1987). Also objective measures result in conflicting findings for cetirizine; with most studies reporting that cetirizine had no impairing effect on psychomotor performance, cognition and driving performance (Seidel, Cohen, Bliwise, \& Dement, 1987; Volkerts, Van Willigenburg, Van Laar, \& Maes, 1992; Walsh, Muehlbach, \& Schweitzer, 1992; Schweitzer, Muehlbach, \& Walsh, 1994; Hindmarch, Johnson, Meadows, Kirkpatrick, \& Shamsi, 2001; Shamsi, Kimber, \& Hindmarch, 2001), whille others did find that these functions were impaired (Ramaekers, Uiterwijk, \& O'tlanlon, 1992, Nicholson \& Turner, 1998; Vermeeren, Ramaekers, \& OHanlon, 2002). Other second generation antihistamines such as acrivastine, terfenadine, loratadine, ebastine and mizolastine have all been tested frequently and have shown to cause impairment but mostly only after higher than their therapeutic dose (Mann et al., 2000; Bender et al., 2003).

\section{RECENT DEVELOPMENTS}

The group of antihistarmines consists of a wide variety of compounds with different pharmacokinetic and pharmacodynamic properties. As described above, the most often used classification is based on the presence or absence of sedation. However, it has been repeatedly demonstrated that this classification is not that clear-cut.

Recently, new antihistamines have been developed from existing compounds. These new antihistamines, fexofenadine, levocetirizine and desloratadine are the active metabolites of terfenadine, cetirizine and loratadine and were found to be as efficient as other antihistamines. Up till now, no signs of impairment have been demonstrated for these antihistamines, even after higher than their therapeutic dose (Hindmarch, Shamsi, Stanley, \& Fairwearher, 1999; Nicholson, Stone, Turner, \& Mills, 2000; Weiler et al., 2000; Hindmarch et al., 2001; Bower et al., 2003; Monroe et al., 2003; Verster, de Weert et al., 2003; Verster, Volkerts et al., 2003; Valk, Van Roon, Simons, \& Rikken, 2004). In some studies, fexofenadine and desloratadine even had mild stimulating effects (Vermeeren \& O'Hanlon, 1998; Vuurman, Rikken, Muntjewerff, de Halleux, \& Ramaekers, 2004). Together, these findings suggest that the active metabolites are less sedating than the parent compounds.

Because fexofenadine, desloratadine and levocetirizine are relatively free of sedative effects, they might be preferred by patients over first and probably also over second generation antihistamines. These antihistamines are not yet classified as a distinctive group, but some researchers have suggested to group them in a new category; the third generation antihistamines.

\section{AIM OF THE DISSERTATION}

This dissertation focuses on the psychoactive effects of antihistamines. The most often reported psychoactive effect of antihistamines is sedation or drowsiness. These sedating effects of antihistamines are consistent with the role of histamine in arousal processes and by blocking $\mathrm{Hl}$ - receptors, antihistamines interact with these processes. In order to get a full view of the sedating potential of antihistamines, they need to be tested extensively using sensitive methods. In addition, it is necessary to examine whether effects are dose dependent and persistent over time.

Stimulating effects of $\mathrm{HI}$-antagonists are less well known and seem in conflict with the 
idea that blockade of the histamine receprors causes sedarion, Nonetheless, several studies have reported stimulating effecrs of antihistamines such as terfenadine and fexofenadine. In the present dissertation, reports of stimularing effects of antihistamines are collected and reviewed. Furthermore, high workload tasks and electrophysiological neasure are used to find further evidence of a stimulating effect of antihistamines. Eventually, the pharmacological mechanism responsible for the stimulating effect of antihistamines is explored.

\section{OUTLINE OF THE DISSERTATION}

In chapter 2 and chapter 3 , it is investigated whether a s0-called non-sedating antihistamine does affect cognitive function and actual driving performance as compared to placebo. Chapter 2, in addition, tries to answer the question whether this anthistamines sedating effects are dose dependent, while chapter 3 examines if behavional tolerance occurs after repeated dosing.

In chapter 4, all the evidence of antihistamines with stimulating effects is gathered and reviewed. Numerous studies demonstrating significant and non-significant better performance after treatment with fexofenadine, terfenadine, ebastine or desloratadine, were discussed. This chapter also explores several possible pharmacological mechanisms that could explain the stimulating effect of antihistamines.

In chapter 5 it is hypothesized that stimulating effecs of antihistamines are more prominent under high workload conditions and after high doses. Therefore, the effects of two doses of fexofenadine in healthy subjects are investigated in cognitive tasks with increasing workloads. In addition, event related potentials are measured during task performance in order to see if the underlying neurophysiological processes show evidence of stimulation.

In chapter 6, the hypothesis that a high dose of fexofenadine improves healthy subjects' psychomotor performance and affects impulsivity control is investigated. This chapter describes a between subject design study performed to compare the effects of $360 \mathrm{mg}$ of fexofenadine with placebo.

In chapter 7 , a hypothesis about the cause of the stimularing effect of fexofenadine is investigated. Using SPECT-scans, it is investigated whether fexofenadine causes a blocking of the dopamine transporter in the striatum of healthy volunteers.

In chapter 8 a few general issues concerning research into antihistamines are discussed. In addition, the implications of the findings of this dissertation are put in a broader perspective and suggestions for further research are proposed. 
Chapter 1 


\section{Gencral inmoduction}

\section{REFERENCES}

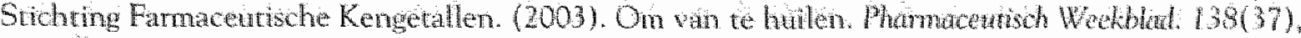
1259.

Bender, B. G. Berning, S., Dudden, R., Milgrom, H. S Tran, Z. V. (2003). Sedation and performance imparment of diphenhyorame and second-generation anthistamines: anera-analysis. Jotmal of Allergy and Clinical lmmunotogy, $111(4), 770 \% 776$.

Blaiss, M. S. (2000). Cognitive, social, and economic costs of allergic thinitis. Allergy and asthmat procedings the official jownal of regional and state allergy societies, 21(1),7-13.

Bower, E. A, Mowre, J. L. Moss, M., Selby, K. A., Austin, M. \& Meeves, S. 2003). The effects of single-dose fexofenadine, diphenhydramine, and placebo on cognirte performance in fligh persomnel. Aafation Space and Enwironmental Mediche, 74(2), $145-152$.

Brown, R. E., Stevens, D. R., \& Haas, H. L. (2001). The phystology of brain histamine Progress in Neurobiology, 63(6),637-672.

Burton, W. N., Conti. D. J., Chen, C. Y., Schult:, A. B., S Edingten, D. W. (2001). The impace of allergies and allergy treatment on worker productivity. Jommal of Ocapatonal and Enwhromental Medicine, 43(1), 64-71.

Casale, T. B., Blaiss, M. S, Gelfand, E., Gilmore, T., Harvey, P. D., Hindmarch, I., Simons, F. E., Spangler, D. L., Szefler, S. J., Terndrup, T. E. Waldman, S. A., Weller, J. \& Wong, D. F (2003). First do no ham: managing antihistamime impatment in pattents with allergic thinits. foumal of allergy and cinical immunology. 111(5), 5835.842 .

Cimbura, G. Lucas, D. M., Bennetr, R. C., Warren, R. A. E Simpson, H. M. (1982). Incidence and toxicological aspects of drags detected in 484 fatally injured arvers and petistrims in Ontario. Jownal of Forensic Sciences, 27(4),855-867.

Craig, T. J., MoCann, J. L., Gurevich, F, S Davies, M. J. (2004). The correlation berween allergic rhinitis and sleep disturbance. Joumat of allergy and dinical immunology, $114(5$ Supply, 5139.145 .

Feldman, R. S., Meyer, J. S. \& Quenzer, L. F. (1997). Principles of Nearopsychopharmacology. Sunderland: Sinouer.

Gengo, F M., Dabronzo, J., Yurchak, A., Love, S., \& Miller, J. K. (1987). The relative antihistaminic and psychomotor effects of hydroxyzine and cetirizine. Clinical phamacology and theraperaics, $42(3), 265-272$

Gengo, E.M. \& Gahos, C. (1987). Anrihistamines, drowsiness, and psychomour impairment: central nervous system effect of ceririzine. Anmals of allergy, $59(6 \mathrm{Pt} 2), 53.57$.

Gilmore, T. M. Alewander, B. H. Mueler, B. A., Q Rivara, F. P. (1996). Qcequational injurics and medication use. American Jownal of Tudustral Medicme, 30(2), 234.230.

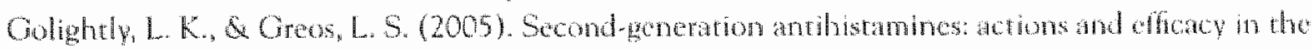
management of allergic disorders. Drugs, $65(3), 341-384$.

Gonzalez, M. A. \& Estes, K. S. (1998). Pharmacokineric overwew ol oral secondegeneration H1

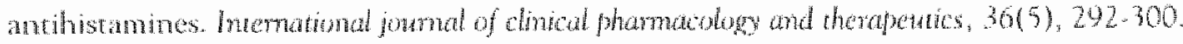

Hill, S. J., Gandin. C. R. Timmeman, H., Schwarz, J. C. Shanklew, N. P., Young, J. M. Schunuk, W., Lewi, R., \& Haas, H. L. (1997). International Union of Pharmaculogy XII Chassification of histamine receptors. Phamacoldgical reviens, 49(3), 253-278.

Hindmarch, 1. Johnson, S, Meadows, R., Kirkparick, T., \& Shamsi, Z. (2001). The wate and sulchronic effects of levoctirine, cetrizine, loratadine, promethazine and plactwo on couguive function, psychomotor perfomance, and weal and flare. Choment medicat rescarch and opinion, $17(4), 241-255$. 


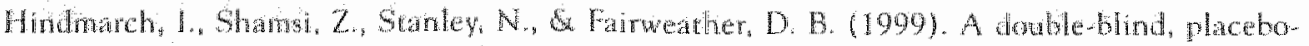

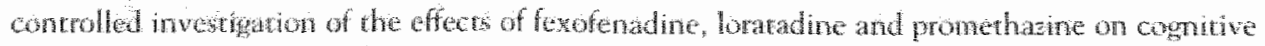

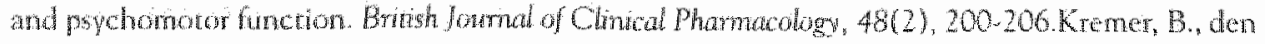
Hartog, H. M. \& folls, J. (2002). Rehrionship between allergic thinis, disturbed cognitive functions and psychological well-beng. Clincal and experimenal allergy joumal of the British Society for Allergy and Clinical Immonology, 32(9), 1310-1315.

Levelle, S. G. Bucher, D. M. Koepsell, T. D., McCloske, L. W. Wolf, M. E., \& Wagner, E. H. (1994). Pspchoutive medications and injurious nutor vehicle collisions imolving older drivers. Epiderniologigy, 5(6),591-598.

Ligneau, X., Lin, J., Vanni Mercier, G., Jonvet, M., Mair, J. L., Ganellin, C. R., Srark, H., Elz, S., Schunack, W. \& Schwart, J. (1998). Neurochemical and behavoral effecs of ciproxifan, a potent histamine H3-receptor antagonist. Jowmal of pharmacoldgy and experimenal tharapeutics. $2872), 658-666$

Lin. ). S. (2000). Brain structures and mechanisms involved in the control of cortical activarion and wakefulness, with emphasis on the posterior hypothalamus and histaminergic nearons. Sleve Medicine Reviews, 4(5), 471-503.

Manm, R. D. Pearce, C. L., Dumn, N., S. Shakir, S. (2000). Sedation with "non-Sedating" antihistamines: four prescription-event monitoring studies in general practice. Brish Medical Ioumal, 320 (243), $1184-1186$.

MaLoughlin, J., Nall, M., Batacs, B. Petrosko, J., Karibo, J., \& Lindsey, B. (1983). The relationship of allergics and allergy treatment to school performance and student hehavior. Annals of allergy. $57(5), 506.510$.

McMenamin, P. (1994). Costs of hay fever in the United States in 1990. Amals of allergy, 73(1), 35-39.

Meltzer, E. O., Nathan, R. A., Selner, J. C., \& Storms, W. (1997). Quality of life and thiniric symproms: Results of a nationwide survey with the SF-36 and RQLQ questionnatres. Jamal of Allergy and Clinical lmmonology, 99(6), \$815-\$819.

Melzer, E. O., Woiler, J. M. \& Widtitz, M. D. (1996). Comparative outdoor study of the efficacyn onset and duration of action, and safery of cetirizine, hratadine, and placeho for seasonal allergic thinists. Joumal of allergy and clinical immunology, 97(2), $617-626$.

Montwe, E. Finn, A, Patel, P. Guerrerw, R., Ramer, P, E Bernstein, D. (2003). Efficacy and safety of destorataline $5 \mathrm{mg}$ ance daily in the trearment of chronic idiopathic urticaria: a double-blind,

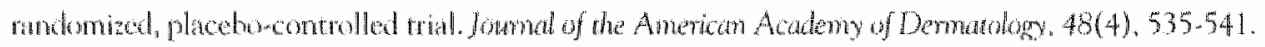

Monti, J. M. Jantos, H. Boussard, M. Aluier, H. Orellana, C. G Olvera, S. (1991). Effects of

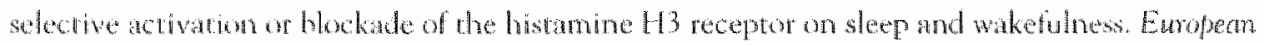
Joumal of Phumacelogy, 205(3), 283-287.

Nathan, R. A. Meltac, E. O, Selner, C., S Stums, W. (1997). Prevalence of allergic rhinitis in the Unired States. Jomal of Allergy and Clinical hmmonology, $99(6), 5808,5814$.

Nicholson, A. N. Pasco, D. A., Tumer, C. Gandlin, C. R. Greengras, P. M. Casy, A. F, S Mercer, A. D. (1991). Sedation and histamine H1 - receptor antagonism: studies in man with the enantiomers of chlorphentranine and dimethindene. Britsh fowal of Phamacology, 104(1), 270-276.

Nicholson, A. N., Stone, B. M. Tumer, C. \& Mills, S. L. (2000). Anthistamines and arerew:

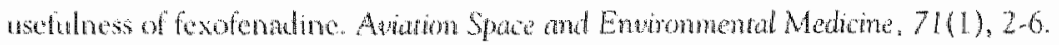

Nicholson, A. N. \& Turner, C. (1998). Centrat effects of the H1-anthistamine, cetirine Aviation Space and Enwmonental Medicine, 69(2), 166-171.

OHanlon, J. F. E Ramakers, J. G. (1995). Anthistamine effects on actual driving perfomance in a standard test: a summary of Dutch experience, 1989-94. Alkergy, 50(3), 234.342. 


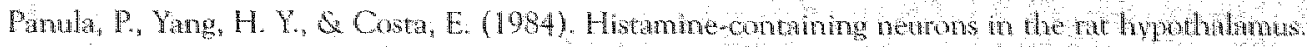
Procedings of the National Academy of Stences of the trited Srates of Amencu, $81(8), 25722576$.

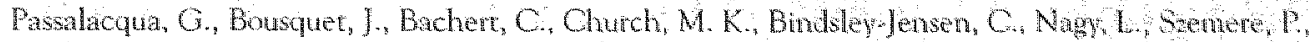

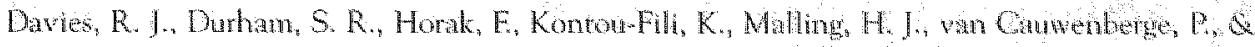
Canonica, $\mathrm{G}$. W. (1996). The dincal satery of HI recepror antagonsts: An EAACl posinom paper. Allergy, 51(10), 666-675.

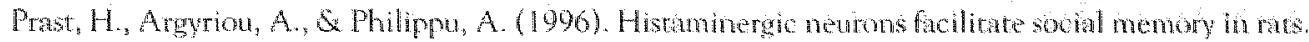
Brain research, 734(1-2), 316-318.

Qusch, T. T., Duchemin, A. M., Rose, C., Schwarr. J. C. (1979). In wiw occupation of cerbial histamine HI-receptors evaluated with $3 \mathrm{H}$-mepramine mat predict sedative properties of psychotropic drugs. European joumal of phamaodogy, 60(4), $391-392$.

Ramaekers, J. G., Uiterwijk, M. M. \& O'tanlon, I. F. (1992). Efects of lonadine and cetrinthe on

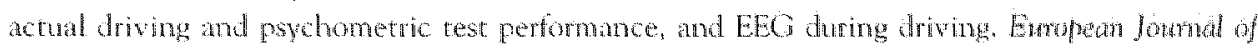
Clinical Pharmacology, 42(4), 363.369.

Ray, W. A. Fought, R. L. \& Decker, M. D. (1992). Pspchonctive drugs and the risk of injurious moror wehicle crashes in elderly driwers. Anuevican Jowmal of Epidemology, 136(7), 873-883.

Rose, C. Quach, T. T., Llorens, C., S Shwarz, ). C. (1982). Relationship between occupation of cerebral Hl-receptors and sedatixe properties of anthistamines. Assesment in the case of rerfenatine. Arzemitrel Forschung, 32(9a), 1171-1173.

Salmun, L. M., Gates, D., Scharf, M., Greding, L., Ramon. F, \& Heithoff. K. (2000). Loratadine versus cetrizine: Assessment of sommolence and motivation during the wothday. Clinical Therapeutics: The Intemational Jounal of Drug Theraty, 22(5), 573.582.

Saper, C. B., Chou, T. C. \& Scammell, T. E. (2001). The steep swith: hypothatamic control of sleep and wakefulness. Trends in newosciences, 24(12), $726-731$.

Schweitzer, . K. Muehlthach, M. J. \& Walsh, J. K. (1994). Sleepiness and performance during whereday administration of cetrime or diphenhydramine. Joumal of Allergy and Clinical Hammology, 9444).716-724.

Seidel, W. F. Cohen, S. Blwise, N. G. \& Dement, W. C. (1987). Cetrizine effects an objective measures of daytime sleepiness and perfornance. Annuls of allergy, 59(6 Pt 2), 58-62.

Shamsi, Z, Kumber, S., 8 Hindmarch, 1. (2001). An investigation into the effects of cetirine on

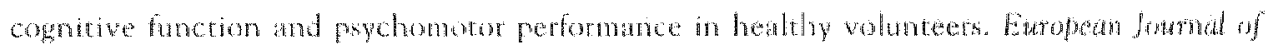
Clinical Phamacology, 56(12), 865,871.

Simons, F. E. (1989). H1-receptor ancagonists: clinical pharmacology and therapentica foumal of allergy and chical inmumology, $84(6$ P 1$), 845-861$.

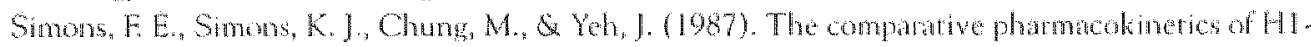
receptor antagonists. Ann Allergy, 5966 Pr 2), 2024.

Shater, J. W. Zechnich, A. D, \& Haxby, D. O (1999), Secondingeneration anthistamines; comparative review Dhegs. $57(1), 31-47$.

Snyder, S. H. \& Snowman, A. M. (1987). Receptor effects of cetirine. Ann Allerg. $59(6$ Pr 2). 4.8.

Steerenherg. P. A., van Loveren, H., Vandehriel, F. J., Vos, I. O. Opherhuizen, A., \& van Amsterdam,

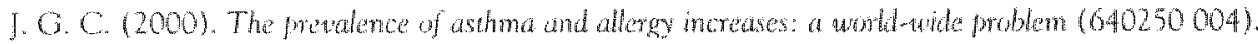
Bilthwer. Rijksinstiturt wor wolksezondheid en milieu.

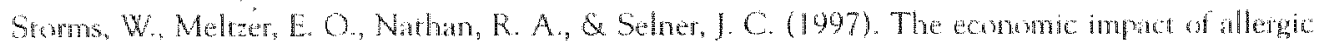

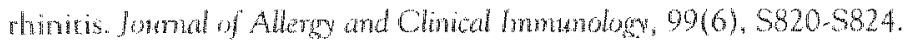


Tagawa, M. Knna M, Okamura, N., Higuchi, M., Matsuda, M., Mruki, Y. Ara, H., Iwata, R., Fuin, T. Komenushi, S., Ido, T., Itoh, M., Saski, H., Watanabe, T., \& Yanai, K (2001). Neuroimaging

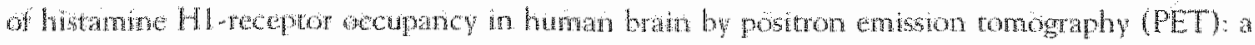
comparave sudy af ehathe, a second-generation antheramine, and (+)-chorphenramine, a dwical antikstamine. British joumal of dinical pharmaciolagy, 52(5), 501-500.

Tasho, M. Mochizuk, H., lwabuchi, K., Sakurada, Y., Itoh, M. Watanabe, T. \& Yanai K. (2002). Roles of histane in regulaton of arousal and cognition. functional newomagng of histanine HI recptors in human brain. Life Sciences, $72(4.5), 409.414$

Valk, P. J. Van Rom, D. B., Simons, R. M., \& Rikken, O. (2004). Desloratad ine shows no effect on perfomance during $6 \mathrm{~h}$ at 8,000 fo simulated cabin altitude. Aviation, space, and enuronmental medictine, $75(5), 433-438$.

van Wijk. R. G. Q Vaessen, M. H. J. (2003). Her allegie formularum. Een pratetische leidradal. (Second d.). Hourer: Bohn Satheu Van Loghum.

Vemeeren, A. \& O'Hanlon, J. E. (1998). Fexofenadine's effecrs, alone and with alcohol, on actual

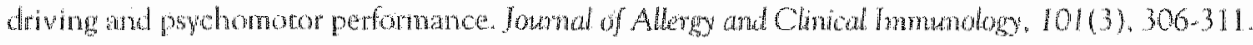

Verneeren, A, Ramatkers, J. G, \& OHanon, J. E (2002). Effects of emetasine and cetirine, alone and with alcohol, wh actual driving of males and femal es. Joumal of Psychopharmocology 16(1), 57-64.

Verster, I. C., de Weert, A. M., Bijtes, S. I., Aarab, M., van Oosterwijck, A. W., Eijken, E. I., Verbaten, M. N. S Volkerts, E. R. (2003). Driving ability after acure and sub-chonic administration af lewocetirane and diphenhylramine: a randomizd, double-bind, placebo-controlled rial. Psychopharmacolugy, 169(1), 84.90 .

Verster, J. C. Volkerts, E. R. van Oosterwigk, A. W., Aarab, M. Bitjes, S. I. De Weert, A. M. Eijken, E. J. \& Verbaten, M. N. (2003). Acute and subchronic effects of levoceririme and diphenhydramine on memory functioning, psychomotn performance, and mood, Joumal of Allergy and Clnical Immunulogy, $111(3), 623-627$.

Volkerts, E. R., Van Willigenbung, A. P. Van Laar, M. W. S Maes, R. A. (1992). Does ceririzine belong to the new generation of anthisamines? An investigation into its acute and subchronic affecrs on highwa driving psychometric test pertormance and dawtime sleepiness. Human Psychopharmacology Clinical and Expermental, 7(4), 227.238.

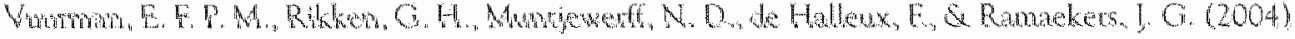

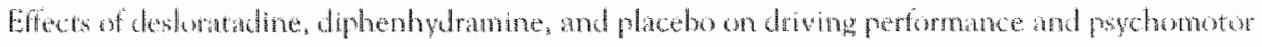

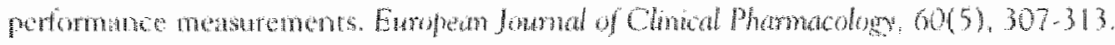

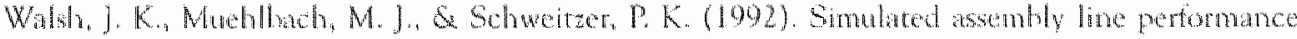
following ingestion of ectirizine of hydroxyme. Antals of allergy 69(3), 195-200.

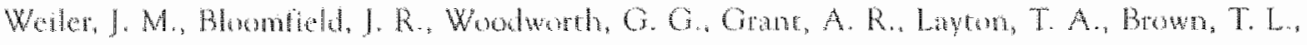
Mckonü, D. R., Baker, T. W. \& Wason, O. S. (2000). Efects of fexotenadine diphenhydramine,

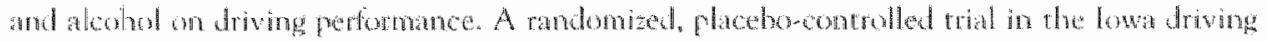
simulator. Andis of themal Matione. 1325), 354-363.

Weiss, K. Haus, M. B likurd, Y. (2004). The ousts of allergy and asthna and the potential benefint of

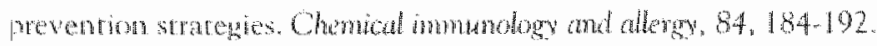




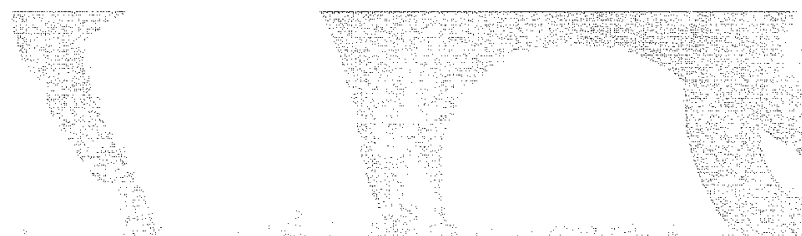




\section{A dose-ranging study of the effects of mequitazine on actual driving, memory and psychomotor performance as compared to dexchlorpheniramine, cetirizine and placebo}

\section{CHAPTER 2}

Published as:

Theunissen, E. L., Vermeeren, A., van Oers, A. C. M., van Maris, I., \& Ramaekers, I, O. (2004). A dose ranging study of the effects of mequitazine on actual driving, memory and psychomotor performance as compared to dexchlorpheniramine, cetirizine:and placebo. Clinical and Experimental Allergy, 34(2), 250-258. 


\section{Chapter 2}

\section{ABSTRACT}

Background: Mequitazine is a so called "non-sedative" second generation antihistamine even though it has never been firmly established that this drug's sedarive potential actually differs from that of the "sedative" first generation antihistamines.

Objective: The present study compares the sedative effects of 3 doses of mequitazine on actual driving, psychomotor performance and memory with those of a first and a second generation antihistamine.

Methods: 18 healthy volunteers received on separate days a single dose of 5,10 and $15 \mathrm{mg}$ mequitazine, $10 \mathrm{mg}$ cetirizine, $6 \mathrm{mg}$ dexchlorpheniramine and placebo. Drug effects were assessed using two actual driving tests (highway driving test and car following test), cognitive and psychometric tests (tracking, divided attention, memory, reasoning and CFF), pupil size and questionnaires.

Results: Highway driving data tevealed an overall effect of Treatment on the Standard Deviation of Lateral Position. (SDLP). Dexchlorpheniramine impaired driving performance as indicated by a significant rise in SDLP. Mequitazine significantly increased SDLP in a dose related manner, but the separate dose effects failed to reach statistical significance. Divicled attention performance was also affected by Treatment. Reaction time (RT) during mequitazine treatments increased in a dose related manner and significantly differed from placebo at the highest dose. Subjects reported to be less alert after treatment with dexchlorpheniramine. Cetirizine did not affect performance in any of the tasks.

Conclusion: It was concluded that mequitazine is mildly sedating. The effects of mequitazine are comparable to those of other $2^{\text {nd }}$ generation antihistamines, in that it causes mild driving impairment, particularly at higher doses. 


\section{INTRODUCTION}

Histamine is an endogenous substance that is stored and released by mast cells in peripheral tissues. When histamine is released, it acts on various tissues, causing a variety of allergic reactions in hypersensinive people, e.g. allergic thinitis, conjunctivitis and urticatia.

Histamine also functions as a neurotransmitter in the brain. The Histaminergic neurons are primarily located in a small region of the posterior hypothalamus, called the tuberomammillary nucleus (Panula et al., 2000). These neurons project to various parts in the bran, primarily to the hypothalamus, medial septum and amygdala (Steinbusch, 1991; Panula et al., 2000). Histamine acts through the activation of three types of histamine receptors, $\mathrm{Hl}$, $\mathrm{H} 2$ and $\mathrm{H} 3$, and is involved in several brain functions, e.g. arousal and the sleep-wake cycle (Onodera, Yamatodani. Watanabe, \& Wada, 1994). Several neurochemical studies have shown that the activity of the central histaminergic system increases during the active phase of rodents, cats and monkeys and decreases while asleep (Yamatodani et al, 1991; Onoe et al., 1992).

Antihistamines cause a reliet of allergic symptoms by blocking peripheral histamine Hl-receptors. However, some antihistamines are also able to cross the blood-brain barriet and block histaminergic and other neurotransmitter systems (e.g. serotonin, choline, noradrenaline) in the brain, and as a consequence produce sleepiness, farigue and sedation (Snyder \& Snowman, 1987; Passalacqua et al."1996). These are considered to cause cognitive and psychomotor impairment observed in a range of studies on antihistamine effects on performance (Rombaut \& Hindmarch, 1994; O'Hanlon \& Ramaekers, 1995; Kay, 2000). In order to reduce the sedative potential of antihistamines, a host of research evolved devoted to developing novel antihistamines that do not cross the blood brain barrier, the so called $2^{\text {nd }}$ generation antihistamines.

Terfenadine, astemizole and mequitazine were among the first compounds to be introduced as non-sedaring $2^{\text {nd }}$ generation antihistamines in the 1980 's. Many studies showed that therapeutic doses of these and subsequent drugs did not cause sedation (Gervais, Gervais, De Beule, \& Van der Bijl, 1975; Blamourier, 1978; Muler \& Blum, 1978; Van Wauwe et al., 1981; Woodward \& Munro, 1982; Hindmarch \& Easton, 1986). Consequently it was suggested that $2^{\text {nd }}$ generation antihistamines are not able to cross the blood-brain barrier and do not interact with histamine brain receptors. However, the difference between $1^{\text {st }}$ and $2^{\text {nd }}$ generation antihistamines turned out to be less distinct. When given in higher doses, most $2^{\text {nd }}$ generation antihistamines produced mild to moderate sedation and performance impairment as measured in tests of actual driving or psychomotor skills (O'Hanlon \& Ramaekers, 1995; Shamsi \& Hindmarch, 2000), suggesting that these drugs do cross the blood brain barrier. The latter notion was definitively confirmed in imaging studies showing that $2^{\text {nd }}$ generation bind to $\mathrm{H} 1$-receptors in the brain in a dose related manner (Yanai, Okamura, Tagawa, Itoh, \& Watanabe, 1999).

Mequitazine is a synthetic antihistamitue selective for $\mathrm{H} 1$-receptors. In parients treated with mequitazine over longer periods, some minor anticholinergic effects (dry mouth, blurred vision) have also been reported (Beaumont, Hugonot, \& Hugonot, 1986), indicating a small affinty for cholinergic receptors as well. Though mequitazine was one of the earliest $2^{\text {nd }}$ generation antihistamines on the market, only few comparative studies were performed to actually establish its sedative properties. These studies generally demonstrated that therapeutic doses of mequitazine $5.10 \mathrm{mg}$ produced no or less psychomotor imparment and subjective drowsiness as compared to $1^{\text {st }}$ generation andihistamines 


\section{Chapter 2}

(Gervats et al, 1975; Blamoutier, 1978; Muler \& Blum, 1978; Caille, 1979; Hindmarch \& Easton, 1986). Most studies, however, used only subjective tests, small sample sizes or a specific population.

The aim of the current study was to assess the dose related effects of mequitazine on cognition, psychomotor funcrion and driving performance, and to compare them to those of a well established $1^{\text {t5 }}$ and $2^{\text {nd }}$ generation anthistamine, i.e dexchlorpheniramine and cetirizine respectively. It was expected that mequitazine would not be completely free of sedative effects but that it would produce mild and dose related performance impairment.

\section{MATERIALS AND METHODS}

\section{Subjects}

Eighteen healthy wolunteers ( 9 males and 9 females), aged between 21 and 44 years were recruited by means of newspaper advertisements. Subjects were first screened using a medical history and a driving experience questionnaire. Each qualified subject underwent a physical examination, an electrocardiogram was made and a blood sample was taken. Mean (SD) age was $32.5(8.29)$ years and mean weight (SD) was $76.1(7.78) \mathrm{kg}$.

Inclusion criteria were possession of a valid driver's license for at least 3 years, driving experience of at least $5000 \mathrm{~km}$ per year and being healthy according to the physical examination. Exclusion criteria were: history of major medical or psychiatric disorder, any non-corrected visual or psychomotor defect, unusual sensitivity to antihistamines, drug abuse, chronic use of medication except contraceptives, using no efficient contraception, pregnancy and lactation. After having received all necessary information, all participants gave their written consent. The study was approved by the Ethics committee of Maastricht University and subsequently carried out in accordance with the World Medical Associations Declaration of Helsinki (Edinburgh, 2000).

\section{Drug administration}

On separate days, participants received a single oral dose of each of the following: 5,10 and $15 \mathrm{mg}$ mequitazine; $10 \mathrm{mg}$ cetirizine; $6 \mathrm{mg}$ dexchlorpheniramine (repetabs) and placebo. Drugs and placebo were administered on 6 separate days, according to a placebo-controlled, double blind, 6-way latin square design. The washout period between treatment days was at least 7 days. Drugs and placebo were administered by means of a double dummy technique because of pharmacokinetic differences between individual drugs. Mequitazine and dexchlorpheniramine reach $T_{m a x}$ at approximately the same time (i.e between 3-4 hours) but cetirizine concentrations are already maximal at $1 \mathrm{hr}$ after administration (Wood, John, Chasseaud, Yeh, \& Chung, 1987; Ylitalo et al., 1989; Rimmer \& Church, 1990; CVZ, 1999). Drugs and placebo were administered according to the following schedule in order to fixate time of testing around $T_{\text {max }}$ in every treatment condition. In the mequitazine and dexchlorpheniramine conditions the active drugs were given at $11.00 \mathrm{~h}$ and placebo at 13.00h; in the ceririzine condition placebo was given at $11.00 \mathrm{~h}$ and the active drug at $13.00 \mathrm{~h}$. In the placebo condition, placebo was given at both times of administration. 


\section{Procedure}

Subjects were individually trained one or two weeks prior to their first treatment condition to perform driving, cognitive and psychometric tests. Subjects were prohibited from consuming alcohol for $24 \mathrm{~h}$ before testing. On test-days, subjects consumed breakfast at home. Consumption of caffeine containing beverages was prohibited and smoking was prohibited 30 minutes prior and during testing. Subjects were brought to the test site where drugs were administered. At $12.00 \mathrm{~h}$ they received a standardized meal. The highwaydriving test started at $14.00 \mathrm{~h}$ and the car-following test at $15.00 \mathrm{~h}$ or $15.30 \mathrm{~h}$. Psychometric rests were performed at $16.30 \mathrm{~h}$. At the end of the test day, participants were transported back home.

\section{Highway-driving test}

During the highway-driving test (O'Hanlon, Haak, Blaauw, \& Riemersma, 1982), the subject's task is to operate a specially instrumented vehicle over a distance of $100 \mathrm{~km}$ (61miles) on a primary highway. A licensed driving instructor, who can intervene if necessary by using duplicate controls, accompanies the subject during all tests. The subject is instructed to attempt to maintain a constant speed of $95 \mathrm{~km}$ ( 58 miles) per hour and a steady lateral position between the delineated boundaries of the right (slower) traffic lane. The subject is allowed to deviate from this procedure in order to pass slower vehicles. Halfway through the circuit, the subject drives off the highway and re-enters, travelling in the opposite direction. The vehicle's speed and lateral position relative to the left lane delineation are continuously recorded using an electro-optical device mounted at the rear of the car. These signals are digitally sampled at a rate of $4 \mathrm{~Hz}$ and stored on a computer disk onboard. The offline editing routine involves removal of all data segments that revealed signal loss, disturbance or overtaking manoeuvres. The remaining data are used to calculate means and standard deviations for lateral position (SDLP) and speed. The primary measure is the standard deviation of lateral position, which measures the continuous road tracking error. SDLP is a very reliable characteristic of individual driving performance: the test-retest reliability coefficient for unmedicated young and middle-aged drivers is $r=0.85$. It has also proven sensitive to many sedating agents, including alcohol in blood concentrations (BAC) as low as $0.35 \mathrm{mg} / \mathrm{ml}$ (Ramaekers, Uiterwijk, \& O'Hanlon, 1992; Vuurman et al., 1996).

\section{Car-following test}

The car-following test (Brookhuis, De Vries, \& De Waard, 1993; Ramaekers \& O'Hanlon, 1994; Ramaekers et al., 2002) involves the use of two vehicles driving behind each other on a secondary highway. The subject controls the following vehicle, while the investigator controls the leading car. A licensed driving instructor accompanies the subject in order to intervene when necessary. During the test the investigator in the leading car initiates sinusoidal speed changes. Berween deceleration manoeuvres, the investigator in the leading car randomly lights up the break lights of his car while the speed of the car remains constant. Subjects are instructed to maintain a $15-30 \mathrm{~m}$ distance to the leading car and to react as fast a possible to the break lights by removing his/her foot from the speed pedal. Test duration is about 25 minutes.

Phase delay, converted into a measure of time to speed adaptation (in ms), and break reaction time (in ms), are the primary outcome variables of this car-following test. Headway (in $\mathrm{m}$ ) and standard deviation of headway (in $\mathrm{m}$ ) are secondary parameters. 


\section{Chapter 2}

\section{Cognitive and Psychometric tests}

- Word Learning Task

In this task (Rey, 1964), subjects are shown 15 words on a computer screen. The words appear on the screen for 2 seconds, one by one. All words are in Dutch, the native language of all subjects. Subjects are instructed to try and memorize these words, and to name as many as they can at the end of the list. This procedure is repeated five times. The highest score in these trials is the immediate recall score. After at least 30 minutes, the subject is asked to name as many words as he/she can, and this score is the delayed recall score. The number of words recalled in the delayed recall compared to the immediate recall is defined as the relative recall score. Finally, a list of 30 words is presented on the computer screen, comprising the original 15 words and 15 new words. The subject has to press a button when he/she recognizes a word that belonged to the original list of words. The recognition score comprises of the number of correct recognitions and correct rejections. Subjects were presented a different version of the task on each test-day.

\section{- Critical Tracking Task}

During this task the subject controls a triangle, which is displayed on a horizontal axis on a computer screen, by moving a joystick. An error signal causes the triangle to become increasingly unstable and therefore it tends to diverge from the centre of the axis. The subject has to make compensatory movements to null the error in order to keep the triangle in the middle. As the frequency of cursor deviations increases as a stochastic, linear function of time, the subject is required to make compensatory movements with a progressively higher frequency. Eventually his response frequency lags the error signal by $180^{\circ}$. At that point, the subject's response adds to, rather than subtracts from, the error and control is lost. The frequency at which control is lost is called the 'critical frequency' or 'lambda' ( $\mathrm{rad} / \mathrm{sec})$. The test includes five trails; the average score is calculated after removing the highest and the lowest scores, and is the primary variable in this test (Jex, McDonnell, \& Phatak, 1966).

\section{- Divided Attention Task}

In the Divided Attention Task (Moskowitz, 1973), the subject performs two tasks simultaneously. Firstly, the subject has to perform the same tracking task as described above, with the difficulty level fixed at $50 \%$ of his/her maximum capacity. Tracking error is measured as the difference in $\mathrm{mm}$ between the position of the cursor and the midpoint of the scale. The absolute mean tracking error over the entire test is taken as the final score in this subtask.

As a secondary task, the subject has to monitor 24 single-digit numbers $(0-9)$, which are present in the four cornets of the display. These numbers change asynchronously every 5 seconds. Inter-target time varies between 5 and 25 seconds. The subject reacts to the target number ' 2 ' by removing his foot as fast as possible from a pedal switch. Reaction times (msec) are recorded, and the mean reaction time is the variable in this subtask.

\section{- Syntactic Reasoning Task}

The Syntactic Reasoning Task measures higher mental processes using sentences of various levels of syntactic complexiry (Baddeley, 1968). A sentence describing the order of the letters $\mathrm{A}$ and $\mathrm{B}$ is presented on the computer display, e.g. "A follows B". Each sentence is immediately followed by a combination of the two letters. The subject has to decide whether the order of the letters is correct according to the sentence and responds by pressing 
the corresponding button as fast as possible. Thirty two sentences are presented and in half of the cases the letter combination is correct according to the sentence. The level of difficulty of the sentences is varied, ranging from simple active sentences to more complicated sentences using passives, negatives and combinations. Number of correct responses and reaction times (msec) are the primary variables of this task.

\section{- Critical Flicker Fusion test}

If a light is repeatedly turned on and off, it is perceived as flickering. When it flickers at increasing frequency, it will finally appear to fuse into a continuous light even though it is actually still moving. The threshold, at which it is perceived as a steady light source, is called the Critical Flicker Fusion frequency (CFF). The Critical Flicker Fusion test is often used in psychopharmacology studies, and is seen as a measure of central nervous system arousal (Curran, 1990). CFF is sensitive to changes in pupil diameter, and pupil size is affected by neurotransmitters as serotonin, noradrenaline and acerylcholine (Sokolski, Nguyen, \& DeMet, 2000; Schmitt, Riedel, Vuurman, Kruizinga, \& Ramaekers, 2002). Therefore it is necessary to control for drug induced variations in pupil size by using an artificial pupil (Smith \& Misiak, 1976).

In order to test if antihistamines have an effect on pupil size, pupil diameter is measured using a Remote Eyetracking Device (SensoMotoric Instruments, Berlin, Germany).

\section{Subjective measures}

Subjective measures were used on each test day to assess sleep quality, effect of treatments on driving and mood. In order to assess the quality of sleep of the past night, subject filled out the Groningen Sleep Quality Scale before treatment (Mulder-Hajonides van der Meulen, 1981). This questionnaire includes specific questions about the total amount of sleep, number of awakens and rime needed to fall asleep, and 14 yes/no questions to score the number of complaints, ranging form 0 (good sleep) to 14 (the worst possible). Subjects predicted their driving ability prior to the highway driving test and subjective driving performance after completion of the test, using visual analogue scales $(100 \mathrm{~mm})$. Before the psychometric tests, subjective evaluation of mood was assessed by means of a 16-item mood scale from which three factors are derived: alertness, contentedness and calmness (Bond \& Lader, 1974). Mood scales were subjected to a square root transformation before entering statistical analyses to correct for positively skewed distributions.

\section{STATISTICAL ANALYSIS}

A power calculation revealed that a sample of 18 subjects was sufficient for providing a power of more than $90 \%$ for detecting a critical mean difference between drug and placebo of $2 \mathrm{~cm}$ in SDLP. Psychometric and driving parameters were analysed using an ANOVA with Subject, Treatment and Period as factors. Subsequently, analyses for comparing treatments with placebo were conducted, using simple contrasts with sequential Bonferonni correction. A polynomial contrast was used to test the significance of linear trends over the administered doses of mequitazine; $0,5,10$ and $15 \mathrm{mg}$. The effects of gender on driving performance were analysed, using a model including Treatment, Period, Gender and Gender by Treatment. The Groningen Sleep Questionnaire and subjective driving ratings were not normally distributed and analysed by means of the non-parametric Friedman test to detect an overall difference between Treatments. These were followed by Wilcoxon's signed- 
Chapter 2

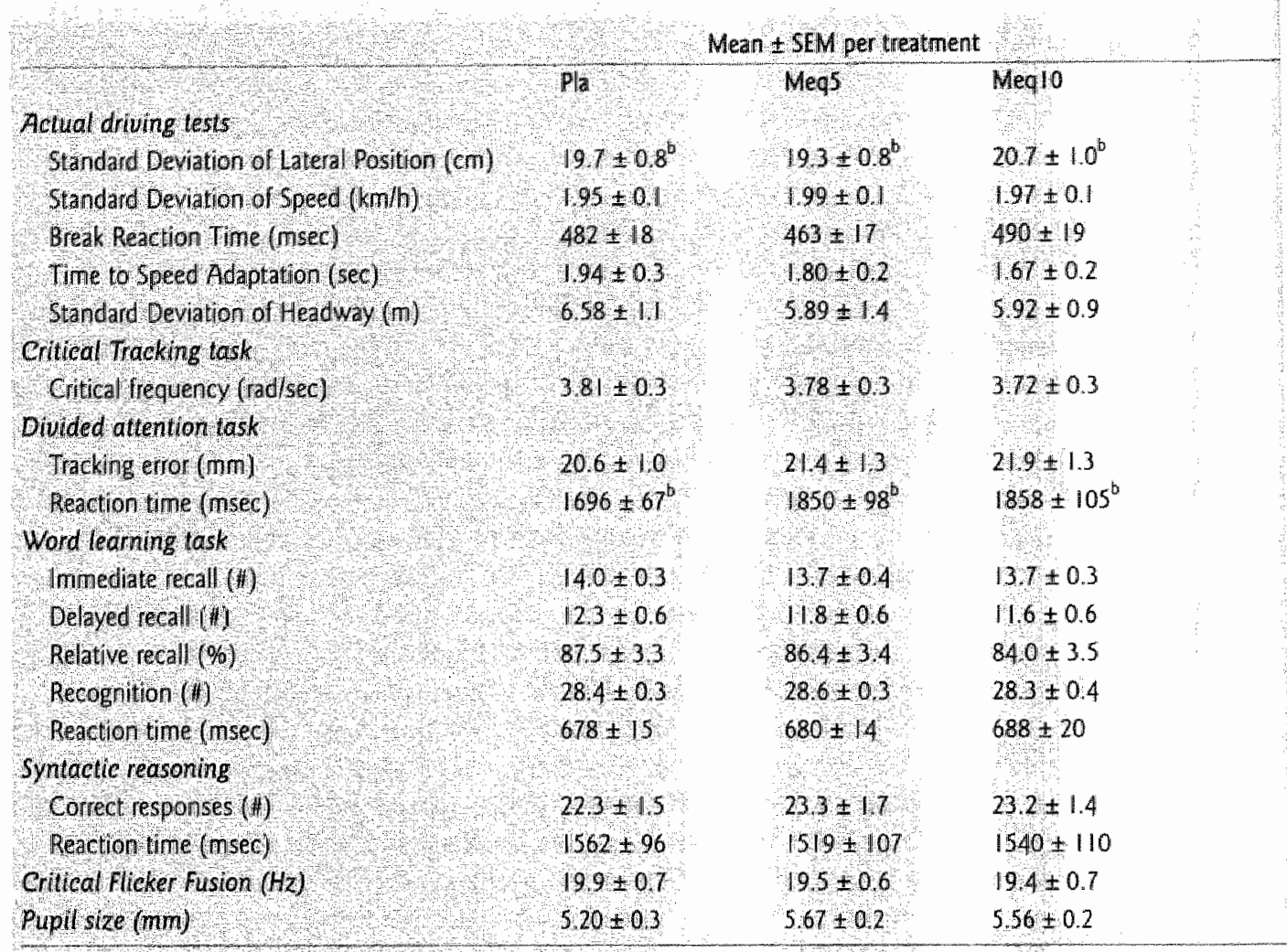

Table 1. Summary of results from the driving, psychomotor and cognitive tests. Treatments are placebo (PLA), mequitazine $5 \mathrm{mg}$ (MEQ5), mequitazine $10 \mathrm{mg}$ (MEQ10), mequitazine $15 \mathrm{mg}$ (MEQ15), cetirizine (CET) and dexchlorpheniramine (DEX). ${ }^{a}$ Drug- placebo differences afrer sequential Bonferroni correction with $p<.01{ }^{b}$ polynomial effect $p<.05$; NS: not significant.

ranked test to compare the effects of drugs and placebo. All statistical tests were conducted using SPSS (version 10.0).

\section{RESULTS}

\section{Missing Data}

In the car-following test, headway data of four subjects was partly lost due to technical problems on five separate occasions. In addition, no data from the syntactical reasoning test was collected on two occasions because of technical malfunctions. Subjects with incomplete data records were not entered into statistical analyses of standard deviation of headway (SDH) and all dependent measures of the syntactical reasoning task. 
Mean \pm SEM per treatment

\begin{tabular}{|c|c|c|c|c|c|}
\hline Meqls & Cet & Dex & I & br & $p$ \\
\hline $208 \pm 10^{6}$ & $19 \| \pm 0.8$ & $221+10^{\circ}$ & 632 & 5,80 & $<001$ \\
\hline $208+0.1$ & $189 \pm 01$ & $212 \pm 0.1$ & 1.67 & 5,80 & NS \\
\hline $483 \pm 15$ & $506 \pm 22$ & $478 \pm 21$ & 0.90 & 580 & NS \\
\hline $1.93 \pm 0.2$ & $2.18+0.2$ & $180+0.1$ & 160 & 5,80 & NS \\
\hline $6.14 \pm 12$ & $4.48 \pm 0.7$ & $594 \pm 12$ & 0.44 & 5,60 & NS \\
\hline $3.68 \pm 0.3$ & $379 \pm 0.3$ & $389 \pm 0.2$ & 1.15 & 5,80 & NS \\
\hline $22.0 \pm 1.4$ & $210 \pm 1.5$ & $221+12$ & 0.86 & 5,80 & NS \\
\hline $1958 \pm 84^{\text {dab }}$ & $1804 \pm 102$ & $1784=76$ & 3.13 & 5,80 & .013 \\
\hline $13.8 \pm 0.3$ & $13.7 \pm 0.3$ & $139+03$ & 0.46 & 5.80 & NS \\
\hline $114.6 \pm 0.6$ & $122+05$ & $|2| 10.6$ & 0.69 & 5,80 & N5 \\
\hline $83.5 \pm 3.8$ & $883+30$ & $811+35$ & 0.48 & 5.80 & NS \\
\hline $28.3 \pm 0.3$ & $28.7+03$ & $28.7 \pm 0.2$ & 0.62 & 5,80 & NS \\
\hline $691 \pm 16$ & $687 \pm 6$ & $681 \pm 14$ & 0,28 & 5,80 & NS \\
\hline $23.6 \pm 1.7$ & $235 \pm 1.4$ & $226+17$ & 0.65 & 570 & NS \\
\hline $1572+107$ & $1671+106$ & $1486+121$ & 1.40 & 5,70 & NS \\
\hline $19.7 \pm 0.7$ & $19.4 \pm 0.7$ & $19.4+0.7$ & 0.79 & 580 & NS \\
\hline $5.74 \pm 0.3$ & $5,60 \pm 02$ & $5.53 \pm 02$ & 111 & 5,80 & NS \\
\hline
\end{tabular}

\section{Failure to complete the driving test}

One subject did not complete the highway driving tests after treatment with dexchlorpheniramine and mequitazine $15 \mathrm{mg}$. In the dexchlorpheniramine condition, the driving instructor decided to terminate the test, because the subject fell asleep. The subject himself chose to stop driving after treatment with mequitazine $15 \mathrm{mg}$, because he felt he was incapable of continuing. The respective rides were 98 and $65 \%$ complete when the rest was stopped. SDLP scores for these rides were calculated using data of the completed part.

\section{Driving Tests}

A summary of descriptive and quantitative statistical analysis of all driving parameters is given in Table 1. The overall effect of Treatment $\left(\mathrm{F}_{5.80}=6.32 ; \mathrm{p}<.001\right)$ and Period $\left(F_{5,30}=4.42 ; p=.001\right)$ on SDLP were highly significant. Contrasting each drug with placebo showed that SDLP significantly increased after treatment with dexchlorpheniramine $\left\langle F_{1,80}=13.73 ; p<.001\right)$. SDLP scores were significantly higher in period 3,5 and 6 compared to the first period $\left(F_{1,80}=13.51 ; p<.001 ; F_{1,80}=9.41 ; p<.016 ; F_{1,80}=10.35\right.$; $\mathrm{p}<.0125$ ). No interaction was found between Treatment and Period. Mean (SEM) Standard Deviation of Lateral Position (SDLP) in each condition is shown in Figure 1. The polynomial contrast showed that SDLP increased in a linear fashion as a function of dose of mequitazine $\left(\mathrm{F}_{3.46}=6.87 ; \mathrm{p}=.012\right)$. 


\begin{tabular}{|c|c|c|c|}
\hline & \multicolumn{3}{|c|}{ Mean \pm sEM per treatment } \\
\hline & Pla & Megs & Meq 10 \\
\hline \multicolumn{4}{|c|}{ Subjective evaluation of nood } \\
\hline Alertiess & $4,76 \pm 05$ & $498+0.5$ & $541 \pm 0.4$ \\
\hline Contentedness & $3.75 \pm 0.5$ & $451+0.4$ & $428 \pm 0.4$ \\
\hline Calnness & $3.59 \pm 0.4$ & $422 \pm 0.4$ & $419 \pm 0.4$ \\
\hline \multicolumn{4}{|l|}{ Sleep questionnatre } \\
\hline Sleep complainis (t) & $122 \pm 0.6$ & $172 \pm 09$ & $144 \pm 0.5$ \\
\hline Sleep (h) & $839 \pm 02$ & $8.22+02$ & $828 \pm 0.2$ \\
\hline Awakenings (H) & $0.56 \pm 02$ & $1,00 \pm 02$ & $0.94 \pm 0.3$ \\
\hline Sleep latency (min) & $10.5 \pm 25$ & $175 \pm 43$ & $12,4 \pm 38$ \\
\hline \multicolumn{4}{|c|}{ Subjective driving quality } \\
\hline Pretest (mm) & $822+43$ & $841+43$ & $719 \pm 57$ \\
\hline Posthest (mm) & $648 \pm 52$ & $674+48$ & $58.5 \pm 59$ \\
\hline
\end{tabular}

Table 2. Summary of results of the subjective measures. Treatments as described in table 1. a drug-placebo differences after sequential Bonferroni correction with $13<.01 ;$ NS: not significant.

Standard Deviation of Speed, Break RT and Time to Speed Adaptation were elevared in women as compared to men $\left(F_{1,91}=12.05 ; p=.001 ; F_{1,91}=8.80 ; p=.004 ; F_{1,91}=11.96 ; p=.001\right)$, but there was no interaction between Gender and Treatment on any driving variable.

\section{Cognitive and Psychomotor Tests}

A summary of descriptive and quantitative statistical analysis of cognitive and psychomotor parameters is given in Table 1. Reaction time in the Divided Attention Task was affected by Treatment $\left(F_{5,80}=3.13 ; p=.013\right)$ and Period $\left(F_{5,80}=2.92 ; p=.021\right)$. Drug-placebo contrasts showed that mequitazine 15 mg produces significantly longer $R T s\left(F_{1,80}=15.04 ; p<.001\right)$. On average subjects responded fastest in the sixth period $(1.73 \mathrm{sec})$, while being slowest $(1.92$ sec) in the fifth period. A polynomial contrast demonstrated that there was no linear trend over the different periods. No interaction was found between Treatment and Period. Mean reaction times of the Divided Attention Task are presented in Figure 2. The polynomal contrast showed a linear effect of mequitazine on the RT $\left(F_{3,46}=11.7 ; p=.001\right)$, indlicating that RT rose linearly with increasing dose. No other variable of the cognitive and psychomotor tests was affected by Treatment.

\section{Subjective measures}

A summary of descriptive and quantitative statistical analysis of subjective measures is given in Table 2. Sleep complaints, hours of sleep, number of awakenings and sleep latency of the night before resting, as well as subjective driving quality did not significantly differ between reatments as expected.

Treatment effect on alertness was significant $\left(F_{5,80}=2.36 ; p=.048\right)$, subjects rated their alertness after dexchlorpheniramine as significantly lower than after placebo $\left(F_{1,80}=9.63\right.$; $\mathrm{p}=.003$ ). Calmness and contentedness were not affected by Treatment.

There was no overall effect of Treatment on subjective driving ability rated before and 


\begin{tabular}{|c|c|c|c|c|c|}
\hline Meqls & $\mathrm{Cet}$ & Dex & F & df & p \\
\hline $542 \pm 0.5$ & $5.10 \pm 0.4$ & $6.15+0.4$ & 236 & 5.80 & 05 \\
\hline $441 \pm 0.4$ & $429+0.5$ & $471 \pm 04$ & 226 & 5.80 & NS \\
\hline $391+0.4$ & $4.50 \pm 0.4$ & $4.55 \pm 0.4$ & 132 & 5,80 & NS \\
\hline & & & $x^{2}$ & df & p \\
\hline $233+08$ & $194+06$ & $2.67+0.8$ & 535 & 5 & Ns \\
\hline $811=03$ & $817 \pm 03$ & $778+0.4$ & 427 & 5 & NS \\
\hline $0.94 \pm 0.2$ & $117+0.4$ & $183+0.6$ & 365 & 5 & Ns \\
\hline $42 \pm 45$ & $116+32$ & $165 \pm 57$ & 799 & 5 & NS \\
\hline $710=6.9$ & $725+52$ & $657+5.8$ & 743 & 5 & NS \\
\hline $549 \pm 62$ & $611+51$ & $500+60$ & 551 & 5 & NS \\
\hline
\end{tabular}

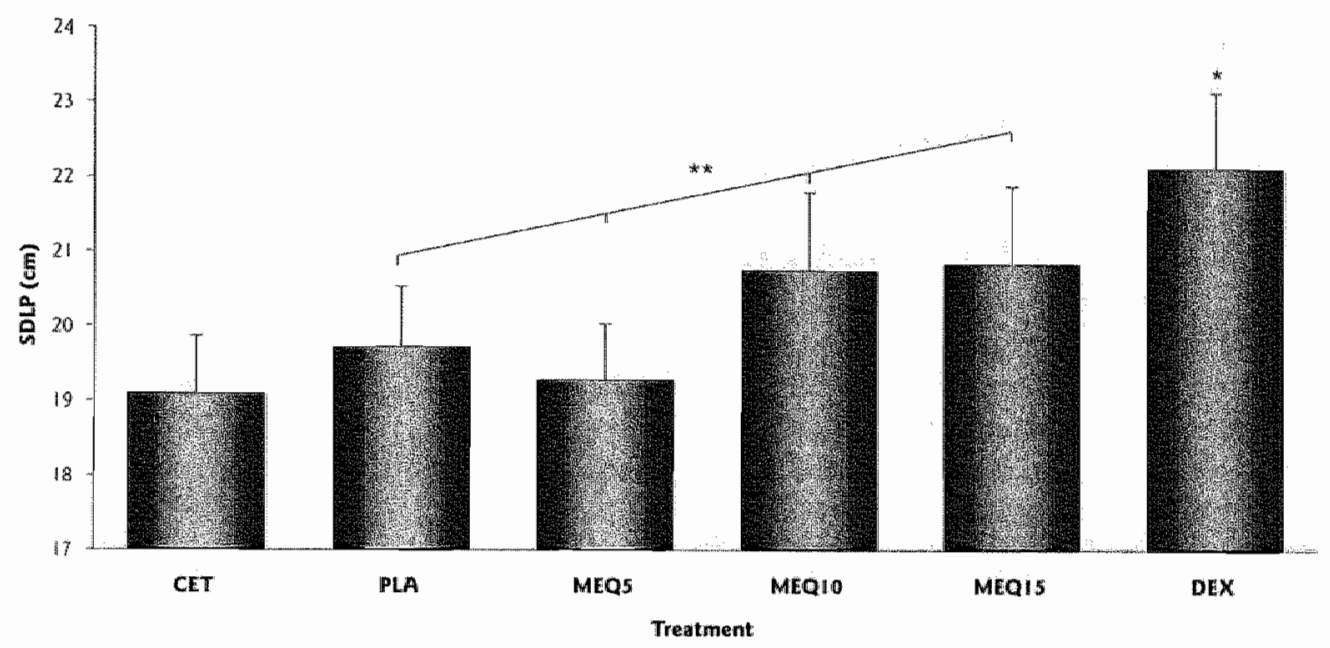

Figure 1. Mean (+SEM) SDLP for each treatment. Treatments are cetirine (CEI), placelbo (PLA), mudutazine $5 \mathrm{mg}$ (MEQ5), mequitazine $10 \mathrm{mg}$ (MEQ10), mequitaine $15 \mathrm{mg}$ (MEQ15) and dexchlorphentatine

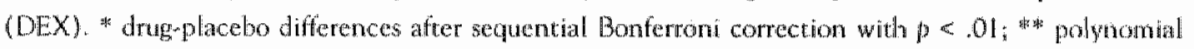
contrase with $p<.05$

after driving. Drug-placebo contrasts showed that subjects expected their driving as going to be more impaired after dexchlorpheniramine than after placebo. However, using sequential Bonferroni correction, this effect was no longer significant $(z=-2.5 ; p=.013 ; 0=.01)$. Contrasts with Bonferroni correction demonstrated that dexchlorpheniramine also did not differ significantly from placebo when driving quality was rated after the test $(z=-2.0$; $p=.045 ; \alpha=.01)$. 


\section{Chapter 2}

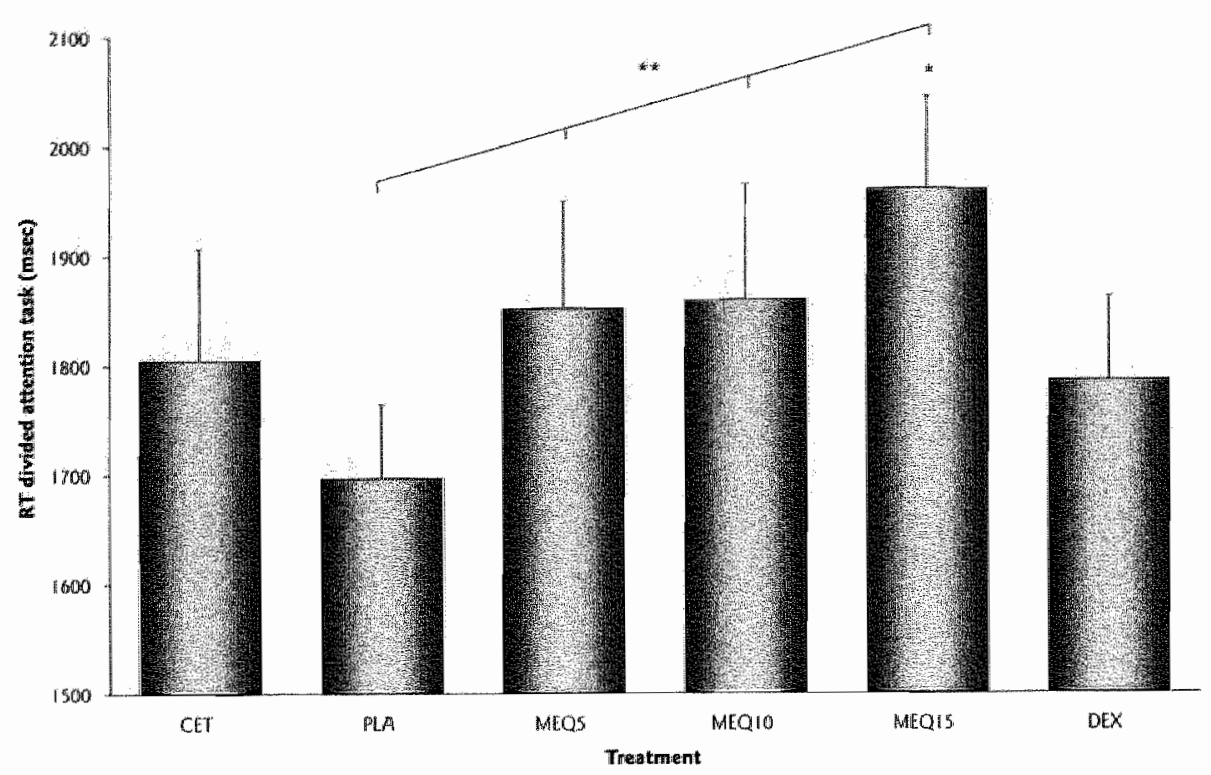

Figure 2. Mean (+SEM) RT of the Divided Attention Task for each treatment. Treatments are cetirizine (CET), placebo (PLA), mequitazine $5 \mathrm{mg}$ (MEQ5), mequitazine $10 \mathrm{mg}$ (MEQ10), mequitazine $15 \mathrm{mg}$ (MEQ15) and dexchlorpheniramine (DEX). "drug placebo differences after sequential Bonferroni correction with $p<.01$; *** polynomial contrast $p<.05$

\section{DISCUSSION}

Only few studies had examined the sedative effects of mequitazine prior to the present study. Most of them indicated that mequitazine was non-sedating on the basis of questionnaires (Gervais et al., 1975; Blamoutier, 1978; Muler \& Blum, 1978). Studies employing objective laboratory tests reported that mequitazine $5 \mathrm{mg}$ produced no impairment of psychomotor and cognitive functions (Caille, 1979; Hindmarch \& Easton, 1986). Only one group of researchers reported performance impairment in tests of visuo-motor coordination and information processing in female volunteers after treatment with a single dose of mequitazine $10 \mathrm{mg}$ (Nicholson \& Stone, 1983). Results from the present study confirmed the latter finding in a mixed population. Mequitazine significantly increased SDLP or "weaving" in the lhighway driving tests in a dose related manner even though the separate dose effects failed to reach statistical significance. Divided attention performance was also affected by mequitazine. Reaction time in the visual search task increased in a dose related manner and significantly differed from placebo at the highest dose. Together these data indicare that mequitazine can produce performance impairment, particularly at higher doses.

Impairment after higher doses of mequitazine was limited to performance during highway driving and in the divided attention task. Performance in memory, syntactic reasoning, critical Aicker fusion frequency and critical tracking test remained unaffected by mequitazine at any dose. The selectivity of this drug effect may indicate that some psychological domains or functions are particularly susceptible to Hl-antagonism. Both affected tasks involve 
attention, the performance in the highway driving task mainly depends on sustained attention, while the capacity to perform two tasks simultaneously involves divided attention. The sensitivity of these tasks for $\mathrm{HI}$-antagonism may be related to the central role of brain histamine in arousal and sleep-wake regulation. Task performance drawing primarily on attentional resources may be more vulnerable to fluctuations in sleep-wake levels as compared to tasks drawing primarily on sensorimotor control (e.g. critical tracking) or memory (e.g. word learning and syntactic reasoning). Curran et al. (1998) confirmed this notion by showing that certain antihistamines, i.e. diphenhydramine, selectively impaired arousal wile leaving memory intact, whereas benzodiazepines and cholinergic antagonists affected both (Curran, Pooviboonsuk, Dalton, \& Lader, 1998).

Driving impairment after mequitazine doses was relatively mild when compared to the effects of $1^{\text {st }}$ generation antihistamines in the highway driving test. The effect of mequitazine on SDLP was small when compared with dexchlorpheniramine in this study, and much smaller when compared with other $1^{\text {st }}$ generation antihistamines tested in previous studies, e.g. clemastine $2 \mathrm{mg}$, triprolidine $5 \mathrm{mg}$ and diphenhydramine $50 \mathrm{mg}$ (Robbe \& O' Hanlon, 1990; Ramaekers \& O'Hanlon, 1994; Vuurman, Uiterwijk, Rosenzweig, \& O'Hanlon, 1994; O'Hanlon \& Ramaekers, 1995). Mequitazine $15 \mathrm{mg}$ increased SDLP by $1.1 \mathrm{~cm}$, whereas increments in SDLP observed after single administration of $1^{\text {st }}$ generation antihistamines were at least twice that size. Triprolidine $10 \mathrm{mg}$ and diphenhydramine $50 \mathrm{mg}$ produced an increase in SDLP of $3.4 \mathrm{~cm}$ and $4.5 \mathrm{~cm}$ respectively compared to placebo (Riedel, Ramaekers, Uiterwijk, \& O' Hanlon, 1990; Ramaekers \& O'Hanlon, 1994), while in the present study dexchlorpheniramine caused an increase of $2.4 \mathrm{~cm}$. The clinical relevance of changes in SDLP has previously been determined by establishing the relationship between blood alcohol concentration and SDLP in the highway driving tests (Louwerens, Gloerich, de Vries, Brookhuis, \& O'Hanlon, 1987). Their findings indicate that a blood alcohol concentration (BAC) of $0.5 \mathrm{mg} / \mathrm{ml}$ produces an increase in SDLP of $2.2 \mathrm{~cm}$ compared to placebo. That change is considered clinically relevant since a BAC > $0.5 \mathrm{mg} / \mathrm{ml}$ is associated with an increase in the risk of a fatal traffic accident (Borkenstein, Crowther, Shumate, Ziel, \& Zylman, 1974). The increase in SDLP after treatment with dexchlorpheniramine should thus be considered as practically relevant, whereas the mean change in SDLP after all mequitazine doses was well below the criterion value of clinical relevance. In fact, the effects of mequitazine were not very different from other "nonsedating" second generation antihistamines given in multiple or higher than normal doses in healthy volunteers (O'Hanlon \& Ramaekers, 1995).

Dexchlorpheniramine's reduction of alertness and driving capacity of healthy volunteers in the present study confirmed the general notion that $1^{\text {st }}$ generation antihistamines can impair performance to significant levels. However, dexchlorpheniramine's effects on the highway driving performance were also less pronounced than these observed for other related compounds. The reason is that dexchlorpheniramine was given as a sustained release formulation. Basically this means that during time of testing only half of the substance (i.e. $3 \mathrm{mg}$ ) had been liberated and absorbed for systemic use, whereas the remaining $3 \mathrm{mg}$ was gradually released 3 to 6 hours post administration. Dexchlorpheniramine's effects would have been twice as big if it had been released all at once. Similar findings have been reported with triprolidine. A single dose of triprolidine $5 \mathrm{mg}$ produced more driving impairment as compared to a controlled release formulation of triprolidine $10 \mathrm{mg}$ (Riedel, Schoenmakers, \& O' Hanlon, 1989; Riedel et al., 1990). 
Cetirizine $10 \mathrm{mg}$ did not affect any performance measure in the present study. This scems somewhat surprising given that clinical studies have shown elevated levels of drowsiness in patients treated with ceririzine (Monroe, 1988; Meltzer, Weiler, \& Widlitz, 1996; Mann, Pearce, Dunn, \& Shakir, 2000). Still, previous studies assessing ceririzine's effects on psychomotor behaviour and driving have provided mixed results. Several studies demonstrated sedative effects of cetirizine ( $5-15 \mathrm{mg}$ ) using psychomotor tasks e.g. reaction speed, tracking behaviour, divided attention, and subjective measures of sleep (Ramaekers et al., 1992; Nichoison \&. Turner, 1998), whereas others did not show this effect in doses up to $20 \mathrm{mg}$ (Gengo, Gabos, \& Mechtler, 1990; Hindmarch, Johnson, Meadows, Kirkpatrick, \& Shamsi, 2001). Using the same highway driving test as the present study, Ramaekers et al. (1992) showed a significantly impairing single dose effect of cetirizine $10 \mathrm{mg}$ on driving, whereas Volkerts et al. (1992) were unable to assess any impairment after the single and repeated administration of the same dose. It was suggested that the discrepancy in results was related to differences in subject population and time of testing in both studies $1 \mathrm{O}^{\prime} \mathrm{Hanlon} \&$ Ramaekers, 1995). The study showing an effecr employed a mixed-gender population, while the one showing no effect used a male population. In the latter study the acute effects of cetirizine were assessed at $T_{\text {max }}$ i.e.1-2 hours post-drug, whereas in the former study performance was assessed between $3-4$ hours post-drug. The hypothesis that males and females cliffered in their sensitivity to cetirizine, or antihistamines in general, was unvestigated in two subsequent studies (Vuurman et al., 1994; Vermeeren et al., 2002). They demonstrated that antihistamine induced impairment is generally more pronounced in female subjects. The study by Vermeeren et al. (2002) employed cetirizine $10 \mathrm{mg}$ as one of the comparative drugs. It showed that single and repeated doses of cetirizine produced mild driving impairment between 3-4 hours post-dosing, and that women were more impaired. The hypothesis that cetirizine's effect also depends on time of testing was basically confirmed by the failure in the present study to establish any effect of cetirizine on driving performance of males and females between $1-2$ hours post-drug. The absence of a cetirizine effect between 1-2 hours post-drug in this study and that by Volkerts et al. (1992) indicates that there is a possible time shift berween peak plasma concentrations and maximal drug effect. This time lag has been found using wheal and flare tests and electroencephalographic measures of sedation (Shall, Barkley, \& Millard, 1989; Sannita, Crimi, Riela, Rosadini, \& Brusasco, 1996; Urien, Tillement, Ganem, \& Kuch, 1999). The likelihood of detecting an impairing effect of cetirizine may therefore increase when testing is conducted between 3-4 hours post-drug, i.e. closer to the time when cetirizine's pharmacodynamic effect is maximal.

Although it is clear that SDLP reflects a fundamental aspect of driving performance, i.e. road tracking control, it should not be taken as an overall measure of driving. Driving is a complex task comprising decision making, risk evaluation, interaction with other road user and a range of other higher-level skills. Drug induced changes in any of these task parameters will not automatically be reflected in SDLP. Nonetheless, performance in the highway driving test seens highly relevant because it has been show to strongly correlate $(r=95)$ with the incidence of somnolence in patients treated with antidepressants, most of which are also strong $\mathrm{H1}$-receptor antagonists (Ramaekers, 2003). In addition, it has been shown that drug effects measured in a range of conventional psychomotor tests, e.g. tracking, reaction time, critical flicker fusion were only moderately related to performance in the highway driving test. The lack of correlation between performance in conventional laboratory test and in the actual driving test suggests the former are less sensitive to drug effects or possess less construct validity (Ramaekers, 2003). 
In conclusion, mequitazine caused mild, dose related impairment of driving and attention. Mequitazine's effect on performance is comparable to other "non-sedative" second generation antihistamines in that impairment is virtually absent at lower doses but apparent at higher doses.

\section{Acknowledgements}

This study was sponsored by Pierre Fabre Médicament, France. We thank Drs. M. van Lansbergen and Dr. N. Muntjewerff for their respective contributions to this study. 
Chapter 2 


\section{REFERENCES}

Baddeley, A. D. (1968). A 3 min reasoning test based on grammatical ranstomaton. Psychomomo Soience, $10(10), 341-342$

Beaumont, D., Hugonot, L. B. Hugonot, R. (1986). Erude comparative de la terfenuline er ale la méquitazine dans le raitemene symptomatique de la thinte allergique pollinique. Tempo Médinal. $224,53-59$.

Blamoutier, J. (1978). Comparative trial of two anthistamines, mequitaine and bomplentannine. Current Medical Research and Opmimn, 5(5), 366-370.

Bond. A. \& Lader, M. (1974). The use of analogue scales in rating subjective feelings. Brish Jomimal of Medical Psychology, 47(3), 211-218.

Borkenstein, R. F, Crowther, R. F, Shumate, R. P., Ziel, W. B. \& Zylman, R. (1974). The role of the drinking driver in traftic accidents. Blwalkohol, II (suppl 1), 1.131.

Brookhuis, K. A., De Vries, G., \& De Waard, D. (1993). Acute and subchronic effects of the H1. histamine receptor antagonist elastine in 10,20 and $30 \mathrm{mg}$ dose, and triprolidine $10 \mathrm{mg}$ on car driving performance. British jothnal of clinical phamacology, 36(1), 67.70.

Caille, E. J. (1979). Endle comparative en double aveugle de la méguitazine, de la dexchlorphenimmine et d"un placebo sur la vigilance. Gazetre Médicale de Framee, 86, 3737-3744.

Curran, H. V. Powibonsuk, P., Dalton, ). A., \& Lader, M. H. (1998). Differentiating the effects of centrally acting drugs on arousal and memory: an event related potential study of scopolatnine, lorazepan and diphenhydramine. Psychophamacology, 135(1),27-36.

Curan, S. (1990). Critical Flicker Fusion Techniques in prsphopharmacology. In I. Hindmarch \& P. D. Stonier (Eds.). Humam Psychophamacology (Vol. 3, pp. 21-38). Chichester: Wiley.

CVZ. (1999). Farmacotherapeutisch Kompas. Amstelveen: College Voor Zorgwarzekering.

Gengo, E. M., Gathos, C. \& Medrtler, J.. (1990). Quantitative effect of cetirizine and diphenhydramine on mental performance measured using an automobile driving simulator.

Amn Allergy, 64(6), 520-526.

Gervais, P., Gervais, A., De Beule, R., \& Van der Bijl, W. (1975). Essai compare d'un nouvel antihistaminicue, la mequitazine, et d'un placelwo. Acta Allergologica, 30(5), 286.297.

Hindmarch, 1., \& Easton, J. C. (1986). A placebo-controlled assessment of mequitazine and astemizole in tests of psychomotor ability. Internatimal Jomal of Clinical Phamacologe Reseath, 6(6), 457464.

Hindmarch, 1., Johnson, S. Meadows, R., Kinpatrick, T., \& Shamsi, 2. (2001). The ante and sul chronic effects of levocetirizine, cetirizine, loratadine, promethaine and placelos an cognitive funcrion, psychonotor performance, and weil and flare. Coment medical reseach and opinion. $17(4), 241-255$

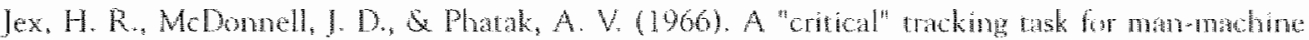
research velated to the operitor's effective delay rime. I. Theory and experiments with a trist-arder divergent controlled wement. NASA CR-616. NASA Contrat Rep NASA CR, 1-105.

Kay, G. G. (2000). The effeets of anthistamines on cognition and pertomance. Joumal of Alloger and Clintal Immonology, $105(6 \mathrm{Pt} 2), \$ 622627$

Lonwerems, J. W. Glocrich, A. B. M. de Vries, G., Brookhuis, K. A., G OHanlon, J. F. (1987),

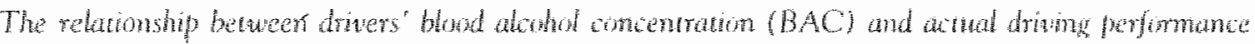

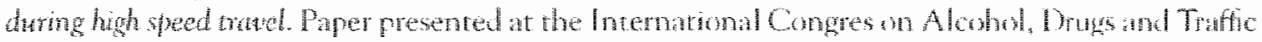
Safery, T86, Amsteralam. 


\section{Chapter 2}

Mam, R. D. Pearce, O.L., Durn, N., Shaki, S. (2000). Sedation with "non-sedating" and histamnes fou prescription-event moniroring studies in general pactice. Brish Medical Joumal, $320(7243)$, 1184.1186.

Melrzer, E. O., Welle, ]. M. \& Widitx, M. D. (1996). Comparative outdoor study of the efficacy. onset and duration of action, and safery of cetrizine, loratadine, and placebo for seasonal allergic thinits Joumal of alletgy and dincal immunalogy, $97(2), 617.626$.

Montoe, $\mathrm{E}$. W. (1988). Chronic urticaria: review of nonsedating $\mathrm{H} 1 \mathrm{l}$ artihistamine in reatment. Joumal of the Americar Academy of Dermatolugy. $19(5 \mathrm{Pr} 1), 842-849$.

Moskowitz, H. (1973). Laboratory studies of the effects of alcohol on some variables related to driving. fot thal of Safery Research: $5,185-192$.

Mulder-Hajonides wan der Meulen, W. R. E. H. (1981). Measurements of subjective sleep cualiry, Procedings of the International European Sleep Congress. Amsterdam: Elsevier.

Muler, H, \& Blum, F. (1978). Essai compare de deux anthistamingues: Mequitazine et

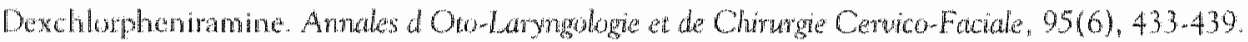

Nicholson, A.N., \& Stone, B. M. (1983). The HI montagonist mequitazine: studies on performance and visual fenction. Eusopean foumal of Clinical Phomacology, 25(4), 563-566.

Nicholson, A. N.\& Turner, C. (1998). Central effects of the HI-antihistamine, ceririme. Aviation Space and Enwrommental Medicine, 69(2), $166-171$.

OHanlon, J. F, Haak, T. W. Blatuw, G. I. S Riemersma, I. B. (1982). Diazepam impairs lateral postion control in highway driving. Srience, 217(4554),79-81.

OHanlon, J. F, \& Ramackers, J O. (1995). Antihistamine ffects on acual driving performance in a standand test: is summary of Dutch experience, 1989-94. Allergy, 50(3), 234-342.

Onodera, K., Kamatodani, A. Watanabe. T., \& Wada, H. (1994). Neuropharmacology of the hiscuminergic netron spstem in the brain and its relationship with behavioral disorders. Progress in Neurobiology, 42(6), 685.702.

Onoe, H. Yamatodani, A., Watmabe, T., Ono, K., Mochizuki, T. Wada, H., \& Hayaishi, O. (1992),

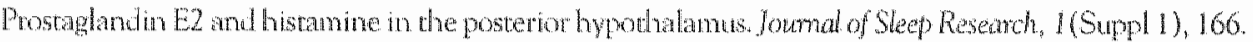

Panula, R., Kartstedt, K., Sallnen, T., Peitsato, N., Kaslin, J. Michelsen, K. A., Anichtehik, O., Kukko-Lukjanov, T., \& Lintunen, M. (2000). The histaminergic system in the brain: structural chanacteristics and changes in hibemation. Joumad of Chemical Nemonatomy, 18(1-2), 65-74.

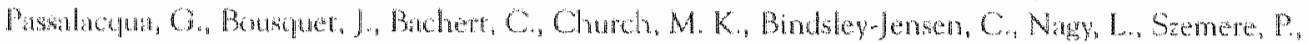
Davies, R. J., Dutham, S. R., Herak, F, Kontow Fil, K., Malling, H. J., van Cauwenberge, P. \& Canonicn, O. W. (1996). The clinical safery of Hl-recepter anagenists. An EAACl position paper. Altergy, $51(10), 606675$.

Rammekers, C., Limers, I. Vorhew, F, Munrjewerf, D. Mobbs, E. Sanders, N. Lewis, M. \& Lockton, A. (2002). A comparane study of the effects of cabamazepine and the MMDA recepor antagonis remacemide on road tracking and car-following performance in actual traffic. Psychohumacolary (Beb) 159(2), 203-210.

Ramakers, J. O. (2003). Antidepressunts and driver impaiment empincal evidence from a standard

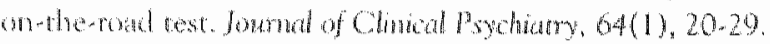

Ramakers, J. C., \& OHanlon, J.E. (1994). Acrivastive, terfendine and diphenhydramine eftects on driving performance as a function of dose and time after dosing. European foumal of Chical Phamacidigy. 47(3), 261-266.

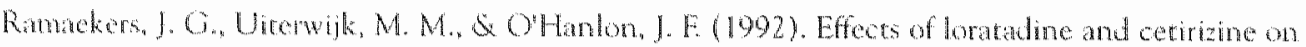
actual driving and psychomervic tese performance, and EEO during driving. European Jowmal of Cimeal Phomuicology, 42(4),363-360). 
Rey, A. (1964). Lexomen Clmuque en Psychologe. Parts Proses Unwerstatre de frawe.

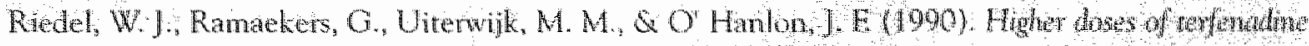

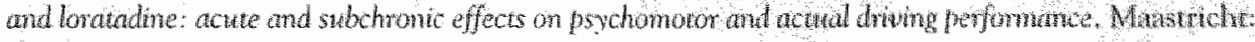
Institute for Drugs, Safery and Behavior, University of Limbarg.

Riedel, W. J., Schoenmakers, E. A. I. M., \& O Hanlon, J. F (1989). Sedation and perfomance imparment with anthistamines. In M. A. Kalmger (Bd.), Mandgenent of allengy we $1990 \mathrm{~s}$ (p). 38-49). Toronto: Hans Huber.

Rimmer, S. J., C Church, M. K. (1990). The pharmacology and mechanisms of action of histamine H1-antagonisrs. Clinical and Experimental Allergy, 20 5tppl 2, 3-17.

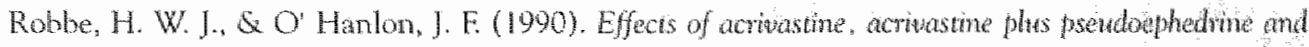
triprolidime on highway drining. Maastricht: Institute for Drugs, Safery and Behavior Universicy of Limburg.

Rombar, N. E. I, S Hindmarch, 1. (1994). Psychometric Aspects of Anthistamines: A Review. Haman Psychophamacology, $9,157-169$

Sannita, W. G., Crimi, E., Rida, S., Rosadini, G. \& Brusasco, V. (1996). Cutaneous anthistaminic action of ceririze and dose-related EEG concomitants of sedation in man. Europeam Jommal of Phamacolog, $300(1-2), 33.41$.

Schmitt, J. A., Riedel, W. J., Vuurman, E. F, Kruizinga, M., G Ramaekers, J. G. (2002). Modulation of the critical ficker fusion effects of serotonin reuptake inhibitors by concomitant pupillarys changes. Psychophamacology (Berl), 160(4), 381-386.

Shall, L., Barkley, A., \& Milland, L. G. (1989). HI receptor antagonism of terfenodine, cetrizine and Loratadine of histamine induced wheds in man. Paper presented at the XVth Congress of the European Academy of Allergology and Clinical Immunology, Berlin.

Shamsi, Z. \& Hindmatch, 1. (2000). Sedation and antihistamines: A review of interadrug differences using proportional impairment ratios. Human Psychophamacology Clinical and Expermental, 15(Suppl 1), 53-530.

Smith, J. M., \& Misiak, H. (1976). Critical flicker frequency (CFE) and psychotropic drugs in normal human subjects-a review. Psychopharmacologia, 47(2), 175-182.

Snyder, S. H. \& Snowman, A. M. (1987). Receptor effects of cetirizine. Am Allergy, 59(6 Pr 2), 4-8.

Solkolski, K. N., Nguyen, B. D., E DeMet, E. M. (2000). Decreases in dilared pupil size in depressed partents with age may reflect atrenergic changes. Psychany $R$ search, 94(3), $267-272$.

Stembusch, H. W. (1991). Distribution of histaminergic neurems and fikers in rat brain. Comparison

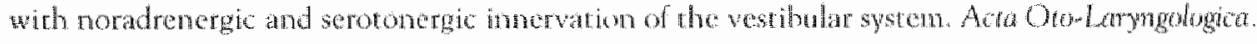
Supplement, $479,12-23$.

Uricn, S. Tillement, 1. P., Ganem, B. S. Kucly, M. D. (1999). A phamacokinctic phatmacodynamic modelling of the antihistaminic $(H 1)$ eftects of cetirizine. Intemational fommal of Clinical Phumatology and Therapentics, $37(10), 499.502$.

Van Wauwe, J., Awouters, F., Neimegeers, C. J., Jansens, F, Wan Nueten, J. M. \& Jansen, P. A.

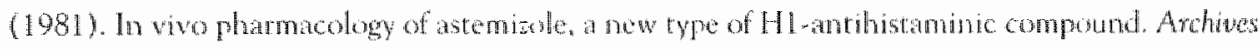
Intenationales de Phamacolymamie et de Therapie, 251(1), 39-51.

Vermeeren, A. Riedel, W. I., van Foxtel, M. P., Darwish, M., Pary, 1, Q Patar, A. (2002). Differencial residuat effects of anlefton and zopiclone on actual driving: a comparison with a low dose of alcohol. Sleep, 25(2), 224-231. 
Volkurts, E. R, Van Willigenburg, A. P, Van Lar, M. W, E Maes, R. A. (1992). Does cerizine belong to the new generation of antihistamines? An investigation into its acute and subchronic efocts on highwy dring psychomerric rest performance and daytime sleepiness. Human Psychowamaladagy Clmical and Expesmental, 7(4), 227-238.

Vuurman, E. F, Muntyeserf, N. D., Uiterwilk, M. M., van Veggel, L. M., Crevoisier, C., Haghnd, L., Kintig, M. \& OHanlon. J. F (1996). Efects of mefloqune alone and with aloohol on psychomotor and driving pertormance European Jownal of Clmical Phamacology, 50(6), 475-482.

Vuarman, E. F, Uiterwik, M. M. Rosenzweig, P. \& OHanlon, I. F (1994). Effects of mizoldstine and clematrine on actual driving and psychomotor performance in healthy volunteers. European Jowmal of Clinical Pharmacology, 47(3), 253-259.

Wood, S. G. John, B. A., Chasseaud, L. F, Yeh, J. \& Chung. M. (1987). The metabolism and pharmacokinetics of 14 Cetirizine in humans. Am Allergy, $59(6 \mathrm{Pt} 2), 31-34$.

Wodward, 1. K. \& Munro, N. L. (1982). Terfenadine, the first non-sedating antihistamine. Arzmeinatelforchumg, $32(9 \mathrm{a}), 1154-1156$.

Yamatodani, A., Inagaki, N. Pancla, P., Itowi, N., Watanabe, T., \& Wada, H. (1991). Structure and Funcrions of the Histaminergic Neurone System. In O. V. R. Born (Ed.), Handbook of Experimental Pharmacology (Vol. 97, pp. 243-283). Berlin: Springer-Verlag.

Yanai, K., Okamura, N., Tagawa, M., Iroh, M., \& Watanabe, T. (1999). New findings in pharmacological effects induced by antibistamines: from PET studies to knock-out mice. Cimical and Experinental Allergy, 29 Suppt 3, 29-36; discussion 37.28.

Yhialo, P., Nieminen, K., Wilen-Rosenquist, G., Fourtillan, J. B., Giraulr, J., Ylitalo, L., Pukander, J. S., S. Karma, P. H. (1989). Serum levels and uninary excretion of mequitazine after a single oral dose. Intemational Jatmal of Clinical Phamacolog Reseanch, 9(5), 305-308. 



\section{Repeated-dose effects of mequitazine, cetirizine and dexchlorpheniramine on driving and psychomotor performance}

\section{Chapter 3}

Accepted for publication as:

Theunissen, E. L., Vermeeren, A., \& Ramaekers, J. G. Repeated-dose effects of mequitazine, ceririzine and dexchlorpheniramine on driving and psychomotor performance.

British Joumal of Clinical Pharmacology. 
Chapter 3

\section{ABSTRACT}

Aims: Previous studies demonstrated that the antihistamines mequitazine, cetirizine and dexchlorpheniramine produce mild sedation after single doses. It is unknown, however. whether acute sedation petsists after repeated dosing. Therefore, the present study assessed the effects of repeated dosing of these antihistamines on driving and psychomotor performance.

Methods: Sixteen healthy volunteers were treated with mequitazine $10 \mathrm{mg} \mathrm{q.a.m.,} \mathrm{cetirizine}$ $10 \mathrm{mg}$ q.a.m., dexchlorpheniramine Repetab $6 \mathrm{mg}$ b.i.d. and placebo for four separate 8 -day periods. Drug effects were assessed on day 1 and day 8 using two on-the-road driving tests (highway driving and car following), psychomotor tests (tracking and divided attention) and subjective questionnaires.

Results: Both dexchlorpheniramine and mequitazine significantly impaired driving performance on the highway driving test on the first day; dexchlorpheniramine increased SDLP-scores by $2 \mathrm{~cm}(95 \%$ confidence interval (CI): 0.5 to 3.8$)$ and mequitazine by $2.5 \mathrm{~cm}$ (CI: 1.0 to 4.3). These effects on driving performance disappeared after 8 days of treatment. No effect of treatment was found on car following, tracking and divided attention. Although subjective ratings confirmed that subjects knew theur driving had been impaired in the mequitazine and dexchlorpheniramine condition after completion of the highway driving test on day 1 , they did not expect their driving to be affected before the start of the test. Cetirizine did not impair performance on any of the tests.

Conclusions: Single doses of mequitazine $10 \mathrm{mg}$ and dexchlorpheniramine Repetab $6 \mathrm{mg}$ cause mild driving impairment. However, when taken over several days, the impairing effect wears off, possibly as a result of tolerance. 


\section{INTRODUCTION}

Antihistamines ( $\mathrm{H} 11$-antagonists) are widely used to treat allergies and do so by blocking peripheral $\mathrm{H} 1$-receptors. However, these drugs also cross the blood-brain barrier and block neuronal histamine transmission as well as other neurotransmitter systems (e.g. serotonin, acerylcholine, noradrenaline) in the central nervous system (Simons \& Simons, 1994). As a consequence they produce sleepiness, fatigue and sedation (Passalacqua et al., 1996). The sedative effects of antihistamines can lead to diminished concentration or productivity and an increased risk for occupational injuries and traffic accidents (Gilmore, Alexander, Mueller, \& Rivara, 1996; Nolen, 1997; Burton, Conti, Chen, Schultz, \& Edington, 2001). Therefore it is necessary to study and compare the sedative and porentially impairing effects of all antihistamines.

First generation antihistamines have been shown to produce significant performance impairment in psychomotor and in driving tests (Moskowitz \& Burns, 1988; O'Hanlon \& Ramaekers, 1995; Hindmarch \& Shamsi, 2001). More recent antihistamines, such as cetirizine, loratadine, ebastine and terfenadine were developed to overcome the sedative side effects of the first generation antihistamines. These second generation antihistamines cross the blood. brain barrier less readily, and consequently are less sedating than their predecessors when given in the recommended dose (Hindmarch \& Shamsi, 1999). Experimental studies have shown that single therapeutic doses of second generation antihistamines produce little or no impairmenr of attention, memory, vigilance, psychomotor performance or driving (Moskowitz \& Burns, 1988; O'Hanlon \& Ramaekers, 1995; Kay et al., 1997; Hindmarch \& Shamsi, 2001). Higher doses, however, were occasionally found to produce significant sedarive effects, although less pronounced than those of first generation antihistamines (Riedel, Ramaekers, Uiterwijk, \& O' Hanlon, 1990; Brookhuis, De Vries, \& De Waard, 1993; Rarnaekers \& O'Hanlon, 1994; Vuurman, Uiterwijk, Rosenzweig, \& O'Hanlon, 1994).

Since antihistamines are usually taken for periods longer than one day in the treatment: of allergic thinitis or urticaria, it is not only relevant to asses their effects after single doses, but also after repeated doses, when blood levels are at steady state. Studies have shown that their impairing effects can either diminish or increase over time (Seppala, Nuotto, \& Korttila, 1981; Riedel et al., 1990; Robbe \& O' Hanlon, 1990; Volkerts, Van Willigenburg, Van Laar, \& Maes, 1992; O'Hanlon \& Ramaekers, 1995; Vermeeren \& O'Hanlon, 1998; Hindmarch \& Shamsi, 2001; Richardson, Roehrs, Rosenthal, Koshorek, \& Roth, 2002; Verster, de Weert et al., 2003; Verster, Volkerts et al., 2003). On the one hand, the effects of triprolidine (5 and $10 \mathrm{mg}$ ), diphenhydramine $(50 \mathrm{mg})$ and clemastine $(2 \mathrm{mg})$, on driving and psychomotor performance were found to diminish, although not disappear with repeated dosing (Seppala et al., 1981; Robbe \& O' Hanlon, 1990; Volkerts et al., 1992; Vermeeren \& O'Hanlon, 1998; Richardson et al., 2002; Verster, de Weert et al., 2003; Verster, Volkerts et al, 2003). On the other hand, high doses of ebastine $(30 \mathrm{mg})$ and terfenadine $(120 \mathrm{mg})$, were found to produce sedation only after repeated doses (Riedel et al., 1990; O'Hanlon \& Ramaekers, 1995; Hindmarch \& Shamsi, 2001). It seems therefore that effects can diminish over time as a result of tolerance, or increase as a result of accumulation, depending on the drug and dose.

The objective of the present study was to asses the effects of repeated doses of mequitazine $10 \mathrm{mg}$, dexchlorpheniramine Repetab $6 \mathrm{mg}$ and cetirizine $10 \mathrm{mg}$ that were previously shown to produce performance impairment after single doses (Muler \& Blum, 1978; Caille, 1979 ; Nicholson \& Stone, 1983; Ramaekers, Uiterwijk, \& O'Hanlon, 1992; Nicholson \& Turner; 
1998; Vermeeren, Ramaekers, \& O'Hanlon, 2002; Theunissen, Vermeeren, van Oers, van Maris, \& Ramaekers, 2004). Impairing effects were assessed using two validated driving tests and psychomotor tests previously shown to be sensitive to antihistamine induced sedation (Ramaekers et al., 1992; Verster, Volkerts et al., 2003; Vuurman, Rikken, Muntjewerff, de Halleux, \& Ramaekers, 2004).

\section{METHODS}

\section{Subjects}

Sixteen healthy volunteers ( 8 malles and 8 females), aged between 22 and 45 years, were recruited by means of newspaper advertisements. Subjects were healthy according to medical history, physical examination, electrocardiogram, blood and urine analysis. All participants possessed a valid driver's license for at least 3 years and had driving experience of at least $5000 \mathrm{~km}$ per year. Subjects with a history of major medical or psychiatric disorders were excluded from the study, as were subjects with unusual sensitivity to antihistamines, drug abuse and chronic use of medication (except contraceptives). Women who were not using an approved contraception or women who were pregnant or lactating were excluded. Written informed consent was acquired from each subject prior to participation. The study was approved by the Ethics Committee of Maastricht University and conducted in accordance with the World Medical Associations Declaration of Helsinki (Edinburgh modification, 2000).

One male subject dropped out for reasons untelated to the treatment. Mean $\pm \mathrm{SD}$ age of the remaining 15 participants was $32 \pm 9.1$ years and mean weight $\pm S D$ was $73.7 \pm 15.1 \mathrm{~kg}$ (women, $64.5 \pm 10.8 \mathrm{~kg}$; men $84.3 \pm 12.4 \mathrm{~kg}$ ). All subjects were non-smokers and used an average of $2.7 \pm 2.2$ caffeine containing beverages per day.

\section{Drug Administration}

This study was conducted according to a 4-way, double blind, cross-over design. Treatments consisted of a regular therapeutic dose: mequitazine $10 \mathrm{mg}$ once daily in the morning (q.a.m.), cetirizine $10 \mathrm{mg}$ q.a.m.; dexchlorpheniramine $6 \mathrm{mg}$ (Repetab) twice daily (b.i.d.), and placebo (b.i.d.). Treatment duration was 8 days starting on the morning of day 1 . Tests were conducted on day 1 and 8 of each treatment period. The washout period between treatment periods was at least 7 days.

On test days, drugs and placebo were administered using a double dummy technique, since cetirizine is more rapidly absorbed than mequitazine and dexchlorpheniramine; cetirizine reaches peak plasma concentrations $\left(\mathrm{T}_{\text {max }}\right)$ approximately 1 hour after oral dosing, whereas mequitazine and dexchlorpheniramine reach $T_{\max }$ between 3 and 4 hours after administration. Therefore, mequitazine and dexchlorpheniramine were administered at 09.00 hours, i.e. three hours before driving, with a placebo capsule at 11.00 hours to maintain blinding. Cetirizine was administered at 11.00 hours, i.e. 1 hour before driving, with a placebo capsule at 09.00 hours to ensure blinding. In the placebo condition, placebo capsules were administered at both times. Between test days, subjects continued treatments at home, taking one capsule in the morning and one in the evening. In the mequitazine and cetirizine conditions, the active drug was taken in the morning while a placebo was taken at night. 
Dexchlorpheniramine and placebo were both taken in the morning and in the evening in the dexchlorpheniramine and placebo condition, respectively. Subjects noted the rimes of drug administration in a diary, as well as the use of any concomitant medication.

\section{Procedure}

Subjects were individually trained in all tests in the two weeks prior to their first treatment period. Subjects had to abstain from alcohol the day before testing and agreed to have a good night's rest of at least 7 hours. On test days consumption of caffeine was not allowed and smoking was prohibited 30 minutes prior and during tescing. On test days, subjects were transported to the laboratory where drugs were administered at 09.00 and 11.00 hours. At arrival, sleep quality of the previous night was measured using the Groningen Sleep Qualiry Scale. Ar 10.00 hours they received a standardized light meal. The highway-driving test started at 12.00 hours and the car-following test at 13.00 or 13.30 hours. Laboratory tests were started at 14.30 hours.

\section{Performance measures}

Tests used in this study have been described in more detail in previous papers (Vermeeren $\&$ O'Hanlon, 1998; Theunissen et al., 2004).

\section{- Driving tests}

In the highway-driving test, the subject drives a specially instrumented vehicle over a 100 $\mathrm{km}$ (61 miles) distance on a primary highway. The subject has to maintain a steady lateral position between the delineated boundaries of the right (slower) traffic lane and to maintain a constant speed of $95 \mathrm{~km}$ ( 58 milles) per hour. The primary dependent measure is the Standard Deviation of Lateral Position (SDLP), which is an index of the continuous road tracking error.

In the car-following test subjects drive a specially instrumented car and follow a vehicle controlled by an experimenter. The latter or "leading" car occasionally changes speed and briefly lights up its brake lights. Subjects are required to keep driving at the same speed as the leading vehicle and to maintain a 15-30 meter distance between the cars. In addition, subjects have to react as quickly as possible to the brake lights of the leading car. The primary dependent measures are time to speed adaptation (in ms), and reaction time (in ms) to the brake lights. Deviation in distance to the leading car (in $\mathrm{m}$ ) is a secondary parameter.

During both driving tests a licensed driving instructor accompanies the subject, and can intervene when necessary by using dual controls.

\section{- Psychomotor tests}

The Critical Tracking Test measures the subjects' ability to control a displayed error signal in a first-order compensatory tracking task. The frequency at which control is lost is called the "criticial frequency" or lambda ${ }_{c}$ ( $\mathrm{rad} / \mathrm{sec}$ ). The test includes five trails; the average score is calculated after removing the highest and the lowest scores, and is the primary variable in this test.

The Divided Attention Task is used to measure the subject's ability to divide attention between two tasks performed simultaneously. The primary task consists of a tracking task in the central visual field and the secondary task is a monitoring task in the peripheral visual field. Subjects react to peripheral targets using a foot pedal. Dependent variables are the absolute mean tracking error over the entire test and mean reaction time to peripheral targets. 


\section{- Subjective measures}

Sleep quality of the previous night was assessed by means of the Groningen Sleep Quality Scale (Mulder-Hajonides van der Meulen ${ }_{i}$ 1981). This questionnaire scores the number of sleep complaints, ranging from 0 (good sleep) to 14 (bad sleep), and specific questions about the total amount of sleep, number of awakenings and the estimated time needed to fall asleep.

Subjective driving questionnaires were used in order to evaluate whether patients' subjective expertence of their driving ability corresponds with their objective performance on the driving tests. Prior to the highway driving test, subjects estimated their driving ability and after completion of the test they rated driving performance, using $100 \mathrm{~mm}$ visual analogue scales ranging from 0 (wery bad driving) to 100 (very good driving).

\section{Statistical analysis}

Driving and psychomotor parameters were analyzed separately for days 1 and 8, using an ANOVA with Subject, Treatment and Period as factors. Subsequently, analyses for comparing treatments with placebo were conducted, using three simple contrasts with sequential Bonferroni correction. In case of a significant effect, one tailed, $95 \%$ confidence intervals (CI) of drug-placebo differences were calculated. The effects of gender on driving performance were analyzed, using a model including Treatment, Period, Gender and Gender by Treatment. All statistical tests were conducted using SPSS (version 10.0).

\section{RESULTS}

\section{Missing data}

Due to technical problems, the car-following test could not be performed by two subjects on two separate accasions. Distance measures between the cars was lost for another two subjects on two separate occasions also as a result of technical problems.

\section{Driving Performance}

Four highway driving tests of a single subject were terminated before scheduled completion, because the driving instructor (on day 1 and 8 of the placebo condition and day 1 of the dexchlorpheniramine condition) or the subject (day 8 of cetirizine treatment) judged it would be unsafe to continue. The respective rides were $91 \%, 90 \%, 68 \%$ and $50 \%$ complete when the test was stopped. SDLP scores calculated over the completed parts of these rides were $23.8,24.6,32.7$ and $24.6 \mathrm{~cm}$, respectively. Statistical analysis of datasets including or excluding scores of incomplete rides revealed comparable results, therefore incomplete rides were included in the analysis.

A summary of descriprives and quantitative statistical analyses of all performance parameters is presented in Table 1. Mean (SEM) SDLP in each condition and for both days is shown in Figure 1.

The overall effect of Treatment on SDLP was significant on day $1\left(\mathbb{F}_{3,39}=8.16 ; p<.001\right)$ but not on day $8\left(\mathrm{~F}_{3,39}=0.99\right)$. Contrasting each drug with placebo showed that on day 1 , SDLP was significantly increased after treatment with mequitazine (mean $2.5 ; \mathrm{Cl}: 1.03$ to $4.25 ; \mathrm{F}_{1,39}=$ $11.03 ; \mathrm{p}=.002$ ) and dexchlorpheniramine (mean 2.0; CI: 0.46 to $3.68 ; \mathrm{F}_{1,39}=6.75 ; \mathrm{p}=.013$ ), but not after cetirizine (mean $0.8 ; F_{1,39}=.79$ ). The overall effect of Period on SDLP was significant on day 1 and $8\left(\mathrm{~F}_{3,39}=4.15 ; \mathrm{p}=.012 ; \mathrm{F}_{3,39}=4.69 ; \mathrm{p}=.007\right)$. Contrasting driving performance in 


\begin{tabular}{|c|c|c|c|c|c|c|c|}
\hline & \multicolumn{4}{|c|}{ Mean \pm SEM per treatment } & \multicolumn{3}{|c|}{ Treatment effect } \\
\hline s. & बा & HA & DAY 1 & & & & \\
\hline & PLA & MEQ & $\mathrm{CET}$ & $\mathrm{DEX}$ & E. & $\mathrm{df}$ & p \\
\hline \multicolumn{8}{|l|}{ Driving tests } \\
\hline SDLP (cm) & $19.2+1.0$ & $217 \pm 1.1^{3}$ & $18.4 \pm 0.8$ & $212+13$ & 8,16 & 3.39 & $<.001$ \\
\hline Time to speed adaptation (sec) & $1.9 \pm 0.2$ & $23 \pm 0.3$ & $2.1 \pm 0.3$ & $20 \pm 04$ & 102 & 338 & NS \\
\hline Brake reaction time (msec) & $476 \pm 19$ & $528 \pm 29$ & $537 \pm 24$ & $492+26$ & 236 & 3,38 & NS \\
\hline SD headway (m) & $52+11$ & $43 \pm 0.7$ & $5.3 \pm 0.7$ & $40+05$ & 0.74 & 3,38 & NS \\
\hline \multicolumn{8}{|l|}{ Critical tracking task } \\
\hline Critical frequency (rad/sec) & $39 \pm 0.2$ & $3.8 \pm 0.2$ & $40 \pm 0.2$ & $39 \pm 02$ & 1.21 & 3.39 & NS \\
\hline \multicolumn{8}{|l|}{ Divided attention task } \\
\hline Tracking error (mm) & $212+15$ & $211 \pm 1.2$ & $20.4 \pm 14$ & $229 \pm 1.4$ & 2.83 & 339 & .05 \\
\hline Reaction time (msec) & $1747 \pm 64$ & $1799 \pm 54$ & $1807 \pm 69$ & $809 \pm 70$ & 0.76 & 339 & NS \\
\hline 8 & & & DAY 8 & 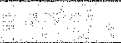 & 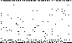 & & \\
\hline & PLA & MEQ & $\mathrm{CET}$ & $\mathrm{DEX}$ & I & $\mathrm{df}$ & $p$ \\
\hline \multicolumn{8}{|l|}{ Driving tests } \\
\hline $\operatorname{SDLP}(\mathrm{cm})$ & $19.9 \pm 1.0$ & $21.0 \pm 1.2$ & $19.6 \pm 10$ & $199 \pm 1,0$ & 0.99 & 3.39 & NS \\
\hline Time to speed adaptation (sec) & $2.2 \pm 0.2$ & $2.2 \pm 0.3$ & $20 \pm 0.2$ & $20 \pm 02$ & 0.80 & 3.38 & NS \\
\hline Brake reaction time (msec) & $506 \pm 23$ & $521 \pm 33$ & $5110 \pm 27$ & $484 \pm 1.4$ & 0.60 & 3,38 & NS \\
\hline SD headway (m) & $5.5 \pm 1.2$ & $5.0 \pm 0.7$ & $5,1 \pm 0.8$ & $4.5 \pm 08$ & 0.41 & 3,36 & NS \\
\hline Critical tracking task & & & & & : & & \\
\hline Critical frequency $(\mathrm{rad} / \mathrm{sec})$ & $40 \pm 02$ & $4.0 \pm 0.2$ & $3.9 \pm 0.2$ & $4.0 \pm 0.2$ & 0.32 & 3.39 & NS \\
\hline \multicolumn{8}{|l|}{ Divided attention task } \\
\hline Tracking error (mm) & $20.0 \pm 1.3$ & $20.6 \pm 1.3$ & $20.4 \pm 13$ & $209 \pm 1.6$ & 0.39 & 3.39 & NS \\
\hline Reaction time (nsec) & $1787 \pm 98$ & $1692 \pm 59$ & $1832+69$ & $1721 \pm 7$ & 1.53 & 3,39 & NS \\
\hline
\end{tabular}

Table 1. Summary of results from the driving and psychomotor tests on day I and day 8 . Treatments are placebo (PLA), mequitazine $10 \mathrm{mg} \mathrm{q.a.m.} \mathrm{(MEQ),} \mathrm{cetirizine} 10 \mathrm{mg}$ q.a.m (CET) and dexchlopheniramine $6 \mathrm{mg}$ Repetab b.id (DEX). Significant drug placebo differences are indiciated by a $p<.017$. NS, not significant; df, degrees of freedom.

period 1 with performance in subsequent periods revealed no systematic change over time, however, and more importantly, no interactions were found between Treatment and Period. There were no significant main effects of Gender or Gender by Treatment interactions on day 1 or day 8 .

Performance in the car-following test was not significantly affected by Treatments, Periods or Gender on days 1 or day 8 . However, it should be mentioned that the incompleteness of the car-following data might be related to the absence of an effect.

\section{Psychomotor tests}

A summary of descriptives and statistical analyses of the psychomotor tests is also presented in Table 1. Tracking performance in the critical tracking test was not significantly affected on day 1 or 8 , and there was only a nearly significant overall effect of Treatment on tracking in the divided attention task $\left(F_{1,39}=2.83 ; p=.051\right)$ on the first day of treatment. Subjects achieved the smallest racking error in the ceririzine condition and the largest in the dexchlorpheniramine condition. Yet, drug-placebo contrasts showed no significant differences. 


\section{Chapter 3}

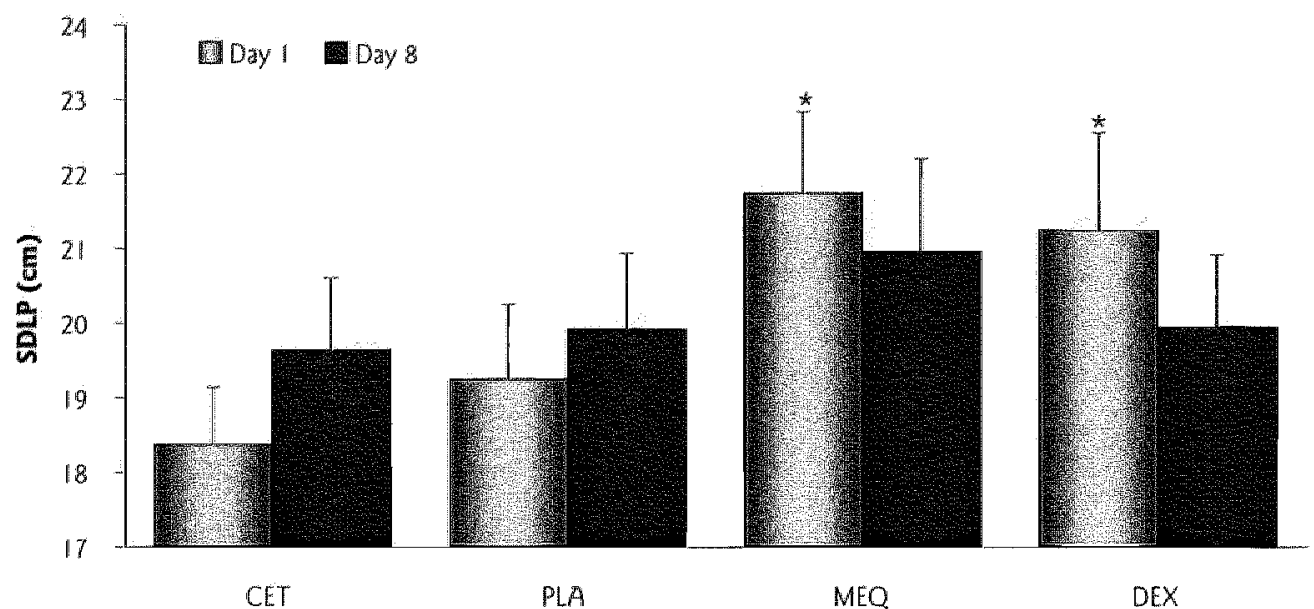

Figure 1. Mean (4SEM) SDLP for each treatment on day 1 and day 8. Treatments are cetirizine $10 \mathrm{mg} q . \mathrm{m}$ (CET), placebo (PLA), mequitazine $10 \mathrm{mg}$ q.a.m. (MEQ), and dexchlorpheniramine $6 \mathrm{mg}$ Repetab b.i.d. (DEX). Agrerisks indicared significant differences from placebo after sequential Bonferroni correction, ine. $p<.017$.

\begin{tabular}{|c|c|c|c|c|c|c|c|}
\hline & & Mean 1 SEI & er treatmen & & Treat & nente & \\
\hline & & 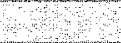 & DAY I & & & & 3 \\
\hline & PLA & MEQ & CET & DEX & F & df & $p$ \\
\hline bjective driving quality & & & & & & & \\
\hline Pretest $(\mathrm{mm})$ & $79,7 \pm 63$ & $791 \pm 65$ & $78.5 \pm 4.6$ & $68.7 \pm 6.3$ & 1,06 & 3,39 & NS \\
\hline Post test $(\mathrm{mm})$ & $679 \pm 6.6$ & $551 \pm 75^{6}$ & $64.7 \pm 6.9$ & $5=5 \pm 8.0^{\circ}$ & 4.55 & 3.39 & .008 \\
\hline Sleep questionmaire & & & 3 & & & & 3 \\
\hline Sleep latency (min) & $12.4+2.2$ & $18.8 \pm 45$ & $189+4.6$ & $22.6 \pm 5.0$ & 1.06 & 3,39 & NS \\
\hline Number of awakenings & $1.1 \pm 0.3$ & $1.0 \pm 0.3$ & $1 . \pm 0.3$ & $1.1 \pm 0.4$ & 0.00 & 3,39 & NS \\
\hline Sleep (h) & $7.6 \pm 0.2$ & $72.2 \pm 0.2$ & $0.7 \pm 0.3$ & $71 \pm 0.3$ & 2.05 & 3.39 & NS \\
\hline Number of complaints & $1.0 \pm 04$ & $17 \pm 09$ & $2,6 \pm 09$ & $2.7 \pm 0.9$ & 123 & 3,39 & NS \\
\hline & & & DAY 8 & 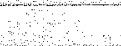 & 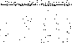 & & 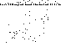 \\
\hline 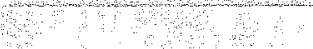 & PLA & MEQ & CET & DEX & $F$ & $\mathrm{df}^{\prime}$ & $p$ \\
\hline subjective driving quality & & & 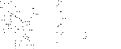 & 9 & & 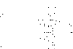 & \\
\hline Prétesl (mm) & $775 \pm 58$ & $73.0 \pm 4.2$ & $86.7 \pm 3.0$ & $72.2 \pm 6.4$ & 266 & 3,39 & NS \\
\hline Post-lest (mm) & $64.3 \pm 5.7$ & $59.5 \pm 6.5$ & $62.7 \pm 7.8$ & $62.3 \pm 6.5$ & 0.23 & 339 & NS \\
\hline Sleep Questionmaire & & $\quad 4$ & & $: 8$ & & 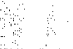 & \\
\hline Sleep latency (min) & $22.3 \pm 6.8$ & $14.6 \pm 3.1$ & $229 \pm 7.1$ & $14.4 \pm 2.1$ & 1.14 & 3,39 & NS \\
\hline Number of awakenings & $0.7 \pm 0.3$ & $0.7 \pm 0.2$ & $0.8 \pm 0.3$ & $1.3 \pm 0.4$ & 1.46 & 3,39 & NS \\
\hline Sleep $(h)$ & $7.4 \pm 0.2$ & $7.5 \pm 0.2$ & $7.2 \pm 0.2$ & $7.3 \pm 0.3$ & 0.36 & 339 & NS \\
\hline Number of complaints & $26 \pm 10$ & $1.5 \pm 0.4$ & $19 \pm 0.7$ & $1.8 \pm 0.6$ & 0.60 & 339 & NS \\
\hline
\end{tabular}

Table 2. Summary of resuls of the sulbjective measures on day 1 and day 8 . Abbrewiations are as indicated in Table 1. Significant drug-placetbo differences are indicated by a $p<.017$; $p<.025$. High scores on the subjective driving quality indicating better driving performance. 


\section{Subjective measures}

A summary of descriptiwes and quantitative statistical analyses of the subjective measures is presented in Table 2.

On day 1 and day 8 sleep quality of the night before resting was comparable in all conditions.

Prior to the driving tests, subjects did not estimate their driving ability to be affected by any of the treatments on day 1 or day 8. At the end of the tests on day 1 however, subjects did notice that their driving performance had been impaired $\left(\mathbb{F}_{3,39}=4.55 ; p=.008\right)$. In line with objective measures of driving performance, subjects tated their driving quality in the mequitazine and dexchlorpheniramine conditions as worse than after placebo (mean - 12.8; $\mathrm{CI}:-24.2$ to $-2.7 ; \mathrm{F}_{1,39}=6.4 ; \mathrm{p}<.025$ and mean $-16.4 ; \mathrm{Cl}-27.8$ to $-6.3 ; \mathrm{F}_{1,39}=10.2 ; \mathrm{p}<.017$, respectively).

\section{DISCUSSION}

Results of this study show that mequitazine $10 \mathrm{mg}$ and dexchlorpheniramine Repetab $6 \mathrm{mg}$ produced mild driving impairment on the first day of treatment. These results were expected and support our previous findings that single doses of these drugs can have impairing effects on actual driving (Theunissen et al, 2004). The magnitude of the driving impairment found after single doses of mequitazine $10 \mathrm{mg}$ and dexchlorpheniramine Repetab $6 \mathrm{mg}$ is comparable to what has been found for second generation antihistamines such as acrivastine $8 \mathrm{mg}$ and mizolastine 10 and $20 \mathrm{mg}$ (Ramaekers \& O'Hanlon, 1994; Vuurman et al., 1994). The present study also showed, however, that these effects disappear within 8 days of treatment.

Although the effects on driving found for mequitazine confirm our previous results, they are not supported by two earlier studies. Blamoutier (1978) and Hindmarch and. Easton (1986) concluded that mequitazine 5 and $10 \mathrm{mg}$ do not produce acute daytime drowsiness. Yer, these investigators used subjective measures and cognitive tests. So their results are in fact in line with those of our present and previous study, showing no significant impairment of mequitazine on performance in psychomotor and cognitive tests or on subjective measures of sedation. This might indicate that these tests are not good predictors for driving ability (Verster, Volkerts, \& Verbaten, 2002; Ramaekers, 2003), or that the effects of these antihistamines were too subrle to be picked up by these tests.

Although dexchlorpheniramine in immediate release formulations ( 2 and $4 \mathrm{mg}$ ) has considerable sedative effects (Okamura et al., 2000; Kamei et al., 2003), results from this study suggests that these effects can be reduced by a controlled release formulation. Similarly it has been shown that controlled release formulations of triprolidine also reduce maximal levels of impairment (Brookhuis et al., 1993; O'Hanlon \& Ramaekers, 1995). Therefore it seems that controlled release formulations are a good way to diminish the sedative effects of antihistamines.

Cetirizine $10 \mathrm{mg}$ had no effects on driving in the present study. Previous studies using the same driving test, however, demonstrated small but significant acute impairing effects after single doses of cetirizine $10 \mathrm{mg}$ (Ramaekers et al., 1992; Vermeeren et al., 2002). The main difference berween the latter studies and the present one is the time of testing with respect to drug administration. Ramaekers et al. 
(1992) and Vermeeren et al., (2002) assessed the effects between 2 and 3 hours after ingestion, whereas in the present study the effects of ceririzine on driving performance were tested between 1 and 2 hours after ingestion (i.e. at $T_{\max }$ ). A previous study (Volkerts et al., 1992) using the same test also failed to find significant effects of cetirizine between 1 and 2 hours after dosing. Together these results suggest that there might be a delay between peak plasma concentrations and maximal effect on performance in the highway driving test. However, because of the impairment demonstrated in two previous driving studies and on psychomotor and subjective measures in other studies, it can not be concluded that cetirizine is always free of sedating effects (Ramaekers et al., 1992; Nicholson \& Turner, 1998; Vermeeren et al., 2002; Tashiro et al., 2004).

The clinical relevance of performance changes in the highway driving test has previously been determined by establishing the relationship berween blood alcohol concentration (BAC) and SDLP (Louwerens, Gloerich, de Vries, Brookhuis, \& O'Hanlon, 1987). Results showed that a BAC of $0.5 \mathrm{mg} / \mathrm{ml}$ is associated with an average increase in SDLP of $2.2 \mathrm{~cm}$. Since a $B A C$ of $0.5 \mathrm{mg} / \mathrm{ml}$ is associated with a significantly higher risk in traffic accidents (Borkenstein, Crowther, Shumate, Ziel, \& Zylman, 1974), an SDLP increase of about $2.2 \mathrm{~cm}$ is considered clinically relevant. On the first day of trearment mequitazine and dexchlorpheniramine increased SDLP with 2.5 and $2.0 \mathrm{~cm}$ respectively. In a previous study, however, mequitazine $10 \mathrm{mg}$ caused an acute SDLP increase of $1.0 \mathrm{~cm}$ and dexchlorpheniramine an increase $2.4 \mathrm{~cm}$ (Theunissen et al., 2004). Although these results seem inconclusive about the degree of impairment caused by mequitazine and dexchlorpheniramine, it shows that some individuals are prone to the sedating effects of these antihistamines and will show signs of impaired driving.

After 8 days of treatment, no treatment caused impairment in driving performance. The fact that the acute impairing effect of these antihistamines disappear after repeated doses has been found previously for other antihistamines and is probably due to tolerance $1 \mathrm{O}^{\prime} \mathrm{Hanlon}$ \& Ramaekers, 1995; Kay et al., 1997; Richardson et al., 2002). Interessingly, a similar tolerance for the effects of $\mathrm{H} 1$-antagonism has been shown with tricyclic antidepressants, whose sedative effects are also mainly caused by H1-receptor blockade (Ramaekers, 2003). The mechanism whereby tolerance for the impairing effects of antihistamines develops, however, is still unclear.

As reported before (Vermeeren et al, 2002), subjects were not aware of the performance impairment caused by antihistamines. On the first day of mequitazine and dexchlorpheniramine treatment subjects were aware of their impaired driving only after the test was completed, but were unable to predict the impairment beforehand. In practice this means that parients treated with antihistamines may be confident about their driving ability, whereas in fact they pose a considerable risk to traffic safery. Therefore, drug labels should warn explicitly for the impairing effects of sedating antihistamines and advice patients to be particularly careful at the beginning of trearment even if they feel capable of driving.

In conclusion, this study showed that mequitazine $10 \mathrm{mg}$ and dexchlorpheniramine Repetab $6 \mathrm{mg}$ can produce mild but clinically relevant effects on driving performance on the first day of treatment but no longer after 8 days of treatment. After 8 days of treatment, the impairing effect of mequitazine and dexchlorpheniramine had disappeared. 


\section{Acknowledgements}

This study was sponsored by Pierre Fabre Medicament, France. We thank Drs. M. van Lansbergen, Drs. 1. van Maris and Dr. N. Muntjewerff for their respective contributions to this study. 
Chapter 3 


\section{RETERENCES}

Blamourier, ]. (1978). Compararive trial of two anchistanines, mequizine and brompheniramine: Cunerat Medical Research and Opinon, 5(5),366-370.

Borkensem, R. F, Crowther, R. F, Shumate, R. P. Zie, W. B. B 2yman, R. (1974). The role of the drinking driver in traffic accidents. Bharalkohol, 11 (suppl $\|$ ), $1-131$.

Brookhus, K. A., De Vries, G., \& De Ward, D. (1993). Acute and subchronic the of the HI. histamine receptor antagonist abastine in 10.20 and $30 \mathrm{mg}$ dose, and triphlidine $10 \mathrm{mg}$ an $\mathrm{cm}$ ariving performance. British joumal of chimal phamacology, $36(1), 67,70$.

Burton, W. N. Conti, D. J., Chen, C. Y., Schultz, A. B., \& Edington, D. W. (2001). The impace of

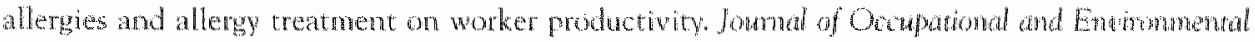
Madicine, $43(1), 64-71$.

Caille, E. I. (1979). Eude compararive en double aveugle de la mequitamen de lat dexchlorphéniramine et d'un placebo sur la vigiance. Gazete Mediede de France, 86, 3737-3744.

Gilmore, T. M. Alexander, B. H., Mueller, B. A. \& Rivara, E. B. (1996). Ocouphrional injuries and medication use. Amurican Jotrual of Industrid Medrone, 30(2), 234.239.

Hindmarch, I., Q Easton, J. C. (1986). A placehocontrolled stsessment of mequitaine and atremizole in rests of psychomotor abiliny. Intemational Joumal of Clincal Phamacologe Research, 6(6), 457.464.

Hindmarch, 1. \& Shansi, Z. (1999). Anthistamines: models to assess sedative propertien, assesement

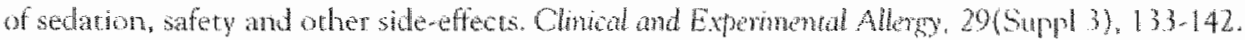

Hindmarch, L, \& Shamsi, Z. (2001). The effects of shygle and repeated administration of elantine on cognition and psychomotor performance in comparson to triprolidine and placelow in hathy wolunteers. Current Medical Resend and Opinion, 17(4), 273-281.

Kanei, H., Noda, K., Ishikawa, K., Senzaki, K., Muraoka, I, Hasegunwa, Y, Hindmarcls, I. \& Nabeshima, T. (2003). Comparative study of acute effects of single doses of fexofenialine. dopatadine, d-chomberimamine and placeloo on psychomotor function in heat thy voluntedr. Human psychophamacology, 18(8), 611-618.

Kay, O. O., Berman. B., Mockoviak, S. H., Morris, C. E., Reeves, D., Starbuck, V, Sukenik, E., \& Harris, A. G. (1997). Inital and steady-sate effects of diphenhydranine and lomatine on sedation, cognerion, mod, and psychomotor performance. Archines of horemal Medicine, 15\%(20), 2350. 2356.

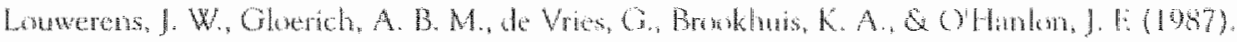

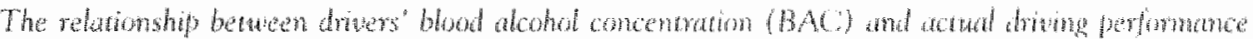

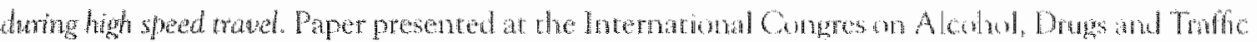
Sifery, T86, Amsterdam.

Moskowitz, H., E Burns, M. B. (1988). Effects of terfenadine, diphenhydrimine, and platedus on skills perfomance. Cuns, $42(4 \mathrm{~A}), 1418$.

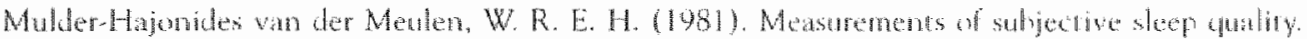

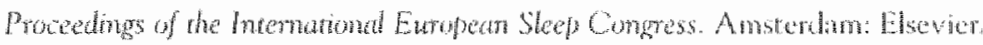

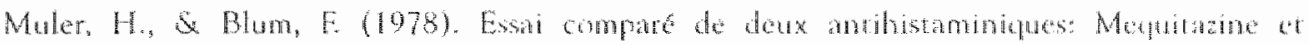

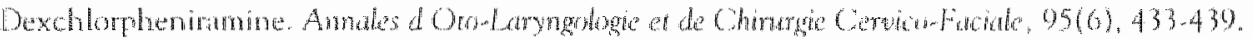

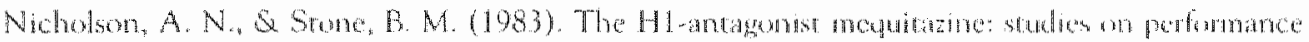

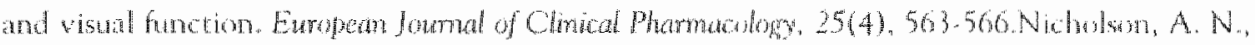
\& Turner, C. (1998). Central effects of the H1- ounthistamine, cenrizme. Antarion Space and Enthommenal Medicine, 69(2), 166-171. 
Wolen, T. M. (1997). Sedative effecs of anthistamines: safery, performance, learning and quality of life. Clintal Theraptitics, $19(1), 39-55$.

O'Hanlon, I. E, \& Ramaders, J. O. (1995). Anthistanine effects on actual dring performance in at stondard pest fo summory of Duech experience, 1989.94, Alletgy, 50(3), 234-342.

Okarsura, N., Yanai, K, Higuchi, M., Sakai, J., Iwata, R, Ido, T, Sasaki, H., Watanabe, T., \& lroh, M. (2000). Funchonal neuroimaging of cogntion impared by a classical ancihstamine, dchorphentamine. British Joumal of Clandal Pharmacology, 129(1). 115.123.

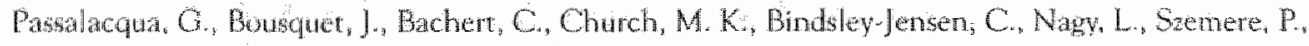
Davtes, R. J Durhan, S.R., Howak, I., Kontou-Fili, K., Malling, H. J, van Cauwenberge, P., \& Canonica, O. W. (1996). The clinical safery of HI-recepror antagonists. An EAACl position paper. Allergy, 51(10), 666-675.

Ramaekers, I. O. (2003). Antidepressants and driver imparment: empirical evidence from a standard on-the-road test. Joumal of Clinical Psychiary, 64(1), $20-29$.

Ramaeker, J. G, \& O'Hanlon, J. F. (1994). Acrivastinc, rertenadine and diphenhydramine effects on driving performance sts a function of dose and time after dosing. European Journal of Clinical Pharmacology, 47(3), 261-266.

Remakekers, I. G. Uiterwijk, M. M. \& O'Hanlon, I. F. (1992). Effects of lonaradine and ceririne on actual dring and psychometric test pertormance, and EQG during driwing. Exropean foumal of Clincal Phamacilogy, 42(4), 363-369.

Richardson, O. S., Roehrs, T. A., Rosenthal, L., Koshorek. G. \& Roth, T. (2002). Tolerance to daytime sedative effects of $\mathrm{HL}$ antihistamines. Journal of Clinical Psychophamacology. 22(5), 511.515.

Ricdel, W. J., Ramackers, G., Uiterwijk, M. M., \& O Hanlon, J. E (1990). Higher doses of terfenadine and lowatine: acue and subchonic effects on psychomotor and actual driving performance. Mastricht: Institute for Drugs, Safety and Behavior, University of Limburg.

Rohbe, H. W. J., \& O Hanlon, J. F. (1990). Effects of acritastine, acrivastine phes pretudoephedrine and wiprolidine on highway drowng. Maastriche: Institute for Drugs, Safety and Behavior Universicy of Limburg.

Seppala, T., Nuoto, E., S Kortula, K. (1981). Single and repeated dose comparison of three anthistamines and phenvlpropanolamine: psychomotor performance and sulpjective appraisals of sleep. Britsh joumat of dincal phamachory. $12(2), 179 \times 188$.

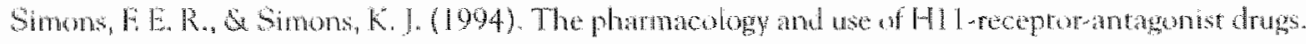
In A. J. J. Wood (Ed.), New England Joumbl of Medicine (Vol. 330, pp. 1663-1670). Boston: Mansichuserts Medical Sociery.

Tashin, M., Solkurata, Y., I wabuchi, K., Mochizuki, H. Kato, M., Aoki, M., Funati, Y., Itoh, M., Twata, R., Wong D. E, \& Yana, K. (2004). Central Effects of Fexofenatine and Cetirizine: Mensurement of Psychomotor Performance, Subjective Sleppiness and Brain Histamine H. Recepur Occupary Using $11 \mathrm{C}$-Doxepin Positron Emission Tomography loumal of chical phamaiology, 44(8), 890,900 .

Theunisen, E. L., Vemeeren, A., van Oers, A. C. M., wan Maris, I. \& Ramaekers, J. O. (2004). A dose ranging study of the effects of mequitame on accual ariving, memory and psychomotor performance as compared to dexchlorpheniramine, cetirine and placebo. Chical and Experintinul Allergy, 34(2), 250258.

Vernecen, A., G O'Hanton, ]. F. (1998). Fexofenadines effecs. alone and with aloohol, on acrual

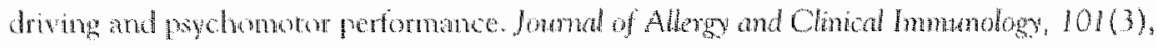
306.311 . 


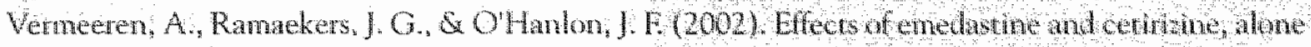

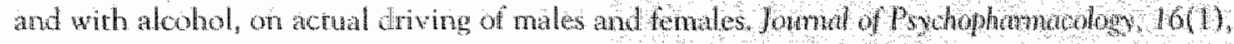
57.64 .

Verster, I. C., de Weer, A. M., Bijtjes, S. I. Aarab, M, wan Oosterwjok, A. W, Eiklen, E. I. Vembaten, M. N., E Volkerts, E. R. (2003), Drning ability ater acuto and subelwonic

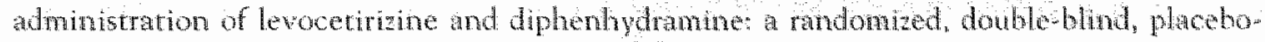
controlled trial. Psychophamacology, $169(1), 34-90$

Verster, J. C., Volkerts, E. R., wan Oosterwijck, A. W. Aarab, M., Bijtics, S. I., De Wewt, A. M., Eijken, E. J., \& Verbater. M. N. (2003). Acute and subchronic effects of levoceririzine and diphenhydramine on memory functioning psychomotor perfornance, and mood. Joumal of Allergy and Clinical Immanology. $111(3), 623-627$.

Verster, J. C., Volkerts, E. R., \& Verbaten, M. N. (2002). The predictive value of driving-relared laboratong tests and subjective assessments to on-the-road driving ability. Joumal of Psychophamacology, 3 (supplement) A62.

Volkers, E. R., Van Willigenburg, A. P. Van Laar, M. W., S Maes, R. A. (1992). Does ceririsine belong to the new generation of antihistamines? An investigation into its acute and sulbotmonic effects on highway driving, psychometric test performance and daytime steepiness.

Human Psychophamacology Clmical and Experimenal, 7(4), 227-238.

Vuurman, E. F, Uirerwijk, M. M., Rosenzweig, ., \& OHHanlon, J. F. (1994), Eftects of mizolastine and clemastine on actual driving and psychomotor performance in thealthy wolunteers.

European Joumal of Clinical Pharmacology, 47(3), 253-259.

Vutrman, E. F. P. M., Rikken, G. IH, Muntjewerff, N. D. de Halleux, E, \& Ramaekers, J. O. (2004). Effecs of desloratadine, dipheahydramine, and placebo on driving performance and psychomotor performance measurenents. European Jounal of Clinical Phamacology, 60(5), 307-313. 


\section{Stimulating effects of $\mathrm{H} 1$-antagonists}

\section{ChAPTER 4}

Accepted for publication as:

Theunissen, E. L. Vermeeren, A., Vuurman, E. F. P. M., \& Ramaekers, J. G. Stimulating effects of H1-antagonists. Current Pharmaceutical Design. 
Chapter 4

\section{ABSTRACT}

Whereas antihistamines are generally known for their sedative side effects, this review shows that several studies also found mild stimulating effects on performance for the H1antagonists terfenadine, ebastine, fexofenadine and desloratadine. These stimulating effects were mostly demonstrated in tasks involving high levels of attention, e.g. divided artention tasks, vigilance tasks and driving tasks. The stimulating effects of these antihistamines were often dependent of the given dose; however the relation was not always linear. The mechanism responsible for the stimulating effects of these four antihistamines is still unclear, though it is hypothesized that it involves other neurotransmitters like dopamine and GABA, or that it acts through the $\mathrm{H} 3$ histamine receptor. Further research is needed to clarify the ambiguous role of histamine in processes of arousal. In addition, it would be useful to determine whether terfenadine, ebastine, fexofenadine and desloratadine can return allergic patient's performance back to their preclinical level. 


\section{INTRODUCTION}

Histamine is an endogenous substance which affects both the central and peripheral nervous system, and acts through activation of three recepror subtypes; $\mathrm{H1}, \mathrm{H} 2$ and $\mathrm{H} 3$ (Steinbusch, 1991; Brown, Stevens, \& Haas, 2001). In allergic persons, peripheral release of histamine by allergens causes symptoms of allergy such as itching and sneezing. H1-receprot antagonists or antihistamines relief symptoms of allergic rhinitis and urticaria by blocking peripheral $\mathrm{Hl}$-receptors. In addition, $\mathrm{H}$ l-antagonists are able to cross the blood brain barrier and enter the CNS where they affect central histaminergic neurotransmission. Histamine in the brain is involved in the regulation of arousal (Lin, 2000). During the active phase of animals, the activity of the central histaminergic system increases while it decreases when the animals are asleep (Yamatodani et al., 1991; Onoe et al., 1992; Vanni Mercier, Gigout, Debilly, \& Lin, 2003).

By blocking central HI-receptors, antihistamines cause side effects such as sedation, sleepiness and drowsiness. These side effects can have serious consequences for daily activities. In response to this problem, a second generation of $\mathrm{H} 1$-antagonists was developed. Studies investigating the effects of these new antihistamines have indeed demonstrared that when given in their therapeutic dose they produce less subjective sedation and have less impairing effects on performance (Ramaekers, Uiterwijk, \& O'Hanlon, 1992; Vuurman, Uiterwijk, Rosenzweig, \& O'Hanlon, 1994; Mann, Pearce, Dunn, \& Shakir, 2000). The lack of sedative effects of second generation antihistamines is often said to be the result of their inability to pass the blood brain barrier and consequent lack of central H 1 -receptor blockade. Several studies, however, dicl demonstrate different levels of occupancy of central H1-receptors after administration of second generation antihistamines. Using PET scans, Tashiro et al., (2002 and 2004), for example, showed that cetirizine accupied about $30 \%$ of the central H1. receptors. Furthermore, receptor occupancy was found to correlate with the degree of sedation and performance impairment caused by antihistamines (Yanai, Okamura, Tagawa, Itoh, \& Watanabe, 1999). For example, the sedating antihistamine dexchlorpheniramine was found to produce larger $\mathrm{H} 1$-receptor occupancy $( \pm 50 \%)$ than the less sedating antihistamine ebastine $( \pm 10 \%)$ (Tagawa et al., 2001 ).

Surprisingly, a few studies, designed to measure potentially sedating effects of antihistamines, found that some of the second generation antihistamines (e.g. fexofenadine and terfenadine) seemed to improve performance suggesting that these compounds somehow increased wakefulness rather than causing sedation (Clarke \& Nicholson, 1978a; Vermeeren \& O'Hanlon, 1998). Initially, such results were spurious and not given further attention. However, over the years more researchers sporadically reported similar effects (Moskowitz \& Burns, 1988; Mattila, Kuitunen, \& Pletan, 1992; Vuurman, Rikken, Muntjewerff, de Halleux, \& Ramaekers, 2004), which wartanted the initiation of studies specifically designed to test the hypothesis that certain antihistamines may have slightly stimulating effects and thereby improve performance (Theunissen, Jonkman, Kuypers, \& Ramaekers, In press).

The present paper intends to review the existing evidence that some antihistamines may have stimulating effects and improve performance. First of all, experimental studies showing stimulant effects of terfenadine, ebastine, fexofenadine and desloratadine on objective and subjective performance measures will be described. Subsequenty, the possible mechanisms whereby $\mathrm{H} 1$-antagonists cause stimulating effects will be explored, discussing the involvement of dopamine, GABA and $\mathrm{H} 3$-receptors. 


\section{ANTIHISTAMINES WITH STIMULATING EFFECTS}

The antihistamine for which most indications of stimulation are found is terfenadine, but similar indications have been found for ebastine, desloratadine and fexofenadine (for an overview see Table 1).

\section{Terfenadine}

Terfenadine was developed in the $1980^{\prime}$ 's as one of the first second generation antihistamines (Emanuel, 1999), and its effect on performance and cognitive function have been tested repeatedly ever since. A few of those studies found significantly stimulating effects of terfenadine in objective performance tests compared with placebo.

The first investigators reporting significant performance improvement in healthy volunteers following the administration of terfenadine were Moskowitz and Burns (1988). These investigators had conducted a study comparing the effects of single doses of terfenadine (60 mg), diphenhydramine (50 mg) and placebo on a critical tracking task, a visual search task, a divided attention task (a combination of critical tracking and visual search) and a vigilance task in 18 healthy males. Performance was measured at 1, 3, and 5 hours after drug or placebo administration. Surprisingly, results showed that subjects demonstrated significantly better performance in the critical tracking task three hours after treatment. with terfenadine than after placebo. Similarly average performance in the visual search task was better although not significantly after treatment with terfenadine at one and three hours after treatment. In the divicled attention task, tracking was also slightly better than placebo at one and three hours after terfenadine treatment, while response time of the visual. search subtask was consistently berter. Furthermore, the ability to sustain attention over an extended period, as measured by the vigilance task, was shown to improve after terfenadine treatment. In contrast, diphenhydramine treatment resulted in impaired performance on all tasks. Consequently the researchers concluded that in all task the subjects demonstrated improved performance after terfenadine treatment compared to placebo treatment.

The second report of significant performance improvement following administration of terfenadine was by Betts, Kenwood, Dalby, Hull and Wild (1989). Betts et al., (1989) demonstrated improved driving performance after a high dose of terfenadine in a study comparing the effects of two doses of terfenadine (60 and $120 \mathrm{mg}$ ) with two doses of cetirizine ( 10 and $20 \mathrm{mg}$ ) and placebo. "Tests used were a driving manoeuvre test, a reaction time test and subjective measures of mood, tension and arousal. In the driving test subjects performed significantly better on the gap estimation test after being treated with terfenadine $120 \mathrm{mg}$ as compared to placebo and cetirizine $(10 \mathrm{mg})$. Terfenadine $60 \mathrm{mg}$ did not improve performance in the driving test and neither dose had an effect on any of the other measures of performance and sedation.

Several other studies found evidence for stimulating effects of terfenadine using objective performance measures, such as driving tasks and EEG's, however the difference from placelo failed to reach significance. The first study showing non-significant stimulating effects of tertenadine was by Betts, Markman, Debenham, Mortiboy and McKevitt (1984). In this study the effects of repeated doses of terfenadine $(60 \mathrm{mg})$ on driving manoeuvres and subjective mood, tension, arousal and fitness to drive were compared with those of triprolidine $(10 \mathrm{mg})$. Treatment with terfenadine $(60 \mathrm{mg})$ caused healthy subjects to complete the driving rest faster than when treated with placebo. Subjects also indicated that 
they felt more alert and fit to drive after terfenadine $(60 \mathrm{mg})$ than after triprolidine treatment. However none of the results of terfenadine in this study differed significantly from placebo.

Three out of four studies using a standardized highway driving test to assess the possible effects of terfenadine on driving, found non-significant improving effects (Riedel, Schoenmakers, \& O' Hanlon, 1989; Volkerts, Van Willigenburg, Van Laar, \& Maes, 1992; Ramaekers \& O'Hanlon, 1994). The highway driving test is a 1 -hour on the road driving rest conducted during normal traffic, which has been used repeatedly to demonstrate the effects of psychoactive drugs on driving performance (O'Hanlon, Haak, Blaauw \& Riemersma, 1982; Ramaekers, 2003; Vermeeren, 2004). In this test, subjects drive a car over a $100-\mathrm{km}$ circuit, while attempting to maintain a constant speed and a steady lateral position in the traffic lane. During the ride, the car's position relative to the white lane boundary is measured with a frequency of $4 \mathrm{~Hz}$ and converted off-line into the standard deviation of lateral position (SDLP), an index of weaving.

The first two studies using this test to assess the effects of terfenadine on driving were conducted by Riedel et al., (1989). They conducted a single dose and repeated dose study in healthy volunteers. No improving effects were found in the single dose study. In the repeated dose study, subjects' performance on day 1 and day 4 of treatment with terfenadine $60 \mathrm{mg}$ b.i.d. was compared with that of placebo. In addition, the combination of each treatment with a dose of alcohol was studied on both days. The results showed that on the first day of treatment with terfenadine subjects performed better on the driving test compared to placebo. Also, terfenadine in combination with alcohol resulted on average in better driving performance than the placebo-alcohol combination on the first day of treatment. However, both performance improvements found after terfenadine trearment (wirh and without alcohol) were not significantly different from placebo. After 4 days of treatment with terfenadine, the performance ameliorating effects of terfenadine seemed to have clisappeared.

In a subsequent study assessing the effects of terfenadine on performance in the highway driving test, a high dose of terfenadine tended to improve performance of healthy subjects (Volkerts et al., 1992). Volkerts et al., (1992) conducted a study to compare the effects of terfenadine 60 (b.i.d.) and $120 \mathrm{mg}$ (q.d.) on driving and psychomotor performance with cetirizine $(10 \mathrm{mg})$, triprolidine $(5 \mathrm{mg})$ and placebo after 1 and 4 days of treatment. On the first day of treatment, subjects in this study demonstrated improved performance on the highway driving test after treatment with terfenadine $120 \mathrm{mg}$, but not after the $60 \mathrm{mg}$ dose. Similar to the findings by Riedel et al., (1989) after 4 days of treatment the effects of driving had disappeared. On the other hand, terfenadine $60 \mathrm{mg}$ was found to increase sleep latency compared to placebo after 4 days of treatment in the study by Volkerts et al., (1992). The improved driving and increased sleep latency caused by terfenadine treatment, however, were not significantly different from placebo.

Finally, Ramaekers and O'Hanlon (1994) demonstrated dose dependent improving effects of terfenadine on performance in the highway driving test. Rámaekers and $\mathrm{O}^{\prime} \mathrm{Hanlon}$ (1994) compared the effects of three doses of terfenadine $(60,120$ and $180 \mathrm{mg})$ on driving performance with those of acrivastine $(8,16$ and $24 \mathrm{mg})$, diphenhydramine $(50 \mathrm{mg})$ and placebo in healthy volunteers. While performance on the highway driving task was significantly impaired after treatment with diphenhydramine and acrivastine, subjects treated wirh terfenadine were better able to drive with a steady lateral position, although not significantly better than placebo. 
Other methods, besides performance measures, to assess the effects of psychoactive drugs on arousal are psychophysiological measures, such as $E E G$, or subjective measures such as questionnaires or visual analogue scales. Simons et al., (1994 and 1996) used event related potentials, in particular the $\mathrm{P} 300$ component, to assess the potential sedative effects of terfenadine (60 mg) in healthy children (Simons, Reggin, Roberts, \& Simons, 1994) and adults (Simons, Fraser, Reggin, \& Simons, 1996). P300 is a measure of sustained attention and processing speed and drugs that adversely affect the central nervous system have the potential to slow P300 latency. As expected, the children's frontal and parietal P300 latency was not increased in the auditory oddball task compared to baseline, after terfenadine treatment, whereas placebo and chlorpheniramine $(4 \mathrm{mg}$ ) caused an increase in P300 latency. In adults however, contrary to expectations, a slight stimulating effect was found on the event related potential 2,5 hours after drug administration, since terfenadine clecreased P300 latency in the auditory oddball task. In the same study, diphenhydramine $(50 \mathrm{mg})$ increased P300 latency. Thus whereas chlorpheniramine and diphenhydramine impaired the cognitive processes underlying the $\mathrm{P} 300$ component, terfenadine did not delay P300 latency but rather had the tendency to accelerate these cognitive processes.

Finally, even studies examining the effects of antihistamines on subjective measures of sedation, have sometimes indicated that terfenadine did not produce more sleepiness than placebo but rather the opposite. Reinberg, Levi, Guillet, Burke and Nicolai (1978) studied the effects of two doses of terfenadine ( 20 and $60 \mathrm{mg}$ ) and clemastine (1 and $3 \mathrm{mg}$ ) in healthy volunteers, in a morning or evening dose. W/hen given in an evening dose, terfenadine $60 \mathrm{mg}$ caused less subjective sleepiness, although not significantly less than placebo. Other measures like eye-hand coordination and mathematical skills were not affected by terfenadine in this study. Clarke and Nicholson (1978b) compared the effects of a morning dose of terfenadine $60 \mathrm{mg}$ with chlorpheniramine, clemastine, promethazine and placebo on visuo-motor coordination and subjective measures of performance and well-being in healthy females. Measurements were conducted at 5 different times after drug intake. Visual analogue scales measuring subjective feelings of sedation showed that subjects reported significantly improved wakefulness and alertness at 0,5 and $3,5 \mathrm{~h}$ after ingestion of terfenadine, although performance in the visuo-motor test was not affected by terfenadine.

Three of the studies described above demonstrated significant improvements after terfenadine treatment ( 60 and $120 \mathrm{mg}$ ). Significant improvements were found on subjective measures of sleepiness (Clarke \& Nicholson, 1978a), driving (Betts et al., 1989) and driving related skills such as divided attention and tracking behaviour (Moskowitz \& Burns, 1988). These results are supported by several other studies finding on average better, but statistically nor significantly better, performance after terfenadine treatment (60 and 120 mg) (Reinberg et al., 1978; Betts et al., 1984; Riedel et al., 1989; Volkerts et al., 1992; Ramaekers \& O'Hanlon, 1994; Simons et al., 1994; Simons et al., 1996).

In sum, the above studies all indicate that terfenadine has stimulating properties. The effects seem to be dependent of dose, however high doses do not always cause significant stimulating effects. Therefore it remains unclear which dose is optimal for detecting stimulant effects. On the other hand, the fact that no study was designed to detect stimulant effects makes the findings of these effects even stronger. And although terfenadine was the first antihistamine to demonstrate stimulant effects, it could be elucidating to investigate whether the effect is specific for terfenadine or whether it has been demonstrated in other antihistamines. 


\section{Ebastine}

One antihistamine for which performance improving effects have also been reported is ebastine. Stimulating properties of ebastine were first measured in a study conducted by de Vries, de Waard and Brookhuis (1989), but not analyzed and reported as such in their paper. O'Hanlon and Ramaekers (1995) performed additional post-hoc analyses on these data, which clearly revealed ebastine's potential of ameliorating driving performance, In the study by de Vries et al, (1989), ebastine's (10,20 and $30 \mathrm{mg}$ ) effect on the highway driving test was compared with triprolidine $(10 \mathrm{mg})$ and placebo after acute and subchronic treatment. The results indicated that subjects were better able to keep a steady position (SDLP) in the traffic lane after an acute dose of ebastine $10 \mathrm{mg}$ and $20 \mathrm{mg}$ compared to placebo. Only the $10 \mathrm{mg}$ dose significantly improved driving performance in the highway driving test (in O'Hanlon \& Ramaekers 1995 ). After 5 days of trearment with ebastine, the improving effect of the $20 \mathrm{mg}$ dose disappeared and the $30 \mathrm{mg}$ dose was shown to significantly impair driving performance on the highway driving test (O'Hanlon \& Ramaekers, 1995).

Further evidence for stimulating effects of ebastine was found in a repeated dose study by Matrila et al., (1992). They assessed the effects of ebastine $(20 \mathrm{mg})$ and placebo on objective as well as subjective measures of performance after 6 days of treatment and on day 7 in combination with alcohol. Testing was done at baseline and at 2, 4 and 6 hours after treatment. When subjects were treated with ebastine, they demonstrated a slightly but significantly improved body balance at $2 \mathrm{~h}$ post-drug compared to baseline. Ebastine treatment also caused a significant improvement in simple tracking in a simulated driving task at $4 \mathrm{~h}$ compared to baseline. Furthermore, ebastine did not enhance the effects of alcohol and even tended to counteract these effects on the reaction time in the simulated driving task.

It seems that like terfenadine, ebastine was found to improve performance significantly (De Vries er al., 1989; Martila et al., 1992) and these improving effects appeared to be dependent of the given dose.

\section{Fexofenadine}

A third antihistamine for which stimulating effects have been reported is fexofenadine. Fexofenadine is the actiwe metabolite of terfenadine and therefore structurally also related to it. Therapeutic doses of fexofenadine range from 60 to $180 \mathrm{mg}$.

The first suggestion of stimulating effects of fexofenadine resulted from a study using the standardized highway driving test described above. Vermeeren and O'Hanlon (1998) studied the effects of fexofenadine (120 and $240 \mathrm{mg}$ ) after single and repeated doses on driving and psychomotor tests and compared it with clemastine $(2 \mathrm{mg}$ ) and placebo. After a single dose of fexofenadine, none of the measures significantly differed from placebo. After four days of treatment, fexofenadine $120 \mathrm{mg}$ b.i.d. was found to significantly improve driving performance on the highway driving task compared to placebo. On the fifth day of fexofenadine treatment, subjects were also given a dose of alcohol. Results showed that fexofenadine 120 mg b.i.d. significantly counteracted the impairing effects of alcohol on driving performance. In addition, this effect was almost significant for the fexofenadine $240 \mathrm{mg}$ o.d. regimen.

There are indications from more recent studies that support the conclusion that fexofenadine may have slightly stimulating effects. Ridout, Shamsi, Meadows, Johnson and Hindmarch (2003) investigated the effects of fexofenadine, alone and in combination with alcohol, on 


\section{Chapter 4}

\begin{tabular}{|c|c|c|c|c|c|c|}
\hline Pielerence & $N$ & Stubjects & Dose (mg) & Regimen & Measture & $\begin{array}{l}\text { Statistical difference } \\
\text { from placebo }\end{array}$ \\
\hline \multicolumn{7}{|l|}{ Terfenadine } \\
\hline \multirow[t]{4}{*}{ (Woskowtz of Buris $[988$ ) } & 18 & $M$ & $600 d$ & $\subseteq$ & Visual sarch & NS \\
\hline & & & & & Critical trackng & $\operatorname{Sign}$ \\
\hline & & & & & Divided atterition & Sign \\
\hline & & & & & Vigilance & Sign \\
\hline (Betts et al. 1989) & 10 & $f$ & $200 . d$ & $S$ & Gap estimation & Sign \\
\hline \multirow[t]{3}{*}{ (Betts et al., 1984) } & 12 & $r$ & $60 \mathrm{bid}$ & Pl & Driving & $\mathbb{N S}$ \\
\hline & & & & & Subjective alertmess & $\mathbb{N S}$ \\
\hline & & & & & hit to drive: & NS \\
\hline \multirow[t]{2}{*}{ (Aiedel et al. 1989) } & 16 & $M$ & 60 b.id. & 5 & Highway driving test & NS \\
\hline & & & 60 b.id t alcohol & $S$ & Highway driving test & NS \\
\hline \multirow[t]{3}{*}{ (Volkerts et al 1992) } & 27 & M & $1200 . d$ & $S$ & Highway driving test & NS \\
\hline & & & & & Sleep Hatency & NS \\
\hline & & & $60 \mathrm{bid}$ & P & Sleep latency & NS \\
\hline \multirow[t]{3}{*}{ (Ramakers \& O'Hanlon. 1994) } & 18 & F & $60 \mathrm{od}$ & $S$ & Highway driwing test & NS \\
\hline & & & $120 \mathrm{od}$ & 5 & Highway driving test & NS \\
\hline & & & $1800, \mathrm{~d}$ & $S$ & Highway driwing test & NS \\
\hline (Simons et al.. 1994) & 15 & MEF & $600 \mathrm{~d}$ & $\$$ & P300 & N5 \\
\hline (Simons et at. 1996) & 15 & $M$ & $600 . d$ & $S$ & P300 & NS \\
\hline (Reinberg et al , 1978) & 10 & MEF & $1600 . d$ & S (evening dose) & Subjective slerpintess & NS \\
\hline \multirow[t]{2}{*}{ (Clarke E Nicholson, 1978b) } & 6 & $f$ & $600 . d$ & $\$$ & Subjective alertness & Sign \\
\hline & & & & & Subjective wakelulness & Sign \\
\hline \multicolumn{7}{|l|}{ Ebastine } \\
\hline \multirow[t]{3}{*}{ (O'Hanlon E Rumaekers, 1995) } & 15 & $M$ & $10 \mathrm{od}$ & $56 R$ & Highway driving test & Sign \\
\hline & & & $200 \mathrm{~d}$ & $S$ & Highway driwing test & NS \\
\hline & & & $30 \mathrm{od}$ & 5 & Highway driwing test & NS \\
\hline \multirow[t]{3}{*}{ (Mattila et al. 1992) } & 12 & MEF & 20 o.d. & $R$ & Tracking in simulated driving & Sign \\
\hline & & & & & Body balance & Sign \\
\hline & & & $200 \mathrm{~d}+$ alcohol & $R$ & RT in simulated driwing & Sign \\
\hline \multicolumn{7}{|l|}{ Fexofemadine } \\
\hline \multirow[t]{3}{*}{ (Vermeeren 6 O'Hanlon, 1998) } & 24 & MGF & l20 bid. & F & Highway driving est & Sign \\
\hline & & & 120 bid. + alcohol & $R$ & Highway driwing test & Sign \\
\hline & & & 240 o.d + alcohol & $\mathrm{R}$ & Highway driving test & NS \\
\hline \multirow[t]{2}{*}{ (Ridout at all, 2003) } & 18 & M & 1800. & $S$ & Subjective sedation & NS \\
\hline & & & & & CRT & NS \\
\hline \multirow[t]{4}{*}{ (Theunissen et al. In press) } & 16 & MEF & $1800 . d$ & $\$$ & Mowement time RT & Sign \\
\hline & & & & & Pl-latency & Sign \\
\hline & & & 3600.0 & 5 & Tracking error & Sign \\
\hline & & .. & & & P3-latency & Sign \\
\hline \multicolumn{7}{|l|}{ Desloratadine } \\
\hline (Valk ell al, 2004) & 21 & $M$ & $50 . d$ & 5 & Vigilance in divided attention task & NS \\
\hline \multirow[t]{2}{*}{ (Nuwman et al. 2004) } & 18 & MGF & $50 . d$ & 5 & Brake reaction time & Sign \\
\hline & & & & & Reaction time diwided attention task & NS \\
\hline
\end{tabular}

Table 1. Summary of studies showing stimulant effects for terfenadine, ebascune, fexofenadine or destoratadine. N: number of subjects, F: female subjects, M: male subjects, od: once daily, bi.d. twice daily, S: single dose, R: repeated dose, NS: not significant, Sign: significant with p-value $\leq .05$. 
subjective and objecrive measures of sedation, such as a critical flicker fusion test, choice reaction time test and brake reaction test. Scores for subjective sedarion showed a significant treatment effect; fexofenadine with and without alcohol resulted in a reduction in sedation from baseline at 1,3 and 5 hours post-drug. However, at no point in time did the subjective sedation score for fexofenadine differ significantly from placebo. In line with this, performance on the chotce reaction tests seemed improved though not significantly by fexofenadine as compared to placebo.

Theunissen et al., (In press) conducted an event related potential study that was specifically designed to detect stimulant effects of fexofenadine. Fexofenadine was administered in relatively high single doses of 180 and $360 \mathrm{mg}$ and the effects were assessed under increasing workload conditions. Event related potentials showed that fexofenadine in general shortened latencies of the P100 and P300 components measured during the divided attention task, indicating faster early attentional processing and faster stimulus evaluation processes. This was supported by results from performance tests showing a significant interaction between effects of the drugs and workload. Workload increased tracking error, yet less so when subjects were treated with fexofenadine $360 \mathrm{mg}$ relative to placebo. In addition, the number of control losses increased less with increasing workload after treatment with fexofenadine $360 \mathrm{mg}$. Fexofenadine $180 \mathrm{mg}$ was also found to improve performance on the movement component of a reaction time task.

It is clear from the above studies that fexofenadine like terfenadine and ebastine has the potential to improve performance especially in tasks that require a high level of attention, such as driving and divided attention skills.

\section{Desloratadine}

Recently, evidence for stimulating effects has been found for desloratadine, a relatively new antihistamine. Desloratadine is an active metabolite of loratadine and is given in therapeutic doses of $5 \mathrm{mg}$.

Valk, Van Roon, Simons and Rikken (2004) studied the effect single doses of desloratadine $5 \mathrm{mg}$ on performance in a simulated flight cabin and compared it with diphenhydramine $(50$ mg) and placebo in healthy volunteers. Performance measures included objective rests, such as a divided attention task measuring vigilance and tracking, and subjective questionnaires for assessing sleepiness. At 2 and 3 hours post-drug, desloratadine seemed to improve performance on the vigilance task compared to placebo. The difference between desloratadine and placebo did however not reach significance.

Vuurman et al., (2004) also compared single doses of desloratadine $5 \mathrm{mg}$ with diphenhydramine $(50 \mathrm{mg})$ and placebo in healthy volunteers. The drugs' effects were measured on two driving tests and several objecrive (memory, tracking, reasoning, divided atrention, critical flicker fusion,...) and subjective performance tasks. Driving tests were the standardized highway driving test described before and a car-following test measuring the ability to adapt to changes in speed and react to brake lights of a preceding vehicle. Results showed that subjects had significantly faster brake reaction times following desloratadine treatment compared to placebo and diphenhydramine. Similarly, desloratadine had a positive effect on driving performance in the highway driving test and response speed in the divided attention task, although these effects did not reach significance for these measures. 
The above studies demonstrate that desloratadine, like terfenadine, ebastine and fexofenadine, also may have stimularing properties. Although the effects seem dose dependerit for different drugs, the relationship is not consistent. It is interesting that all four antihistamines belong to the piperidine group. This suggests that the mechanism underlying these stimulating effects might be related to the chemical structure of these compounds.

In conclusion, the experimental studies described above were almost all designed to examine the safery of second generation antihistamines on cognitive and psychomotor performance. Unexpectedlly however, they showed that terfenadine, ebastine, fexofenadine and desloratadine have the potential to improve cognitive and psychomotor performances, suggesting that they had stimulant rather than sedative effects. The fact that the performance improving effects of these antihistamines reached significance in only a few studies indicates that if they do have stimulating effects, these effects are very mild compared to known stimulants like caffeine or amphetamines. In addition, some drugs stimularing effects have only been demonstrated after higher than therapeutic doses or after repeated doses e.g. fexofenadine, whereas others, e.g. ebastine, no longer stimulated performance but rater caused impairing effects when doses were increased or given over longer periods. Interestingly, the stimulating effects were in many cases demonstrated in tests which rely heavily on divided and/or sustained attention, e.g. the standardized highway driving test was shown to be sensitive for the stimulating effects of all four antihistamines (see figure 1).

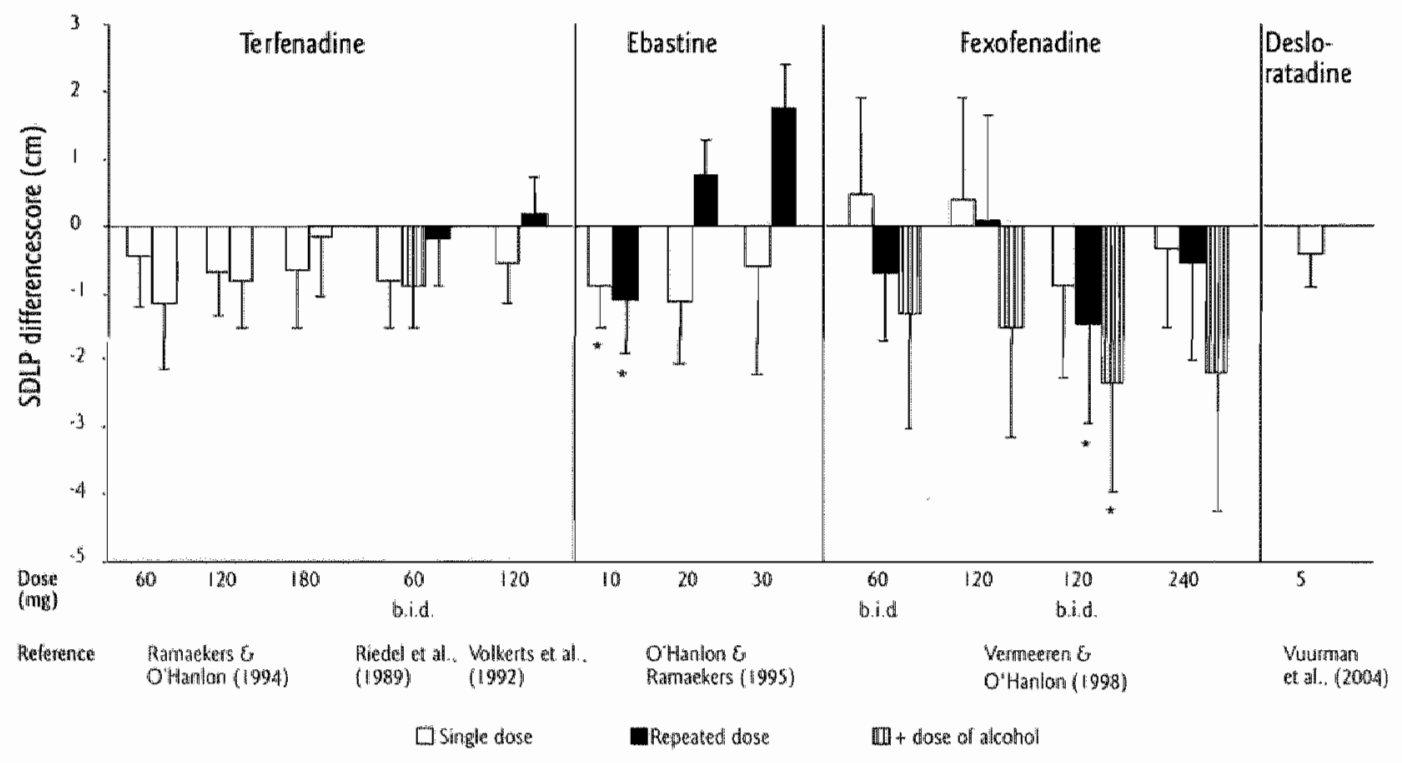

Figure 1. Effects of terfenedine, ebastine, fexotenadine and desloratadine on performance in the standardized highway driving test. Shown are mean changes from placebo in Sandard Dewiation of Lateral Position (SDLP), a negarive score indicaces better pertormance. Iri the study of Ramaekers S OHanlon (1994), the driving rest was performed rwice; once between 1 and 2 hours, and once between 3 and 4 hours after drug intake. "indicate signifucant improwement compared to placebo $(\mathrm{p}<.05)$ 


\section{POSSIBLE MECHANISMS UNDERLYING STIMULATING EFFECTS OF H1-ANTAGONISTS}

Assuming that the seemingly stimulating effects found for some $\mathrm{Hl}$-antagonists are real, what could be the explanation? What could be the underlying neural mechanism and how does it explain the differences between antihistamines? A few suggestions, based on animal research, have been put forward which might explain the mild stimulating effects that were found for terfenadine, ebastine, fexofenadine and desloratadine.

\section{Inhibition of dopamine reuptake}

One suggested mechanism is that antihistamines, besides blocking H1-receptors, also inhibit dopamine reuptake. This blockade causes an increase in the dopamine availability (Dringenberg, de Souza-Silva, Schwarting, \& Huston, 1998), which is known to increase arousal and attention (Robbins, 1997). Psychostimulants, like cocaine and amphetamine, increase levels of dopamine and noradrenaline by blocking their reuprake and increasing their release, thereby improving psychomotor functions, such as attention, vigilance and reaction times (Fleming, Bigelow, Weinberger, \& Goldberg, 1995; Johnson et al., 1998). So, if H1. antagonists also block dopamine reuptake they could produce effects similar to psychostimulants (Vermeeren, 2003), yet they must do so in a more limiced way in the doses tested, since their effects are very mild as compared to cocaine or amphetamines.

The inhibition of dopamine reuptake by some antihistamines has been demonstrated in rats and mice (Oishi, Shishido, Yamori, \& Saeki, 1994; Matsunaga et al., 1998). Oishi et al., 1994) studied in vivo effects of several ancihistamines on monoamine tumover in mice. Seven antihistamines (diphenhydramine, tripelennamine, promethazine, chlorpheniramine, mepyramine, clemizole and homochlorcyclizine) were found to significantly decrease dopamine turnover. The effect was suggested to be caused by inhibition of dopamine reuptake. This hypothesis is supported by a study by Matsunaga et al., (1998). These investigators specifically examined the inhibiting effects of antihistamines on neuronal dopamine uptake into striatal synaptosomes. Results showed that four of the antihistamines studied inhibited neuronal dopamine reuptake. Interestingly, ebastine and terfenadine were found to be the most potent inhibitors of dopamine reuptake.

Behavioural studies in animals also provide additional evidence that some antihistamines have the ability to stimulate dopamine transmission. Several studies reported antihistamines to have rewarding and reinforcing effects, which for most drugs are related to dopamine increases in mesolimbic areas (Bergman \& Spealman, 1988; Sato et al., 1996; Suzuki et al, 1999). Bergman \& Spealmarn (1988) studied the reinforcing effects of chlorpheniramine, diphenhydramine, loratadine and astemizole, using rate of selfadministration in squirrel monkeys. Chlorpheniramine and diphenhydramine produced increases in response rate to the same extent as dopamine reuptake inhibitors, bupropion and cocaine. In addition, Bergman \& Spealman (1988) demonstrated that some of the behavioural effects caused by dopamine reuprake inhibitors (bupropion and cocaine) and an HI-antagonist (diphenhydramine) could be attenuated by a dopamine receptor antagonist. Therefore, the authors suggested that the behavioural effects caused by $\mathrm{H}$-antagonists and dopamine reuptake inhibitors are mediated by the same neurochemical mechanism, namely dopamine reuptake inhibition.

Suzuki et al., (1999) studied the rewarding effects of antihistamines in rats using a place preference paradigm. In this test, the animals are first place condirioned, i.e. rats were given 
an injection with an antihistanine in one compartment, while they received a saline injection in another comparment. After the conditioning phase, rats demonstrated a preference for the compartment where they were given tripelennamine or the optical isomers of chlorpheniramine, indicating a rewarding effect which is thought to be related to an enhanced dopaminergic transmission (Leshner \& Koob, 1999). The behavioural effects caused by tripelennamine and dl-chlorpheniramine disappeared after treatment with a dopamine antagonist. Together these results suggest that some, but not all, H.1-antagonists increase dopamine transmission. The researchers added that the rewarding effects are not mediated by histamine blockade, since the rewarding effects caused by the optical isomers of chlorpheniramine did not correlate with their $\mathrm{H} 1$-antagonistic potency.

Sato et al., (1996) investigated the effects of antihistamines on L-dopa-induced behavioural excitement in mice. Their study indicated that several antihistamines (e.g. $d$ chlorpheniramine and diphenhydramine) enhanced the behavioural excitement caused by a combination of $\mathrm{L}$-dopa and the MAO-inhibitor pargyline. A selective dopamine antagonist, on the other hand, inhibited the excitement induced by L-dopa and pargylline. The results of this study are again an indication for dopamine reuptake inhibition by H1 antagonists.

\section{Disinhibition of dopaminergic activity through GABA}

A second mechanism suggested to underlie the stimulating effects of $\mathrm{H} 1$-antagonists, involves GABA-neurons. Korotkova, Haas and Brown (2002) examined the effects of histamine on spontaneous firing of GABA and dopamine neurons in vitro. Their study demonstrated that histamine increased the firing frequency of GABA neurons. Histamine did not affect the firing of dopamine neurons, suggesting that histamine has no direct effect on dopamine neurons. In viwo, however, stimulation of GABA-ergic neurons causes inhibition of dopaminergic activity. Therefore, Korotkova et al. (2002) suggest that histamine inhibits dopaminergic neurons indirectly through histamine induced excitation of GABA-ergic neurons. In addition, their study demonstrated that mepyramine, an $\mathrm{HL}$-antagonist, blocked the histamine induced excitation of GABA neurons. As a consequence, it is likely that HIantagonists might also stimulate dopaminergic neurotransmission by decreasing the tonic OABA-ergic inthibition of dopamine pathways, i.e. disinhibition of dopaminergic activicy (Vermeeren, 2003).

\section{H3-antagonism}

A final explanation for the stimulating effects of some $H 1$-antagonists might be found in their interaction with orher histamine receptors, in particular the $\mathrm{H} 3$-receptor. The histamine H3-receptor, discovered in the 1980 s, is located presynaptically acting as an autoreceptor, but also as a heteroreceptor. As an autoreceptor it regulates the synthesis and release of histamine; and as a heteroreceptor the release of other neurotransmitters (Arrang, Garbarg, \& Schwart, 1983; Blandina, Bacciotrini, Giovannini, S Mannaioni, 1998).

Evidence that antihistamines do not bind solely on $\mathrm{HL}$-receptors comes from a study by Sharif, Su and Yanni (1994). They showed that the several H1-antagonists also bind to central $\mathrm{H}_{2}$-and $\mathrm{H}_{3}$-receptors in rodents, although with different affinicies. It was shown that various antihistamines have different ratios in binding affinity for $\mathrm{H} 1$ - and $\mathrm{H} 3$ receptors (e.g. the receptor affinity ratio $H 3: H 1$ was 9,562 for emedastine while 82 for levocabastine). 
Since blockade of the $\mathrm{H} 1$ - and H3-receptors has opposing effects on histamine transmission, it is possible that some antihistamines with relatively high affinity for the $\mathrm{H} 3$. receptors stimulate rather than block histaminergic transmission depending on the dose. Stimulation of histaminergic transmission by $\mathrm{H} 3$-antagonists increases arousal. For example, Monti et al., (1991) and Monti, Jantos, Ponzoni and Monti (1996) showed that the H3antagonists thioperamide and carboperamide increased wakefulness and decreased slow weave sleep and REM sleep in rats, whereas an $\mathbf{H}$-agonists increased slow wave sleep.

Although the increased wakefulness following administration of an $\mathbb{H} 3$-antagonist can be the result of increased histamine levels, Monti er al., (1996) already noted that the noradrenaline, dopamine, serotonin and acerylcholine neurotransmitter systems might also be involved, since $\mathrm{H} 3$-receptors are also heteroreceptors. These receptors have indeed been shown to regulate release of dopamine, noradrenaline, serotonin and acetylcholine (Schlicker \& Kathmann, 1998; Witkin \& Nelson, 2004).

Nevertheless, two studies suggest that the effect of $\mathrm{H} 3$-antagonists on wakefulness mainly results from the enhancement of histamine release. In one study, ciproxifan, an $\mathrm{H} 3$. antagonist, was also shown to have a waking effect in cats and an attention enthancing effect in rats (Ligneau et al., 1998). When ciproxifan was given in combination with a H1. antagonist (mepyramine), the enhancement of wakefulness did not appear, indicating that the effect of ciproxifan was probably caused by increased release of histamine through $\mathrm{H} 3$ blockade (Ligneau et al., 1998). Parmentier et al., (2002) also demonstrated increased wakefulness (delayed sleep latency, suppression of slow wave sleep and paradoxical sleep) in mice after ciproxifan treatment. Knockout mice lacking the enzyme histidine decarboxylase responsible for histamine synthesis, however, did not show evidence of changes in wakefulness. This finding also suggests that the increase in arousal and wakefulness after $\mathrm{H} 3$. antagonism is mediated through the increased synthesis and release of histamine.

\section{CONCLUSIONS}

In this review we have demonstrated that there is evidence suggesting that at least four $\mathrm{HI}$ antagonists have the potential to stimulate psychomotor performance. First of all, this finding implicates that these "nom-sedating" $H \mathrm{l}$-antagonists also have central effects, suggesting that they are able to cross the blood brain bartier. So even though it is often stated that second generation antihistamines do not cause sedation because they do not act centrally, the stimulating effects found for some second generation antihistamines bears evidence that they do enter the central nervous system.

In treatment of allergies, sedation is one of the most reported side effects of antihistamines. In choosing the right treatment, less sedating second generation antihistamines are recommended over the older, highly sedating first generation antilhistamines. It can now even be proposed that antihistamines with small stimulating properties should even be more beneficial for patients with allergies, since they may also experience disease-related impairments (Blaiss, 2000; Burton, Conti, Chen, Schultz, \& Edington, 2001). The studies described above, however, were all done in healthy populations. One previous study, examining the effect of the second generation antihistamine, loratadine, found that it improved allergic children's learning performance compared to symptomatic children without treatment, but that their performance was still impaired compared to that of healthy children (Vuurman, van Veggel, Uiterwijk, Leutner, \& O'Hanlon, 1993). It would therefore be enlightening to see whecher 


\section{Chapter 4}

any of the four mildly stimulating antihistamines is able to bring patients' perfomance back to its baseline level.

A few hypotheses for the stimulating effects of $\mathrm{H} 1$-antagonists have been outlined, suggesting a role for dopamine, GABA and $\mathrm{H} 3$-receptors. It is possible that different mechanisms ate responsible for the stimulating effects of the different antihistamines, or that combinations of these factors sometimes add up to a measurable effect. As Matsunaga et al, (1998) demonstrated, ebastine and terfenadine were found to be the most potent dopamine reuptake inhibitors. However, there are no studies available resting the dopamine reuptake inhibiting potential of fexofenadine and desloratadine. In addition no study has tested any of the four antihistamines on their GABA-inhibiting potential or $\mathrm{H} 3$ binding potency. So the exact mechanism whereby each antihistamine produces its stimulating effects remains uncertain.

Recently more research is dedicated to $\mathrm{H} 3$-antagonists and their effect on cognitive functioning (Esbenshade et al., 2004; Vohora, 2004). Several H3-antagonists are being developed and have been reported to effect wakefulness and cognition in rodents (Monti et al., 1996; Prast, Argyriou, \& Philippu, 1996; Bernaerts, Lamberty, \& Tirelli, 2004). In addition, enhanced performance was demonstrated in animal models for ADHD (Fox et al., 2002; Fox et al., 2003). Since H3-antagonists are so far not approved for clinical use, the therapeutic benefits in humans have not been studied yet. However, if the stimulant effects of the antihistamines described in this review are a result of $\mathrm{H} 3$-antagonism, it is a first indication that $\mathrm{H} 3$-antagonists are not only able to improve cognitive performance in animals but also in humans.

This review showed that there is extensive evidence indicating that the non-sedating antihistamines, terfenadine, ebastine, fexofenadine and desloratadine have the potential to stimulate performance in healthy volunteers, especially in attention demanding tasks. Although the mechanism whereby these antihistamines cause stimulant effects remains unclear, the finding could mean an important improvement in the quality of life of allergic patients. 


\section{REFERENCES}

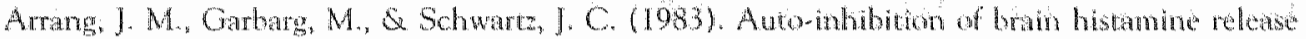
mediated by a novel class (H3) of histamine receptor. Name $302(5911), 832-837$.

Bergman, J., S Spealman, R. D. (1988). Behavional effect of histamine HI antagonists comparion with orher drugs and modificarion by haloperidol. Joumal of phamacology and expermental wherapeutics, $245(2), 471-478$.

Bemaers, P. Lamberty, Y., \& Tirelli, E. (2004). Histmine H3 antagonist thioneramide dosedependenty enhances memory consolidarion and reverses amonsta induced by dizocilpme or

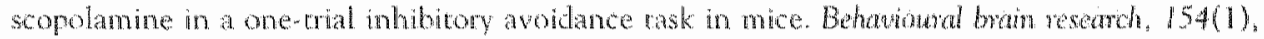
211.219

Berts, T., Kenwood, C. Dalby, O. Hull, B. \& Wild, J. (1989). A comparison of the effers of wo non sedating intihistamines (rerfenatine and cetriane) on tests of CNS hunction including driving. Joumal of Psychophomacology, 3/4, 101P (Abstma).

Berts, T., Markman, D., Debentham. S., Morriboy, D., A McKevitc, T. (1984). Bfiens of wo anthistamine drugs on actual driving performance. British medical joumal Clinical resend ed. $288(6413), 281-282$

Blaiss, M. S. (2000). Cognitive, social, and economic costs of allergic thinitis. Allergy and asthma procedings the officid jow mal of regional and state allergy socieves, 21(1),7-13.

Blandina, R. Bacciotcini, L., Giowannini. M. G., \& Mannaioni, P. F. (1998), H3 receptor mudulation of the release of neurotransmitters in wivo. In R Leurs \& H. Timmerman (Eds). The Hisumine H3 Receptor (pp. 27.40). Amsterdam: Elsevier.

Brown, R. E., Stevens, D. R, \& Haas, H. L. (2001). The physhology of bratin himamine. Prowgens in Neurobiology, 63(6), 637-672.

Burton, W. N., Conti, D. J., Chen, C. Y. Schultz, A. B., Se Edington, D. W. (2001). The inpact of allergies and allergy treatment on worker productivity. Joumal of Occuparional and Enwommental Medicine: 43(1), 64-71.

Clatk, C. H, \& Nicholson, A. N. (1978a). Pertornance studies with anthistamines. British foumal of Clinical Pharmacology, 6(1), $31-35$.

Clarke, C. H., S Nicholson, A. N. (1978b). Performance studies widh antihistamines. British jourmal of chmol phamadogy, 6(1), 31-35.

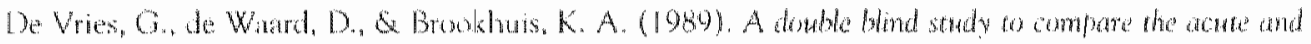

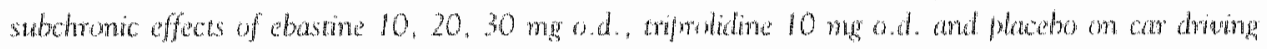
perfomance (VK 89-22). Groningen: Traffe Resench Center Universty of Graningen.

Dringerberg, H. C., de Souza-Silva, M. A. Schwarting, R. K. \& Huscon, I. I. (1998). Increatsed levels of extracellular dopatnine in nesstriatum and nucleus accumbens afrer histamine HI receptor

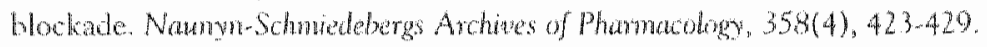

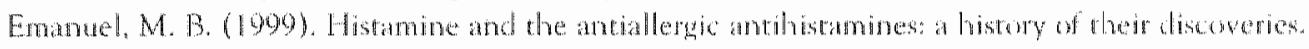

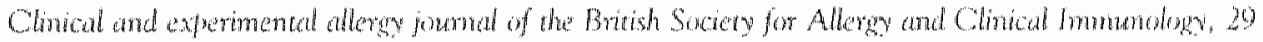
Supp $3.1 \cdot 11$, discussion 12

Eshenshate, T. A., Fox, G. B., Krneger, K. M., Baranowski, J. L., Miller, T. R., Kand, C. H., Denny, L. I., Witre, D. G., Yao, B. B., Pan, J. B., Faghih, R., Bemant, Y. L. Wiblims, M. G Hancock, A. A. (2004). Pharmacological and hebavional properties of A-349821, al selectiwe and potent human

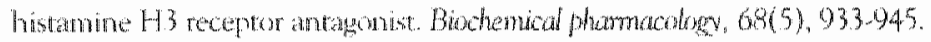

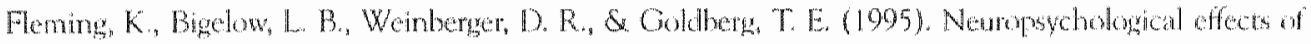

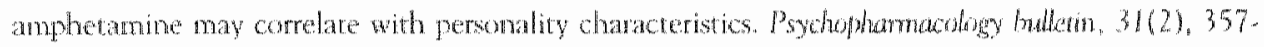
362. 


\section{Chapter 4}

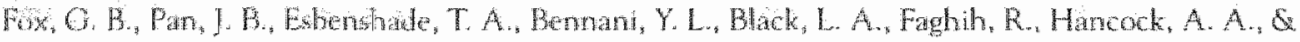
Decker. M. W. (2002). Effects of histamime H(3) receptor ligands OT.233 and ciproxifan in a repeated acquisition awoldance response in the spontaneously hyperensive rat pup. Behuwoural brain reweanch, 131(1-2), 151-161.

Fox, C. B. Pan; J. B., Radek, R. J., Lewis, A. M. Bimer R. S., Esbenshade, T. A., Faghh, R, Bemani, Y. L. Whlians, M., Yao, B. B., Decker, M. W., E Hancock, A. A. (2003). Two novel and selective nonimichale $\mathrm{H} 3$ receptor antagonists A-304121 and A-317920: II. In wo behavoral and netophysiological characteriation. Jound of phamacology and expermental therapeutics, $305(3)$. 897.908.

Johnson, B., Overnon, D., Wells, L. Renny, P., Abramson, D. Dhother, S, Cher, Y R, \& Bordnick, P. (1998). Effects of actite intravenous cocaine on cardiovascular function, human leaming, and performance in cocane addicts. Psychiom research, 77(1), 35-42.

Korotkowa, T. M. Hats, H. L., B. Brom, R. E. 2002). Histamine excites GABAergic cells in the rat sulstantia nigra und wentral tegmental area in vitro. Neuroscience Letters, 320(3), 133-136.

Jesther, A. I. \& Koob, O. F. (1999). Drugs of abuse and the brain. Procedings of the Association of American Physicions, $111(2), 99,108$.

Ligneau, X., Lin, J, Vanni Mtercier, G. Jouvet, M., Muir, J. L., Ganellin, C. R., Stark, H., Elz, S., Schunack, W. Schwatt, 1. (1998). Neurochemical and behavioral effects of ciproxifari, a portent histanine H3-receptor antagonist. Joumal of phomacology and expermental therapeutics, $287(2), 658.666$

Lin. I. S. (2000). Brain structures and mechanisms involved in the control of cortical accivation and wakefuness, with emphass on the posterior hypothalamus and histaminergic neurons. Slevp Medicine Reviews. 4(5), 471.503.

Mann, R. D., Pearce, O. L., Dunn, N. \& Shakir, S. (2000). Sedation with "non-sedating" antihistames: four prescription-event monitoring studies in general practice. British Medical Joumal. $320(7243), 1184.1186$.

Matsuthaga, K., Saco, T., Shuto, H., Tsuruti, Y., Suemaru, K., Gomita, Y., S Oishi, R. (1998). Intuithion of neuromal dopamine uptake by some antiallergic drugs. European Joumal of Pharmacology, 350(2-3), 165 169.

Mattila, M. J., Kuitunen, T., \& Plecan, Y. (1992). Lack of phamacodynamic and pharmacokineric

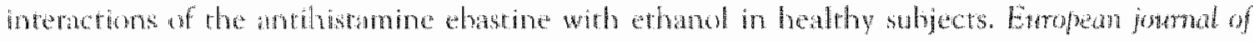

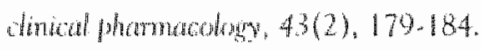

Mont, J. M., Jantos, H., Beussard, M., Alter, H., Orellana, C. \& Olivera, S. (1991). Effects of

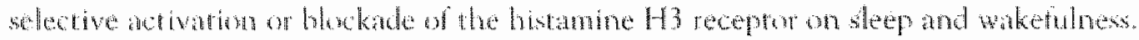

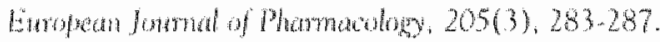

Monti, J. M. Jantos, H. Ponzmi, A., S Monti, D. (1996). Sleep and waking during acute histanine H3 agenist $\mathrm{BP} 2.94$ or 43 andagenist atboperamale (MR 16155) administration in rats.

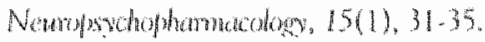

Muskswirz, H., Berm, M. B. (1988). Eftect of terfenadine, diphenhydramine, and placebo on skills performamce. Cutis, $42(4 \mathrm{~A}), 1418$

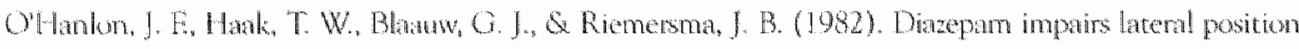
cutrol in highwo driving. Sconce, 217(4554), $79-81$.

OHontun, ]. E, se Ramackers, ], G. (1995). Antihistamine effects on actual driving performance in a stmblat rest a summary of Dutch experience, 1989-94. Allerg, 5063), 234-342. 


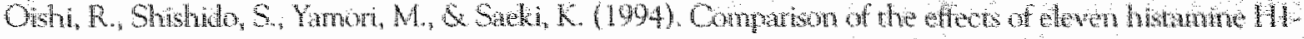

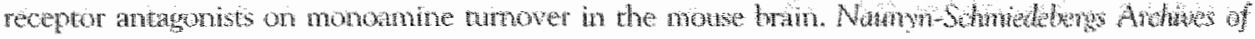
Phamecology, $349(2), 140.144$.

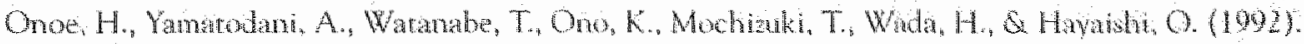

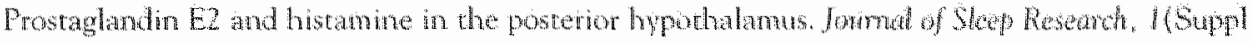
1), 166 .

Parmentier, R., Ohrsu, H., Djehbara Hannas, Z., Vahex, 1. L., Watanabe, T. \& Lin, I. S. (2002). Anatomical, physiological, and phamacological characteristics of hiscidine dectrboxylage knock. our mice evdence for the role of brain histamine in behaworal and sleep-wake control Jownal of

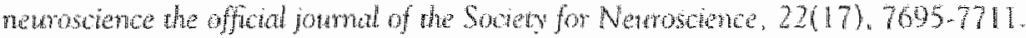

Prast, H., Argyrion, A. Q Philppu, A. (1996). Histaminergic nenrons facilitate social memory in rats. Brain reseawh. $734(1-2), 316-318$

Ramackers, J. G. (2003). Amidepressmts and driver imparment: empirical exdence froma stindurd on-the road rest. Jomud of Cinical Psydiatry, 64(1), 20-29.

Ramaekers, J. G. \& OHankon, J. F. (1994). Acrivatine, terlenadine and diphenhydrumine eftects on driving performance as a function of dose and time after dosing. European fowmal of Chinal Pharmacology, 47(3), $261-266$.

Ramackers, J. O, Uiterwilk, M. M., \& OHanton, J. F (1992). Effects of lonathe and cetinine on

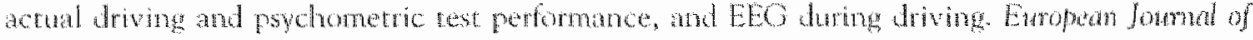
Clinical Pharmacolong, 42(4), 363-369.

Reinherg, A. Levi, F, Guiller, P., Burke, J. T., \& Nicolai, A. (1978). Chomophammologicat study of anthistames in man with special references to tertenadine. Eumpean jonmol of chical Whamacology, $14(4), 245-252$

Ridout, E, Shansi, Z, Meadows, R., Johnson, S. \& Hindmarch, I, (2003). A single-center, randomized, doubleblind, placebarontrolled, crosswer investigntion of the affects of fexofenadine hydrochlorde $180 \mathrm{mg}$ alone and with alcolvol, with hydroxyzine hytrochlorite 50 mg as a positive internal control, on aspects of cognitive and psechomoton function retated to driwing a can Clincal therapeutics, 25(5), 1518.1538.

Riede, W. J., Schoenmakers, E. A. J. M., \& O Hantm, J. E. (1989). Sedation and performance

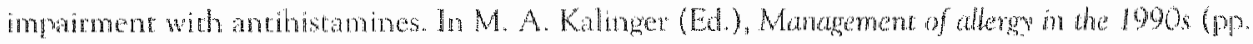
38-49). Toronro: Hans Huber:

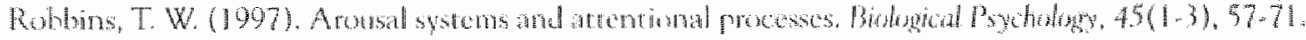

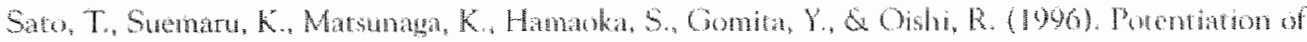
L-dopa-indeced behavional excitement by histame H. receptor antagonists in mice. Japanese Jenmal of Phamaidory. 71(1), 81-84.

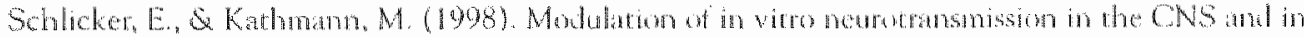

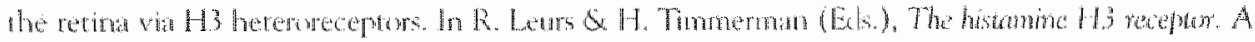

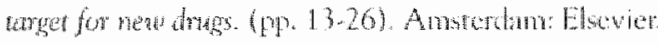

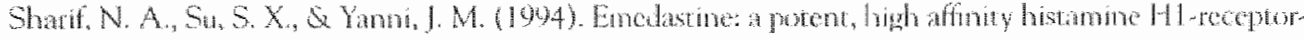

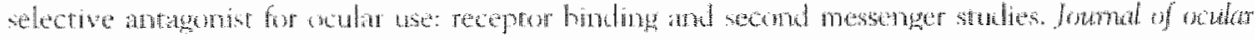
Whamacoldgy, $10(4), 653-664$

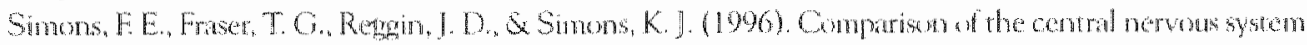

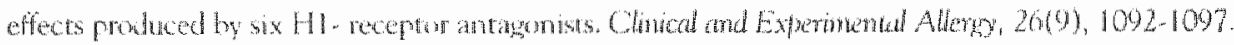

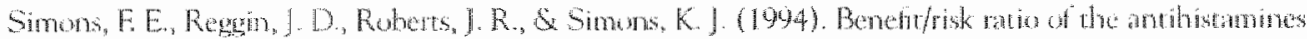
(H1-receptor antagonists) refonadine and chlothlentmine in children.

Joumal of Pediamic, $124(6), 979.983$. 


\section{Chapter 4}

Stenbusch, H. W. (1991). Derribution of histaninende netirons and fibers in rat brain. Comparison

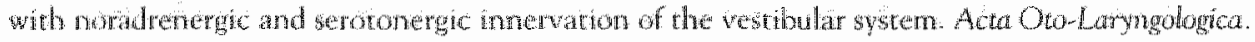
Suplement, $479,12-23$

Suzuk1, T., Mori, T., Tsuj, M. Nonura, M., Misawa, M. \& Onodera, K. (1999). Evaluarion of the histamine $H 1$-antagonise-induced place preference in rats. Japonese foumal of Pharmacology. $81(4)$. $332-338$

Tagawa, M., Kano, M. Okamura, N., Hguchi, M., Matsuda, M., Mizuki, Y, Arai, H., Iwara, R. Funi, T., Komemushi, S. Ido, T., Icoh, M., Sasaki, H. Waranabe, T., \& Yanai, K. (2001). Neuroimaging of histamine HI.receptor occupancy in human hrain by postron emission tomography (PET): a comparative study of ehasthe, a second-generation anthistamine, and (*)-chlorpheniramine, a classical antihistamine. British journal of clinical phamacalogy, 52(5), 501.509.

Tashito, M., Mochizuki, H., Iwalbuchi, K., Sakurada, Y., Itoh, M., Watanabe, T., \& Yanai, K. (2002). Roles of histamine in regulation of arousal and cognition: functional neuroimaging of histamine HI receptors in human bram. Lfe Sciences, $72(4,5), 409-414$.

Tashiro, M., Sakurada, Y, Iwabuchi, K., Mochizuki, H., Karo, M., Aoki, M., Funaki, Y., Iroh, M., I wata, R. Wong, D. F, Gonat, K. (2004). Central Effects of Fexotenadine and Cetirizine: Measurement of Psychomotor Performance, Subjective Sleepiness, and Brain Histamine HI Receptor Occupancy Using $11 \mathrm{C}$ Doxepin Positron Enission Tomography. Journal of clinical phatrocology, 44(8), $890-900$

Theunissen, E. I., Jonkman, L. M., Kuypers, K. P. C., \& Ramakers, J. G. (In press). Stimulating effects of fexofenadine under high workload conditions. A combined neurophysological and bethwioral apmoach.

Valk, P. J., Van Rion, D. B., Simons, R. M., \& Rikken, O. (2004). Desloratadine shows no effect on performatince during $6 \mathrm{~h}$ at $8,000 \mathrm{ft}$ simulated cabin altitude. Aviation, space, and enwrommental mediche: $75(5), 433-438$

Vanni Mercier, G., Gigont, S. Debilly, G., S Lin, J. S. (2003). Waking selective neurons in the posterior hypohalamus and their response to histamine $\mathrm{H} 3$-receptor ligands: an electrophysiological study in freely moving cats. Behaioural brain resectrch, $144(1-2), 227-241$.

Vermeeren, A. (2003). Hypnotics and anthistamines. Euffects on cognitive functions and driving performance. Maastrich University, Maastricht.

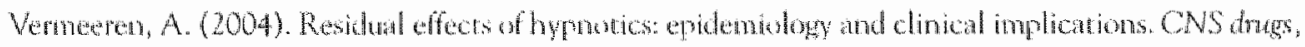
$18(5), 297.328$

Vermetren, A, O'Hanlon, J. F (1998). Fexofenadire's effects, alone and with alcohol, on accual

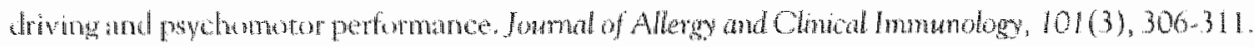

Vohor, D. (2004). Histamine-selective 43 receptor ligands and cognitive functions: an overview.

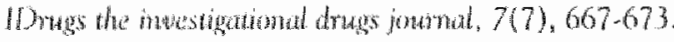

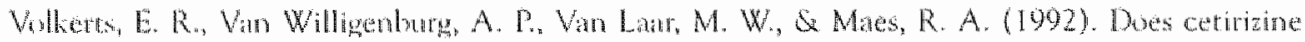
betong to the new gencration of antihistamines? An investigation into its acute and subchronic effects on highway dring. psychometric test performanee and dayrime sleepiness. Human Psychophammoology Climical and Experimental, 7(4),227,238

Vutuman, E. F, Uhterwijk, M. M, Rowenzweig, P, \& OHanlon, J. F. (1994). Effects of mizotastine and clemascine on actual driving and psychomotor performance in healthy volunteers. Europern Jomal of Clinical Phamacology, 47(3), 253-259.

Vutrman, E. F, wan Veggel, L. M. Uiterwijk, M. M. Leutner, D. \& O'Hanlon, I. F. (1993). Seasonal allergic thintis and anthistawine effects on children's leaming. Amals of allergy, $71(2), 121.126$. 
Vumman, E. F. P. M., Rikken, G. H, Muntewerf, N. D. de Hallew, E, S Ramatken, I G. (2004).

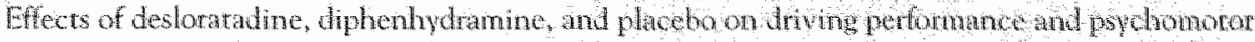

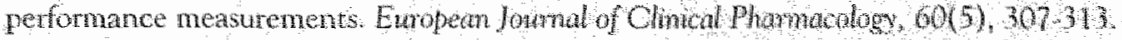

Witkin, J.M. \& Nelson, D. L. (2004). Selective histamine H(3) recepror antagonists for reatment of cognitive deficiencies and other disonders of the ontral nervons spitcm. Pharmacology and therapetitics, $103(1), 1-20$.

Yamatodani, A., Inagaki, N., Panula, P. Irowi, N., Watanabe, T., \& Wada, H. (1991). Stricture and Funcrions of the Histaminergic Neurone System. In G. V. R. Bom (Bd.), Homobok of Experment Phamacology (Vol. 97, pp. 243-283). Berlin: Springer-Verlag.

Yanai, K., Okamura, N., Tagawa, M, toh, M. \& Watanabe, T. (1999). New findings in pharmacological efeces induced by anthistamines: from PET studies to knock-out mice.

Clinical and Experimental Allergy, 29 Suppl 3, 29-36; discussion 37.28 


\section{Stimulating effects of fexofenadine under high workload conditions. A combined neuro- physiological and behavioral approach}

\section{CHAPTER 5}

Accepted for publication as:

Theunissen, E. L., Jonkman, L. M., Kuypers, K. P. C., \& Ramaekers, J. G. Stimulating effects of fexofenadine under high workload conditions. A combined neurophysiological and behavioral approach. Journal of psychopharmacology. 


\section{Chapter 5}

\section{ABSTRACT}

Antihistamines are known for their sedative effects. However, some studies suggested mild stimulant effects in case of fexofenadine. The goals of this study are to examine whether fexofenadine possesses stimulating properties and to determine whether such stimulating effects are related to workload. 16 healthy volunteers received a single dose of 180 and 360 mg fexofenadine and placebo on separate test days. Drug effects were assessed using a divided attention task (DAT), continuous performance task (CPT) and motor choice reaction time test (MCRT). Sensitivity of the tasks was increased by manipulating the workload during task performance. Event Related brain Potentials (ERP's) were measured in the DAT and CPT to study the underlying neurophysiological processes. An interaction effect of Treatment and Workload was found on tracking performance in the DAT and on movement time in the MCRT. Performance on the DAT was less affected by increments in workload after fexofenadine as compared to placebo. P1 and P3 latency were affected by Treatment $\mathrm{x}$ Workload and Treatment respectively and indicated faster attentional and information processing latencies following fexofenadine treatment. Treatment did not influence performance in the CPT task or in the ERP"s measured during this task. The MCRT demonstrated faster movement times following fexofenadine treatment. These results suggest that although the neurophysiological data indicate central nervous system (CNS) activation after fexofenadine treatment, the magnitude of the centrally activating effects is too small to produce relevant performance improvement at the behavioral level. 


\section{INTRODUCTION}

Allergies such as allergic rhinitis, conjunctivitis and urticaria are caused by hypersensitivity for peripheral histamine. Relief of symptoms is accomplished by antihistamines which reach their therapeutic effect by blocking peripheral histamine receptors (H1). The first antihistamines developed were lipophilic and therefore entered the brain easily where they also blacked central histamine neurotransmission. Central histamine neurotransmission is involved in the maintenance of arousal (Onoe et al., 1992; Onodera, Yamatodani, Watanabe, \& Wada, 1994). Blocking central $\mathrm{Hl}$-receptors by antihistamines has been shown to induce sommolence and to seriously diminish cognitive, psychomotor and driving performance in healthy volunteers (Rombaut \& Hindmarch, 1994; Simons, 1994; O'Hanlon \& Ramaekers, 1995). Other side effects of first generation antihistamines, such as diphenhydramine, triprolidine, clemastine or chlorpheniramine, are blurred vision and dry mouth as a result of muscarinic antagonism (Snyder \& Snowman, 1987; Gengo, 1996; Passalacqua er al., 1996).

Second generation antihistamines (also called non-sedating antihistamines) were developed to overcome the problem of sedation. These antihistamines are less lipophilic and cross the blood-brain barrier more slowly then their predecessors. However, recent studies have shown that also $2^{\text {nd }}$ generation antihistamines have the potential to cause sedation (O'Hanlon \& Ramaekers, 1995). Several $2^{\text {nd }}$ generation antihistamines (acrivastine, cetirizine, mizolastine and emedastine) mildly impaired driving when given in therapeutic doses (Ramaekers \& O'Hanlon, 1994; Vuurman, Uiterwijk, Rosenzweig, \& O'Hanlon, 1994; Vermeeren, Ramaekers, \& O'Hanlon, 2002). Other $2^{\text {nd }}$ generation antihistamines (loratadine, mequitazine and terfenadine) did not have significant effects on driving performance when taken in recommended doses but had at least measurable effects after doubling the dose (Riedel, Ramaekers, Uiterwijk, \& $O^{\prime}$ Hanlon, 1990; Theunissen, Vermeeren, van Oers, van Maris, \& Ramaekers, 2004). These results indicate that not all second-generation antihistamines share the same low tendency to produce sedation.

Recently some $2^{\text {nd }}$ generation antihistamines were even found to possess stimulating effects. Fexofenadine, for instance, did not impair psychomotor and driving performance when given in single doses ranging from 60 to $240 \mathrm{mg}$ (Vermeeren \& O'Hanlon, 1998; Hindmarch \& Shamsi, 1999; Nicholson, Stone, Turner, \& Mills, 2000; Weiler et al., 2000; Bower et al, 2003) but rather improved driving performance (Vermeeren \& O'Hanlon, 1998), an effect which was previously also demonstrated for ebastine $10 \mathrm{mg}$ (O'Hanlon $\&$ Ramaekers, 1995). Single doses of desloratadine $5 \mathrm{mg}$ also did not cause impairing effects on actual driving and psychomotor performance but did improve brake reaction time in the driving test (Vuurman, Rikken, Muntjewerff, de Halleux, \& Ramaekers, 2004). Terfenadine is yet another antihistamine which has shown not to impair performance but rather improve performance on psychomotor tasks (Moskowitz \& Burns, 1988) and subjective alertness and wakefulness (Clarke \& Nicholson, 1978; Reinberg, Levi, Guiller, Burke, \& Nicolai, 1978). Improved psychomotor performance and body balance were also found after single doses of ebastine (Mattila, Kuitunen, \& Pletan, 1992). The clinical significance of these findings is unclear, but they indicate that these antihistamines do enter the brain and can cause stimulating effects.

The goals of this study are to examine whether fexofenadine possesses stimulating properties and to assess whether its stimulating effects are related to workload. It is expected that tasks with a high workload are more sensitive for a stimulating drug effect. Dependent variables include behavioral measures as well as Event Related brain Potentials (ERP's). 
ERPs are particularly useful for measuring temporal and cognitive information processes that precede an overt, behavioral response.

\section{MATERIALS AND METHODS}

\section{Subjects}

Sixteen healthy volunteers ( 8 males and 8 females), aged between 21 and 35 years were recruited by means of newspaper advertisements. Subjects were first screened using a medical history questionnaire. Each qualified subject underwent a physical examination in which an electrocardiogram was made and a blood sample was taken. Mean (SD) age of the participants was $23.3(3.19)$ years.

Exclusion criteria were: history of major medical or psychiatric disorder, any noncorrected visual or psychomotor defect, unusual sensitiviry to antihistamines, drug abuse and chronic use of medlication. Female subjects could not participate when pregnant or lactating, and were required to use an effective contraceptive during the study. After having received all necessary information, every participant gave their written consent. The study was approved by the medical Ethical committee of Maastricht University and subsequently carried out in accordance with the World Medical Associations Declaration of Helsinki (Edinburgh modification, 2000).

\section{Procedure}

Drugs and placebo were administered according to a 3-way, double-blind, cross-over design. A wash-out period of at least 7 days proceeded in between treatments. Treatments consisted of single doses of placebo, fexofenadine $180 \mathrm{mg}$ and fexofenadine $360 \mathrm{mg}$ (therapeutic dose of fexofenadine is 120 to $180 \mathrm{mg}$ ). Drugs and placebo were administered in orally identically appearing formulations to ensure blinding.

All subjects were trained on all tests a few days prior to their first treatment period. Subjects were prohibited from consuming alcohol for $24 \mathrm{~h}$ before testing. Half an hour before drug intake all subjects received a standard meal. Consumption of caffeine containing beverages was not allowed on test days. Smoking was prohibited 30 minutes prior and during testing. Behavioral and ERP testing were performed between 2-3 hours after drug intake.

\section{Assessments}

\section{- Critical Tracking Task (CTT)}

In the critical tracking task, the subject controls an unstable cursor on a computer screen using a joystick (Jex, McDonnell, \& Phatak, 1966). An error signal causes the cursor to become increasingly unstable on a horizontal axis, causing it to diverge from the centre of the axis. The subject's task is to try to keep the cursor in the center of the axis by continuously making compensatory joystick movements. The frequency of cursor deviations increases as a stochastic, linear function of time, therefore the subject is required to make compensatory movements with a progressively higher frequency. Eventually, the subject's response adds to, rather than subtracts from, the error and consequently control is lost. The frequency at which the subject loses the control is the critical frequency $\left(\lambda_{c}\right)$. The test is performed five times; the average critical frequency is calculated without the lowest and highest score and is the dependent variable of this test. Depending on the competence of the subject, this task takes 3 to 8 minures. 


\section{- Divided Attention task (DAT)}

The Divided Attention Task measures the ability to divide atrention berween mo simultaneous tasks (Moskowirz, 1973). As a primary task, the subject performs the same tracking rask as described above but at a constant level of difficulty. The task is repeated 3 times, each with the primary task set at a different level of difficulty in order to assess the interaction between mental workload and drug treatment. Task difficulties $\left(\lambda_{c}\right)$ are set at 50,60 and $70 \%$ of each subjects' maximal performance as measured during training sessions of critical tracking task. As a secondary task, the subject monitors a central display upon which single digits $(0$ to 9) are presented for 17 milliseconds with a variahle inter stimulus interval berween 1.03 and 1.23 seconds. The occurrence of the digit " 2 " is a signal for the subject to remove his/her foot from a pedal as rapidly as possible. In total, 75 targets and 375 distractors are presented. Mean absolute tracking error ( $\mathrm{mm}$ ) is the dependent variable in the primary task; number of correct responses and mean reaction time (ms) of these responses are the performance measures in the secondary task. Depending on the competence of the subject, this takk rakes about 10 minures.

It is hyporhesized that performance in the primary task will decline as a result of the increased workload and in addition performance on the secondary task will be negatively influenced by the increased workload of the primary task.

\section{- Continuous Performance Task (CPT)}

Continuous Performance Tasks (Conners, 1992) have been used repeatedly to study vigilance and attention, and several variants of this test have been developed. The version used in the present experiment is the CPT-ax task. In this task, letters are presented to the subject one by one on a computer screen for $150 \mathrm{msec}$ with an Inter Stimulus Interval (ISI) of 600 msec. The subjects" task is to press a button as fast as possible when the target letter $X$ appears, but only when it is preceded by an $A$ (Go condition). In situations in which the cue letter $A$ is not followed by the target $X$, subjects have to inhibit their prepared responses (NoGo condition). Thus, the task measures attention associated with Go responses as well as inhibition processes (evoked by NoGo trials). The task included 48 Go stimuli (A-X), 96 NoGo trials (A-nontarget) and 240 randomly presented letters. Nontarget letters were $\mathrm{E}, \mathrm{H}$, $\mathrm{L}$ and $\mathrm{K}$. The task was divided in four blocks and lasted in total approximately 10 minutes,

In order to differentiate workload conditions in the CPT-ax task a high load version wass developed. In this version, the target letter is an $X$ with a small dot on top of it. The letter $X$ with a small dot underneath was added as a nontarger, and had to be ignored. In total this task included 48 Go trials (A-X-dot on top), 144 NoGo trials (48 A.X-dot below and $96 \mathrm{~A}$. nontarget) and 288 randomly presented letters. Except for the changed target letter and the added nontarget, the task is identical to the easy version. The variables measured in both rasks are number of correct responses, number of false alarms and reacrion time of these responses.

\section{- Motor Choice Reaction Time (MCRT)}

The Motor Choice Reaction Test is a test in which reacrion time is studied as a funcrion of task difficulty (Houx \& Jolles, 1993). The subject is presented with a computerized panel with one central red and 5 white buttons. The subject is asked to hold the central red button until one of the white buttons lights up. As soon as a white button illuminates, the participant has to release the red button and press the illuminated button and return to the red central button as fast as possible. Three task conditions with increasing difficulty were used: simple reaction time, in which only the upper button illuminates; choice reaction 
time, in which one of a defined set of three buttons illuminates; and incompatible reaction time, which is the same as the previous condition but the task is to press the button located to the right of the illuminated button. Reaction time was divided into an iniriation phase, i.e. time from stimulus onset until release of the red button, and a movement phase, i.e. time between release of the red button and pressing the response button. Initiation time represents the time needed for perception, decision and motor planning while movement time represents the time needed for actual movement execurtion. Dependent measures are median initiation and movement time in the three workload conditions (simple, choice and incompatible condition). Task cluration is approximately three minutes.

\section{- Event Related Potentials}

Recording - EEG-activity was recorded by means of an electro-cap from an array of 30 electrodes from the standard $10-20$ system $(\mathrm{Fz}, \mathrm{Cz}, \mathrm{Pz}, \mathrm{Oz}, \mathrm{F} 3, \mathrm{~F} 4, \mathrm{~F} 7, \mathrm{~F} 8, \mathrm{C} 3, \mathrm{C} 4, \mathrm{~T} 3, \mathrm{~T} 4$, T5, T6, P3, P4, O1, O2, Fp1, Fp2, Ft7, Fr8, Fc3, Fc4, Tp7, Tp8, Cp3, Cp4, FCz, CPz). Electrodes were filled with electro-gel. All electrodes were referenced to the left mastoid; FPz was used as ground electrode. Horizontal EOG was recorded using electrodes attached to the outer canthi of the eyes, while vertical EOG were recorded from infraorbital and supraorbital electrodes placed in line with the pupil of the left eye. All electrode impedances were kept below $5 \mathrm{~K} \Omega$. ERP's were collected using the Neuroscan 4.1 software, and SynAmps amplifiers were used. All signals were continuously sampled at a rate of $250 \mathrm{~Hz}$ and digitally filtered online with a high-pass filter of $0.05 \mathrm{~Hz}$ and a low-pass filter of $50 \mathrm{~Hz}$. Continuous signals were epoched into 1200 msec sweeps for the divided attention task and into $950 \mathrm{msec}$ sweeps in the CPT-ax tasks, both including a $200 \mathrm{msec}$ pre-stimulus baseline. Signal Analysis - All of the sampled EEG and EOG epochs were baseline corrected and filtered off-line using a $30-H_{2}, 24-\mathrm{dB} /$ oct digital low-pass filter. EEG's were corrected for vertical eye movements according to a procedure by Semlitsch, Anderer, Schuster, andPresslich (1986). Sweeps containing an artifact exceeding +75 or $-75 \mu \mathrm{V}$ were rejected. ERP-components - The ERP-components of interest in the tasks used are the occipital P1, the frontal N2 and parietal P3 (or P3b). P1 is a positive peak which appears around 100 msec, above visual cortex and reflects early attentional processes (Mangun \& Hillyard, 1990; Mangun, 1995), and is specifically sensitive to spatial attributes of the stimulus (Rugg, Milner, Lines, \& Phalp, 1987), task load and salience (Taylor, 2002). In go-nogo tasks, the $\mathrm{N} 2$ wave (a negative wave occurring around $200 \mathrm{msec}$ post-stimulus) is reported to be related to response inhibition (Jodo \& Kayama, 1992; Falkenstein, Hoormann, \& Hohnsbein, 1999). The parietal P3 "a positive wave between $300-800 \mathrm{msec}$, has mostly been demonstrated in so-called oddball tasks (Picton, 1992; Polich \& Kok, 1995). In these kinds of tasks, subjects are presented with frequent and rare stimuli in a random order. P3 amplitude is shown to be affected by the probability of the rare stimulus (DuncanJohnson \& Donchin, 1977), in both passive and active tasks (Mertens \& Polich, 1997). Other factors like attention, stimulus quality and task relevance also appear to affect P3 amplitude (Smulders, Kok, Kenemans, \& Bashore, 1995). The P3 component has also previously shown to be an indicator for processing capacity in dual tasks. P3 elicited by a secondary test, has been found to decrease in amplitude with increases in the perceptual or cognitive difficulty of the primary rask (Isreal, Chesney, Wickens, \& Donchin, 1980; Wickens, Kramer, Vanasse, \& Donchin, 1983; Brocke, Tasche, \& Beauducel, 1996; Kok, 2001). On the other hand, P3 latency of the secondary task is 
affected mainly by stimulus evaluation time of the primary task (Duncan-Johnson, 1981; Smulders et al., 1.995).

In the dual-task (divided attention task), ERP's were measured in relation to the secondary task. ERP-averages for individual subjects were calculated for targets and distractors. Artifact-free epochs ranged between 60 and 75 for targets and between 300 and 375 for distractors. Parietal $\left(\mathrm{P}_{z}\right)$ P3 peak amplitude and larency was derermined in a window between 350 and $650 \mathrm{msec}$ as a measure of the amount of invested capacity in the secondary task under different workload conditions. It is expected that the $\mathrm{P} 3$ amplitude will decrease as a function of workload because of the diminished capacity available for the secondary task. Furthermore, the maximum $\mathrm{P} 1$ amplitude and latency at $\mathrm{O}_{2}$ was scored between 80 and $200 \mathrm{msec}$ to examine effects of primary task load on early attentional processing of stimuli in the secondary task.

For the easy CPT-ax version, individual ERP averages were calculated for correctly detected targets, for correctly rejected nontargets following $A$ that shared no features with the target letter $(E, H, L)$, and for the correctly rejected nontarget letter $K$ following $A$, which has similarities with the target letter. For the harder CPT-ax task, averages were calculated for correctly detected targets (X-dor on top following A) and 3 types of correctly rejected distractors (random letters $(E, H, L), K$ 's and X"s-dot below, all following the cue letter A). All ERP's were calculated based on at least 23 and maximum 48 artifact-free epochs. In both tasks the maximum amplitude and peak latency of the frontal N2 (Fz) was measured between 150 and $350 \mathrm{msec}$ following onset of the stimulus as an indicator of response inhibition which is expected to be larger in distractor than target conditions. The maximum parietal P3 peak and its latency were measured at Pz between 250 and $600 \mathrm{msec}$ after stimulus onset and was taken as a measure of attention invested in the processing of targets (compared to nontargets). All time windows were defined after inspection of the grand averages.

\section{Analysis}

All parameters that were normally distributed were subjected to repeated measures analysis of variance (ANOVA). Performance data from the DAT were tested for the main effects of Treatment (3 levels), Workload ( 3 levels) and Treatment by Workload. ERP data were tested for an additional factor Stimulus-type (2 levels). Performance and ERP data from the CPT tasks were tested for the main effect of Treatment in the easy and high load conditions separately. ERP-analysis also included the additional factor Stimulus-type (3 levels in the easy version and 4 levels in the difficult version). Performance data from the MCRT task were tested for the effects of Treatment ( 3 levels) and Workload ( 3 levels). Type 1 errors associated with inhomogeneity of variance were controlled by decreasing the degrees of freedom using Greenhouse-Geisser corrections, and the probability estimates were based on these reduced degrees of freedom. Separate drug-placebo comparisons were conducted only in case of a significant main effect of Treatment or Treatment x Workload by means of simple contrasts with Bonferroni correction. The main variables of the divided attention task (RT, tracking error and P3) were tested 1-tailed because of the one-sided nature of the prediction. All other evaluations were carried out in a similar fashion, but were tested 2-tailed and significance level was $p<.05$ in all cases. Variables that were not normally distributed were analyzed using the non-parametric Friedman test. All statistical tests were conducted using SPSS (version 10.0). 


\section{Chapter 5}

\section{RESULTS}

A summary of descriptive and quantitative statistical analyses of the behavioral results in each treatment condition are shown in Table 1 and of ERP-measures in each trearment are shown in Table 2 .

\section{Critical Tracking Task}

There was no effect of Treatment on CTT.

\section{Divided Attention Task}

In the primary task of the DAT, tracking error was significantly affected by Workload level $\left(\mathrm{F}_{2,30}=128.1 \mathrm{p}<.01\right.$, one sided $)$, i.e. tracking error increased when workload increased. There was no main effects of Treatment, but the interaction between Treatment and Workload

\begin{tabular}{|c|c|c|c|c|c|c|c|c|c|c|}
\hline & Mean & SEM per th & atment & & tment & effect & & Treatm & it $\times$ Wor & kload \\
\hline & Placebo: & fexo 180 & $\operatorname{texo} 360$ & 5 & $x^{2}$ & dI & $p$ & $\mathrm{~F}$ & df & $p$ \\
\hline CT: & & & 8 & & & & & & & \\
\hline Lambida-C (radsec) & $431+016$ & $134 \pm 0,15$ & $4.35 \pm 0.14$ & 48 & . & 2,30 & N5 & - & . & . \\
\hline DAT & & & 8 & & & & & & & \\
\hline Jrakking erior (nm) & $140+08$ & $130 \pm 0.8$ & $13.2 \pm 0.7$ & .87 & . & 2,60 & $\mathrm{NS}$ & 4.47 & 1.15 & .026 \\
\hline Workload 50 & $107+09$ & $10, \pm 1$ & $10,7 \pm 10$ & & & & & & & \\
\hline 43 Worload 60 & $13,6 \pm 11$ & $131 \pm 13$ & $12.7 \pm 0.9$ & & & & & & & \\
\hline 3 Workload ol & $176+13$ & $159 \pm 13$ & $162+1$ & & & & & & & \\
\hline nearton Tine (nised) & $557+1$ & 561412 & $562+11$ & . & 13 & 2 & NS & . & - & $=$ \\
\hline Workloadso & $560+20$ & 559420 & $572 \pm 17$ & & & & & & & \\
\hline सै। Workload 60 & $550+22$ & $563 \pm 22$ & $551 \pm 18$ & & & & & & & \\
\hline W'Worload ro & $561+18$ & $562 \pm 20$ & $565 \pm 21$ & & & & & & & \\
\hline (lits (1) & 72.1406 & $7 \mathrm{6} 6 \pm 07$ & $71.8 \pm 0.6$ & - & .90 & 2 & $\mathbb{N S}$ & - & - & - \\
\hline Horkload so & $724 \pm 09$ & $71.6 \pm 1: 0$ & $72.1 \pm 0.7$ & & & & & & & \\
\hline Workload 60 & $723+12$ & $72.5 \pm 0.9$ & $72.2 \pm 1.0$ & & & & & & & \\
\hline , Workload 70 & $71,4 \pm 1,0$ & $70.6 \pm 1.7$ & $70.9 \pm 11.4$ & & & & & & & \\
\hline CPT & & 3 & & & & & & & & \\
\hline sy load & & & & & & & & & & \\
\hline hits $($ t) & 49407 & $469 \pm 06$ & $46.9 \pm 0.6$ & . & 4.78 & 2 & NS & - & . & - \\
\hline Rentition time (onsec) & $380 \pm 15$ & $3 \pi \pm 13$ & $382 \pm 12$ & 1.90 & - & 2.30 & NS & . & - & - \\
\hline High lond & $\therefore \quad 3$ & 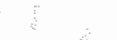 & & & & & & & & \\
\hline Hits (A) & 46.940 .4 & $46.1 \pm 0.8$ & $46.7 \pm 0.5$ & - & 1.59 & 2 & NS & - & - & - \\
\hline Reartion time (nised) & $398+13$ & $392 \pm 14$ & $411 \pm 13$ & 3.28 & . & 230 & $.05 \%$ & . & - & - \\
\hline MCRT & & & & & & & & & & \\
\hline Inithation fame (msec) & $344 \pm 8$ & 34148 & $342 \pm 11$ & 0.61 & - & 2.56 & NS & 2.52 & 26366 & NS \\
\hline Simple & 29847 & $292 \pm 6$ & $303 \pm 13$ & & & & & & & \\
\hline Choice & $336 \pm 7$ & 33449 & $337 \pm 10$ & & & & & & & \\
\hline$\therefore \quad$ uncompotible & $399+1$ & $398+12$ & $389 \pm 12$ & & & & & & & \\
\hline Moventant time (msec) & $102 \pm 6$ & $97 \pm 6$ & $101 \pm 5$ & 2.08 & . & 2.56 & NS & 2.58 & 4.56 & .047 \\
\hline Simple & $104 \pm 6$ & $97 \pm 6$ & $98 \pm 6$ & & & & & & & \\
\hline Choice & $98+6$ & $97 \pm 6$ & $101 \pm 5$ & & & & & & & \\
\hline Mncompalible & $105 \pm 6$ & $99 \pm 6$ & $104 \pm 5$ & & & & & & & \\
\hline
\end{tabular}

Table 1. Summary of the results on the cticical tracking task, divided attention task, continuouts performance task and notor choice reaction task. Treaments are placebo, texofenadine $180 \mathrm{mg}$ (fexo 180) and fexofenadine $360 \mathrm{mg}$ (fexo 360 ). NS: not significane; df: degrees of treedom. 


\begin{tabular}{|c|c|c|c|c|c|c|c|c|c|}
\hline & \multicolumn{3}{|c|}{ Mean \pm SEM per reatinent } & \multicolumn{3}{|c|}{ Treatment effecl } & \multicolumn{3}{|c|}{ Treatmen $\times$ Wonkload } \\
\hline & Placeloo. & $F e \times 0180$ & $1 \mathrm{e} \times 0360$ & T. & 11 & n: & t & df & 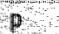 \\
\hline \multicolumn{10}{|l|}{ DII } \\
\hline DItalengy (bused) & 137728 & $137+21$ & $1399+26$ & 3 & 230 & Ms & 303 & 4,60 & 024 \\
\hline Targets & 138240 & 1360129 & $133 \times+28$ & & & & & & \\
\hline Nontargets & $|373+3|$ & $130,4+30$ & $138,4+29$ & & & & & & \\
\hline Pr-amplizude (N) & $45 \pm 03$ & $43+02$ & 44403 & 54 & 2,30 & NS & 81 & 460 & No \\
\hline Targets & $48+03$ & $4.4+03$ & 41104 & & & & & & \\
\hline Nonlangets & $41 \pm 03$ & $4.2+02$ & $41 \pm 03$ & & & & & & \\
\hline P3 latency (msec) & $51,7+66$ & $5045 \pm 71$ & $4930 \pm 64$ & 4492 & 230 & 02 & 13 & 460 & NS \\
\hline . Torgets & $4843+67$ & $471+78$ & $4713+57$ & & & & & & \\
\hline Nontargets: & 539.1490 & $31,0+92$ & $5157+96$ & & & 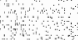 & & & \\
\hline P3-amplitude ( $\mathrm{N})$ & $87+0.5$ & 82405 & 84405 & 087 & 230 & NS & 0.49 & 460 & Ns \\
\hline Targets & 46040.8 & $137+9$ & 139400 & & & & & & \\
\hline Nontargets & $2.8 \pm 02$ & $27 \pm 0.2$ & $28 \mathrm{~g}+03$ & & & & & & \\
\hline \multicolumn{10}{|l|}{ CPT } \\
\hline \multicolumn{10}{|l|}{ Easy load } \\
\hline $\mathrm{NL}$ Haten $/(\mathrm{msec})$ & $2639+50$ & $2678+46$ & $2652+54$ & 1044 & 230 & 18 & & & \\
\hline M2 amplitude (UV) & $22 \pm 06$ & $24+08$ & $26+08$ & 9.444 & 230 & NS & & & \\
\hline P) latengy (risec) & 376.5447 & $3764+4$ & 3809445 & 0,51 & 230 & NS & & & \\
\hline P3-amplitude (WV) & $130+10$ & $14.4 \pm 1.0$ & $12.7+10$ & 314 & 230 & 058 & & & \\
\hline \multicolumn{10}{|l|}{ High load } \\
\hline N2 lateng (mser) & $2728+36$ & $2745 \times 35$ & 2741136 & 0286 & 2,30 & NS & & & \\
\hline N2 amplitude $(\mathrm{N})$ & $12 \geq 05$ & $19+05$ & 20106 & 1,041 & 230 & NS & & & \\
\hline Pultency (msec) & $4068+57$ & $4048+58$ & $4056+49$ & 0133 & 230 & NS & & & \\
\hline Puamplitude (NU) & $12+09$ & $138+09$ & 13,409 & 0.463 & 230 & NS & & & \\
\hline
\end{tabular}

Table 2. Summary of ERP latencies and amplitudes in the divided artention task and continuous performance tasks. Treatments are placebo, fexofenadine $180 \mathrm{mg}$ (fexo 180) and fexolenadine $360 \mathrm{mg}$ (fexo 360). NS: not significant; df degrees of freedom.

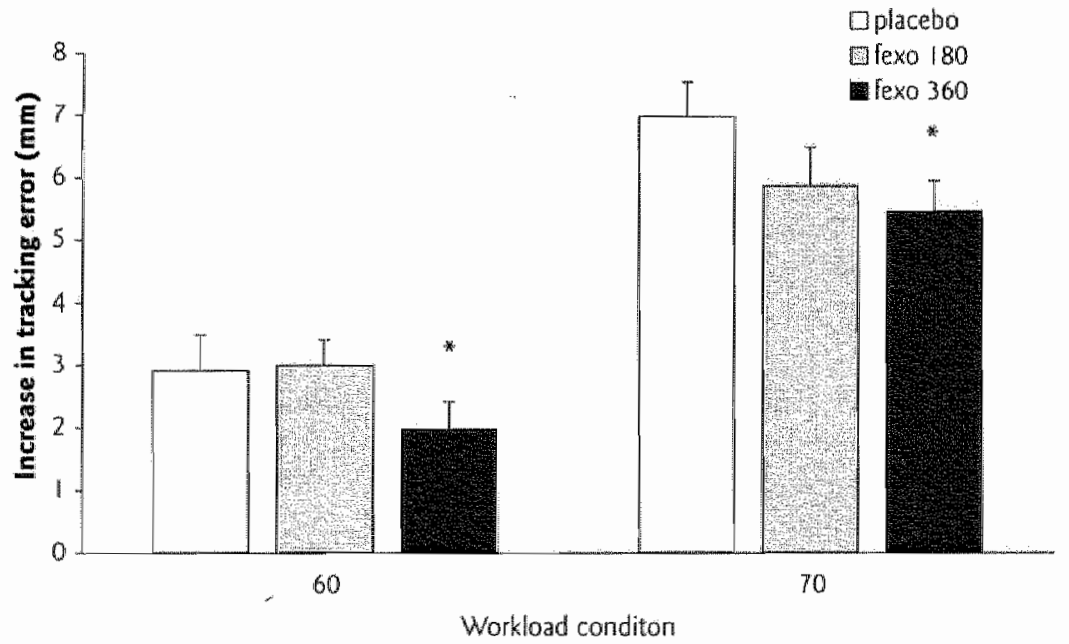

Figure 1. $\Delta$ tracking error (mun) in the divided atcention task for workload 60 and 70 condition and for each trearment; placebo, fexofenadine $180 \mathrm{mg}$ (fexo 180) and fexofenadine $360 \mathrm{mg}$ (fexo 360 ), * indicate significan $(p<05)$ drug placebo diferences poolect over worklond. 

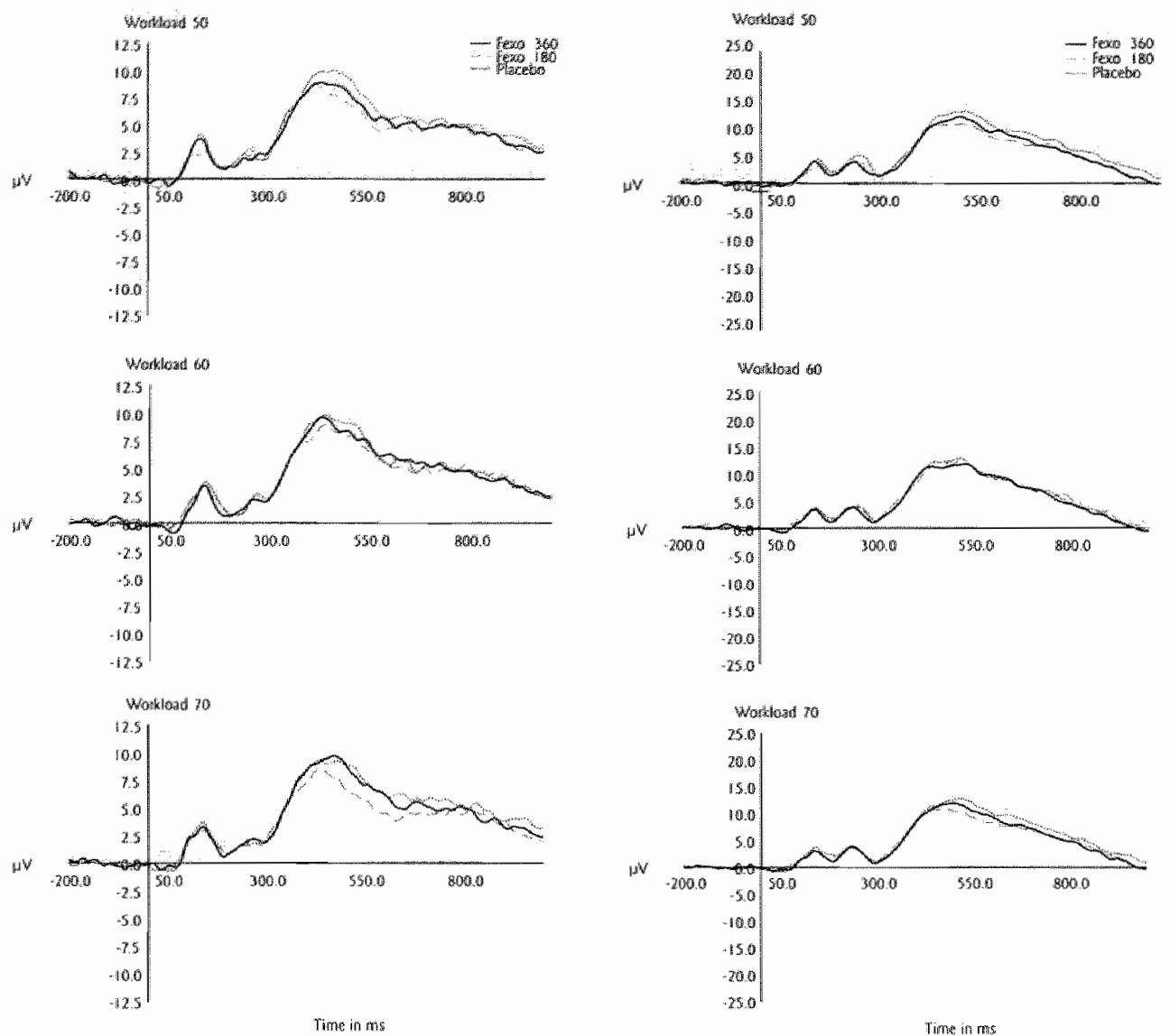

Figure 2. Orand average ERP's showing $P 1$ at $O z$ for vargets and for workload 50,60 and 70 of the divided attontion task. Ablyeviations as in ligutel.

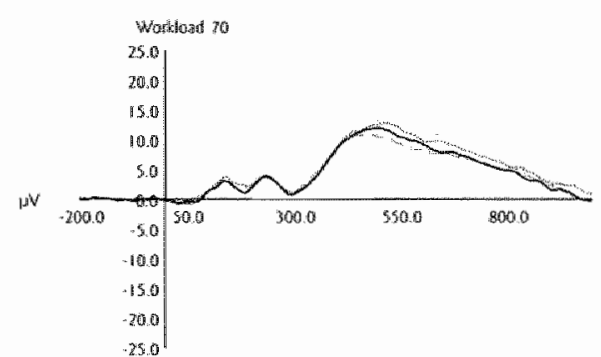

Timus in ms

Figure 3. Grand average ERP"s showing P3 at $\mathrm{Pz}$ for targets and for workload 50,60 and 70 of the divided atrention ask. Abbreviations as in figure 1.

reached significance $\left(F_{1,15}=4.47 ; p=026\right)$. As can be seen in table 1 , the increase in tracking error in the two hardest workload conditions was less during fexofenadine treatment as compared to placebo. Additional analyses employing difference scores from the 2 highest workload conditions versus the easiest workload condition provided further support for this notion as indicated by an overall effect of Treatment $\left(\mathrm{F}_{2,30}=2.948 ; \mathrm{p}=.034\right)$. Separate drugplacebo contrasts furthermore revealed that increments in tracking error were less after fexofenadine $360 \mathrm{mg}$ as compared to placebo $\left(\mathrm{F}_{1.15}=4.793 ; \mathrm{p}=.023\right)$. Mean increments of tracking error in the highest workload conditions for each treatment are shown in Figure 1. Reaction time and the number of hits were not significantly affected by Treatment.

ERP P1 latency demonstrated significant effects of Treatment x Workload $\left(F_{4,60}=3.03\right.$; $\mathrm{p}=.024)$ and Stimulus-type $\left(\mathrm{F}_{1,15}=20.0 ; \mathrm{p}<.01\right)$. The Treatment $\mathrm{x}$ Workload interaction indicated that that while workload augmented, PI amplitude increased in the placebo 
$a$

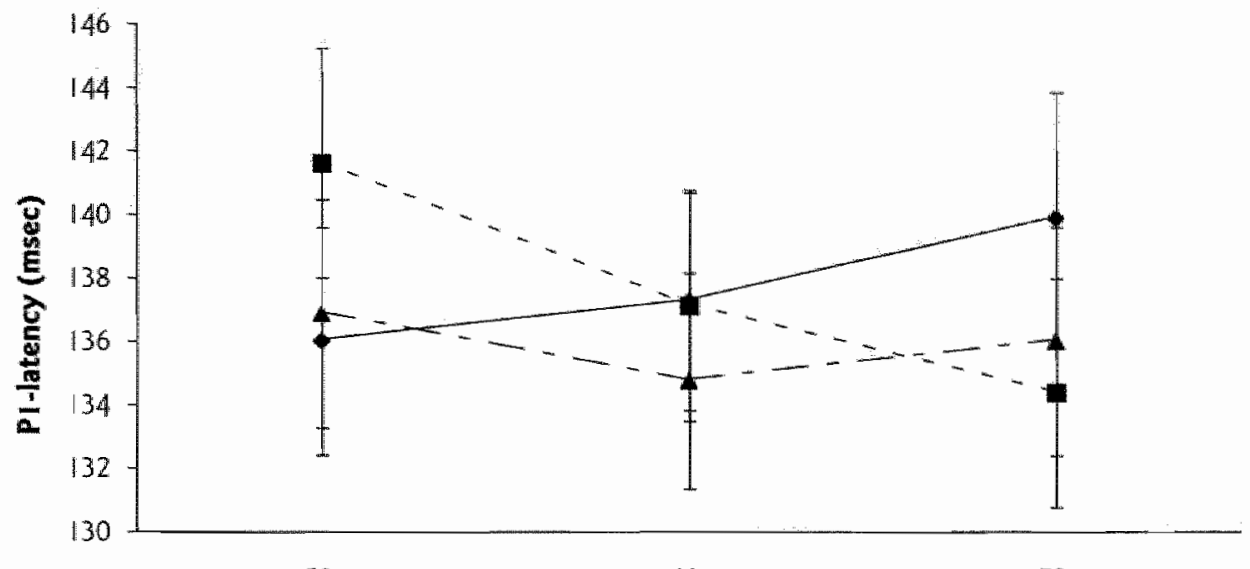

b

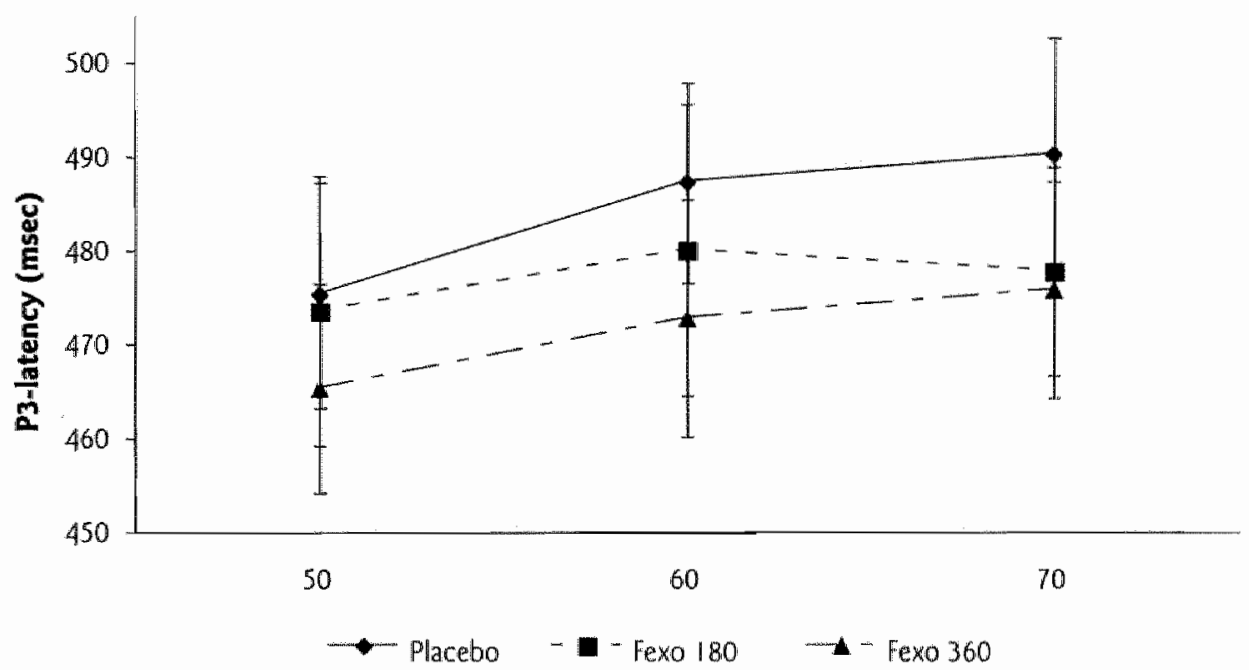

Figure 4. P1 watency (nsec) on the secondary task of the DAT (a) and P3-latency (msec) for the targets in the secondary task of the DAT (b). Latencies are given for each workload condution $(50,60,70)$ and for each dose of fexofenadine. Abbreviations as in figure 1.

condition, but decreased in the fexofenadine conditions (see figure 4). PI amplitude was only affected by Stimulus-type $\left(F_{1,15}=4.55 ; \mathrm{p}=.05\right)$.

P3 latency revealed significant main effects of Treatment $\left(F_{2,30}=4.5 ; p=.02\right)$, Stimulustype $\left(\mathrm{F}_{1,15}=17.2 ; \mathrm{p}<.01\right)$ and Workload $\left(\mathrm{F}_{2,30}=5.6 ; \mathrm{p}<.01\right)$. P3 latency occurred earlier after fexofenadine $360 \mathrm{mg}$ as compared to placebo $\left(\mathbb{F}_{1,15}=8.8 ; \mathrm{p}=.01\right)$. However, there were no interactions between Treatment $x$ Workload or Treatment $x$ Stimulus-type on P3 latency. For P3 amplitude there was only an effect of Stimulus $\left(F_{1,15}=96.0 ; p<.001\right)$, with amplitudes being larger for targets. P1 and P3 grand averages recorded in each treatment and workload condition are given in figures 2 and 3 respectively. PI and P3 latencies as a funcrion of workload and dose are shown in figure 4. 


\section{Continuous Performance Task}

There was no significant effect of Treatment on the percentage of correctly detected targets or hit reaction time in the easy CPT-ax. In the difficult version there was an almost significant overall effect of Fexofenadine on hit reaction time $\left(F_{2,30}=3.28 ; p=.051\right)$. Mean scores demonstrated that subjects in the fexofenadine $180 \mathrm{mg}$ condition responded fastest, followed by placebo and then by fexofenadine $360 \mathrm{mg}$. However, further testing with simple contrasts did not yield significant differences between drug conditions. Other parameters of the CPT-tasks showed no significant effects of the factor Trearment.

As mentioned earlier, parietal P3 and frontal N2 ERP' components were determined in Go (target) and NoGo (distractor) conditions. No Treatment effects were found for P3 or N2 components. A main effect of Stimulus-type was found for parietal P3 latency in the easy version $\left(\mathrm{F}_{2,30}=4.9 ; \mathrm{p}=.015\right)$ and the difficult version $\left(\mathrm{F}_{3,45}=6.4 ; \mathrm{p}=.001\right)$. In both versions of the CPT-ax task, an effect of Stimulus-type on latency $\left(\mathrm{F}_{1.5,22.1}=28.2 ; \mathrm{p}<.001\right)$ and amplitude $\left(\mathrm{F}_{2,30}=44.0 ; \mathrm{p}<.001\right)$ of the frontal $\mathrm{N} 2$ was found.

\section{Motor Choice Reaction Time}

There was no main effect of Treatment on initiation time or movement time. However the interaction berween Trearment $\mathrm{x}$ Workload (task difficulty) did significantly affect movement time $\left(\mathrm{F}_{4,56}=2.58 ; \mathrm{p}=.047\right)$. The interaction indicated that fexofenadine produces faster movement times in the Simple and the Incompatible conditions, relative to placebo. Drugplacebo contrasts showed that fexofenadine $180 \mathrm{mg}$ produced a significantly faster movement time than placebo $\left(\mathrm{F}_{1,14}=6.53 ; \mathrm{p}<.025\right)$.

\section{DISCUSSION}

Previous studies found that in contrast to most second generation antihistamines, fexofenadine does not produce sedative effects (Hindmarch, Shamsi, Stanley, \& Fairweather, 1999; Bower et all, 2003; Ridout, Shamsi, Meadows, Johnson, \& Hindmarch, 2003) and one study even suggested small stimulating effects after fexofenadine treatment (Vermeeren \& O'Hanlon, 1998). In the present study the stimulating effects of fexofenadine were investigated using behavioral and electrophysiological measures.

The behavioral results of the divided attention task in this study showed that the primary tracking task was affected by workload. Increasing the workload caused the subjects to have more trouble keeping the cursor stable, resulting in an increase in tracking error. In addition, after treatment with fexofenadine tracking error increased less as a function of workload. There was no effect of fexofenadine on the behavioral results of the secondary task of the DAT.

Due to the nature of the task, ERP's could only be measured in relation to the secondary task of the divided attention task. The ERP-data showed that brain activity in the secondary task of the divided atrention task was significantly affected by fexofenadine and workload. Spatial attention studies have earlier demonstrated that P1-latency reflects the timing of early attentional processes (Mangun \& Hillyard, 1990, 1995). In the present study, P1 amplitude was larger for targets than distractors, indicating an attention effect in a nonspatial attention test. P1-latency increased as a function of workload when subjects were treated with placebo but the opposite happened in the fexofenadine condition. It appears that especially the timing of early attentional processing is affected by the task difficulty by being delayed when the task gets harder. However, when treated with fexofenadine, this early processing occurred faster in the harder task conditions, thus fexofenadine appeared 
to have a facilitating effect on early attentional processing when primary rask tequirements are higher.

Fexofenadine caused faster P3 latencies in the secondary task of the DAT, while higher workload conditions caused a delayed P3 response. As P3 latency has been linked with stimulus evaluation processes (Duncan-Johnson, 1981; Willard, Johnson, \& Rosenfeld, 1994; Smulders et al., 1995; Kok, 1997), these results indicate that when workload is increased, stimulus evaluation time increases, demonstrated by the larer $\mathrm{P3}$ peak. Fexofenadine on the other hand causes the stimulus evaluation process to be completed faster. P3 amplitude in response to secondary task stimuli was not affected by fexofenadine or workload. Previous studies have demonstrated that $\mathrm{P} 3$ amplitude is a measure of the amount of mental capacity that is invested in a task (Kok, 1997). The lack of an effect of workload or fexofenadine on P3 amplitude would therefore indicate that these factors did not affect the amount of mental capacity available for the secondary task. Using an auditory oddball task as primary task and a tracking task as secondary, Wickens, Isreal and Donchin (1977) and Isreal et al., (1980) did find a decrease in P3 amplitude in the primary task when introducing this concurrent task, but found no further decrement in P3 when the secondary task became more difficult. It was interpreted that tracking difficulty and oddball task performance are mainly dependent on different processes; with the tracking task relying mostly on response-related resources, while the oddball task is thought to mainly address perceptual resources (Kok, 1997).

Fexofenadine did not influence performance in the CPT-ax tasks. Only in the difficult version an effect of drug was found on the reaction time, it was however unclear which drug condition caused this effect. The event related potentials measured during the CPT-ax tasks were unaffected by drug treatment. Task manipulations, however, had an effect on event related porentials involved in target processing and target inhibition of the CPT-ax tasks. These effects confirm that stimuli that must be attended to generate larger $\mathrm{P} 3$ peaks than stimuli that are to be ignored (Picton, 1992; Coull, 1998). The frontal N2 peak, thought to represent an inhibition process in Go/NoGo tasks, was later and larger when NoGo stimuli did share features with the target letter (e.g. $\mathrm{K}$ and $\mathrm{X}$-dot below). This finding points to increased inhibitory effort in conditions in which NoGo stimuli resemble Go stimuli in at least some stimulus features and supports an inhibition hypothesis of the frontal N2 (Jodo \& Kayama, 1992).

A stimulant effect of fexofenadine was also demonstrated in the motor choice reaction task. Fexofenadine interacted with task difficulty of the motor choice reaction time and fexofenadine $180 \mathrm{mg}$ caused faster movement times. As there was no effect on initiation or reaction time, this suggests that fexofenadine only affected the purely motor component and not the cognitive aspect of this task.

On the basis of the effects found in the motor choice reaction task and the divided attention task, behaviorally as well as physiologically, it can be concluded that fexofenadine has slightly stimulating properties. Consequently it is evident that fexofenadine has the capability of crossing the blood brain barrier and act centrally. However, it is still unclear by which mechanism fexofenadine stimulates cognitive processes. One hypothesis is that fexofenadine has an effect on the dopamine system, where it blocks the reuprake of dopamine presynaptically, causing an increase in the dopamine availability. This increased dopamine availabiliry could produce effects similar to psychomotor stimulants. The inhibitory effect of anrihistamines on the neuronal uptake of dopamine has already been demonstrated in rats and mice (Oishi, Shishido, Yamori, \& Saeki, 1994; Matsunaga et al., 


\section{Chapter 5}

1998) e.g. in the neostriatum and nucleus accumbens (Dringenberg, de Souza-Silva, Schwarting, Huston, 1998). Evidence for the dopamine reuptake hypothesis is also found in behavioral animal studies reporting antihistamines to increase the rate of fxed interval responding (Bergman \& Spealman, 1988) and potentiate conditioned place preference (Suzuki et al., 1999). These effects were probably mediated by dopamine uptake inhibition since the effects attenuated after treatment with dopamine antagonists (Bergman \& Spealman, 1988; Suzuki et al, 1999).

In conclusion, the neurophysiological data indicated CNS activation after fexofenadine treatment. However, the stimulant effects of fexofenadine at the behavioral level were minor and only demonstrated in high workload conditions. Together, these results suggest. that fexofenadine's centrally activating effects are generally too small in magnitude to produce clinically relevant performance improvement at the behavioral level.

\section{Acknowledgements}

We thank Drs. E. Engelen and Dr. N. Muntjewerff for their respective contributions to this study. 


\section{REFERENCES}

Bergman, J., Speatman, R. D. (1988). Behavionl efects of histamine HI antagonists companon with other drugs and modificarion by haloperidol. Jownal of phantaology and expermenal wherapeutres, $245(2), 471-478$.

Bower, E. A., Monte, J. L., Mos, M., Sellyy, K. A. Austin, M. S Meeves, S. (2003). The effect of single-dose fexofenadine, diphenhydramine, and placebo on cognivive performance in fight personnel. Aquation Space and Envirommental Medicine, 74(2), $145 \times 152$.

Brocke, B., Tasche, K. O., \& Beaducel, A. (1996). Bropsychological foundations of extraverstem:

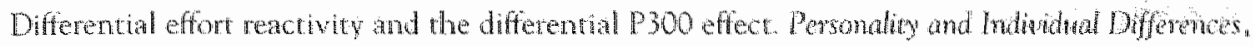
$21(5), 727.738$

Clarke, C. H., S Nicholson, A. N. (1978). Perfomaince sudies with antihiswmines. Brothin jownd of dinical phamacology, 6(1), 31.35.

Conners, C. K. (1992). Conners" Continuous Perfomance Test computer progran user's guide. Toronto: Multi-Heald Systems.

Coull, J. T. (1998). Neural correlates of atrention and arousal: insights from electrophysiology. funcrional neuroimaging and psychopharmacology. Progess in Neurobiology, 55(4),343-361.

Dringenberg, H. C., de Souza Siva, M. A., Schwarcing, R. K., \& Huston, J. P. (1998). Increned levels of exracellular dopamine in neostratum and nucleus accumbens after histamine $H 1$ receptor blockade. Nawnym-Schmiedebergs Arthives of Phamouology, 358(4), 423.429.

Duncan-Johnon, C. C. (1981). Young Psychophysiologist Awand address, 1980. P300 latency: a new metric of infomation processing. Psychophsiology, $18(3), 207-215$.

Duncan-Johnson, C.C., \& Donchin, E (1977). On quantifying surprise the vatution of eventrelated porentials with sebjective probability. Psychophysiology, 14(5), 456.567.

Falkenstein, M. Hoomann, J., \& Holunghein, 1. (1999). ERP components in Go/Nogo casks and their relation to inhibition. Acta psychologica, $101(2-3), 267-291$.

Gengo, F. M. (1996). Reduction of the central nervous system adverse effects associated with antihistamines in the management of allergic disorders strategies and progress. Joumal of Allergy and Clinical Immunology, $98(6 \mathrm{Pt} 3), 5319.325$.

Hindmarch, I., \& Shamsi, Z. (1999). Anthistamines: models to assess sedative properties, assessment of sedation, safery and other side effects. Clinical and Experimental Allergy, 29(Suppl 3), 133-142.

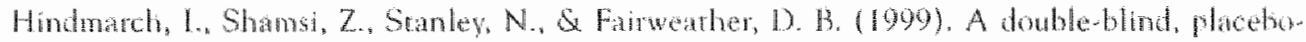

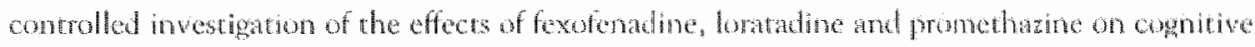
and psychomotor function. Brish Jownal of Clanical Pharmawagry, 48(2), 200,206.

Houx, P. J., \& Jolles, J. (1993). Age-related decline of paychomuror speds effects of age, hrain hosih, sex, and education. Perceprual and mator shills, $70(1), 195,211$.

[sreal, J. B., Chesney, O. L., Whkens, C. D., Donchin, E. (1980). P300 and tracking diffectly: exidence for multiple resources in dial task perfomance. Psychophsology. 17(3), 259-273.

Jex, H. R. McDonnell, J. D. S Phatak, A. V. (1966). A "crical" tracking task for man-machine research related to the operanor's effective delay time. L. Theory and experiments with a hrat wher divergent contrulled element. NASA CR-616. NASA Contrat Rep NASA CR. 1-105.

Jodo, E, \& Kayama, Y. (1992). Relarion of a mergave ERP component wo response inhbition in a

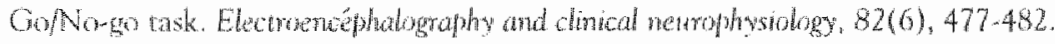

Kok, A. (1997). Event related potential (ERP) reflectons of mental resources: a rewiew and synthesis. Binlugical Pychology $45(1-3), 19.56$

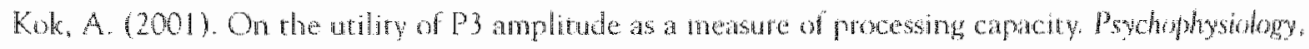
$38(3), 557.577$ 


\section{Chapter 5}

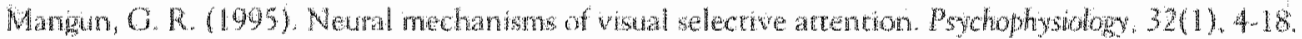
Mangu, O.R. \& Hillyard, S. A. (1990). Electroptissiologtcal studes of visual selective attention in

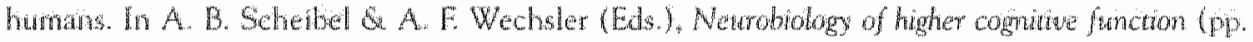
271295). New York: Cuilford.

Mangun; O.R., \& Hllyord, S. A. (1995). Mechanisms and nodels of selective attention. In M. D.

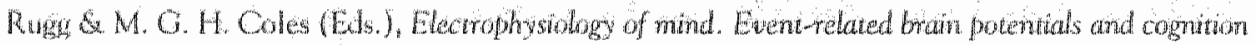
(pp. 40,85). Osford: Oxford Unwersity Press.

Matsunga, K., Sato, T., Shuto, H., Tsuruta, Y., Suemart, K. Gomita, Y., \& Oishi, $\mathbb{R}$ (1998). Inhbition of neuronal dopamine upake by some antallergic drugs. European fotmal of Pharmacology, $350(2-3), 165,169$

Matcila, M. 1. Kuitunen, T. \& Pletan, Y. (1992). Lack of pharmacodwnamic and phamacokinetic interactions of the antihistanine elastine with ethanol in healthy subjects. European jowmal of dinical pharmacolog, 43(2), 179,184.

Mertens, R. \& Polich. J. (1997). P300 from a single-stimulus paradigm: passive versus active tasks and stimulus modality. Eletroencephalography and dinical the urophysiology. 1046), 488-497.

Moskowit, H. (1973). Labotatory stulles of the effects of alcohol on some varialules related to dring. Joumal of Safoty Research, 5, 185-192.

Moskowit, H. S Bums, M. B. (1988), rffects of terfenadine, diphenhydramine, and placebo on skills performance. Cotis, 42(4A), 14-18.

Nicholson, A. N. Stone, B. M., Turner, C. \& Mills, S. L. (2000). Anrihistamines and aircrew: usefulness of fexolenadine. Awhaton Sprece and Entirommental Medicine, $71(1), 26$.

OHanlon, J. F, \& Ramakers, J. G. (1995). Antihistamine effects on actual driving puformance in a standard test: a stmmary of Durch experience, 1989-94. Alergy, 50(3), 234-342.

Oishi, R. Shishido, S., Yamori, M., S Saeki, K. (1994). Comparison of the effects of eleven histamme HI-receptor antagonists on monomine rumover in the mouse brain. Namyn-Schmidubergs Archines of Phamocology, 349(2), 140.144.

Onodera, K., Yamatodani, A., Watanabe, T., \& Wada. H. (1994). Neuropharmacology of the histaminergic neuron system in the brain and its relationship with behavional disorders.

Progress in Newobiology, 42(6), 685.702

Onve, H, Yamatodmi, A, Watanahe, T. Ono, K, Mochizuk, T., Wada, H., \& Hayashi, O (1992)

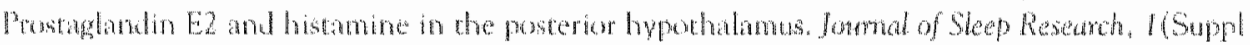
1). 166.

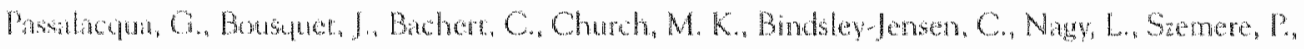

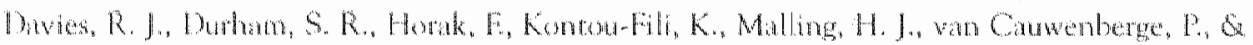
Canonim, G. W (1996). The clincal sabty of H1-receptor antagonists. An EAACl position papeer. Allergy, 51(10), 666-675.

Piom, T W. (1992). The P300 wave of the human eventrelared porental. Jommal of Clind Netriphysuge, $9(4), 456,479$

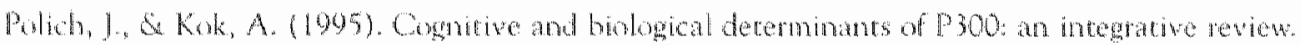
Buhlogtal prychologe 41(2), 103-146.

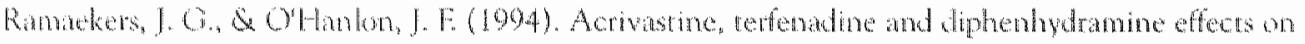

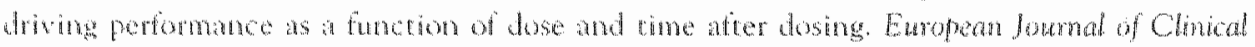
Phamatodsy. $47(3), 261266$

Remberg, A., Len, E. Guillen, D. Burka, 1. T. S Micolai, A. (1978). Chronophamacological sudy of anthistamines in man with special references to refenadine. European jumal of dinical phamathog, $14(4), 245-252$ 
Ridout, F, Shamsi, Z., Meadows, R., Johnson, S., \& Hindnath 1. (2003). A anmenenter randomized, double-blind, placebo-controlled, cossover meenghnof of the effers of

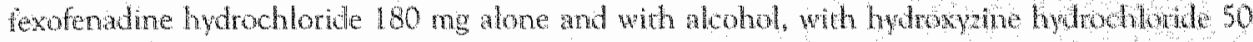

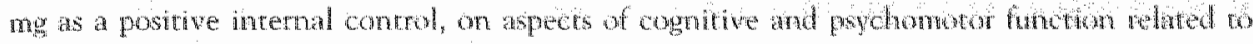
Uriving a car Chincal herapentics, 25(5), 1518-1538.

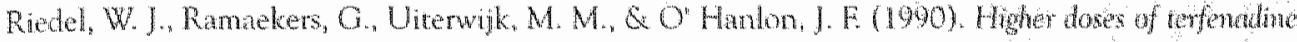

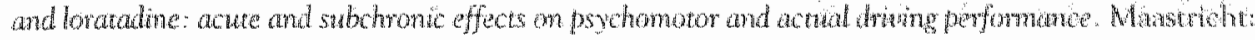
Inscitute for Dugs, Safery and Behavior, Unversing of Limburg

Rombaut, N, E. I., \& Hindmarch, I. (1994). Psychonetre Aspects of Anthistumes: A Revew. Human Psychophamatology, 9.157-169.

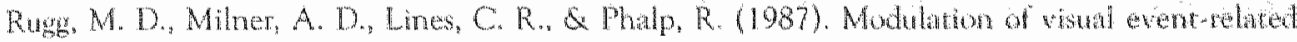
potentials by spatial and non-spatial visual selecrive sttention. Newopychologia. 25(1as,85.96.

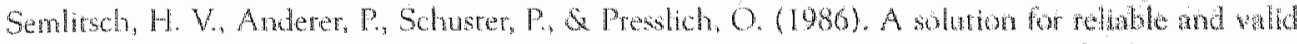
reducrion of ocular artiacts, applied to the P300 ERP. Psychophysiology, 23(6),695.703.

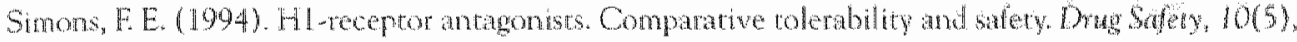
$350-380$.

Smulders, F. T. Kok, A. Kenemans, J. L., B Bashore, T. R. (1995). The temporat selectivity of additive factor effect on the reacron process revealed in ERP compontent latencies. Acta psychologica, $90(1-3), 97-109$.

Snwter, S. H., Snownan, A. M. (1987). Recepor effect of cetrizine. Anm Alery, 596 Pt 2), 4.8 .

Suzuki, T., Mori, T., Tsuji, M., Nomura, M., Misama, M., E Onodera, K. (1999). Evaluathem of the histamine $\mathrm{Hl}$-antagonist-induced place preference in rats. Japanese Jound of Phamacology, 8 /(4). 332.338.

Taylor, M. ). (2002). Non-spatial attentional effects on P1. Clincal netrophysiology, $113(12)$. 1903-1908.

Theunissen, E. L. Vermeeren, A., van Oers, A. C. M., van Maris, I., B Ramackers, J. O. (2004). A dose ranging study of the effects of mequitazine on actual driving memory and peychomotor performance as compared to dexchlorpheniramine, cetrime and placebo. Chinical and Experimentad Allergy, 34(2), 250.258.

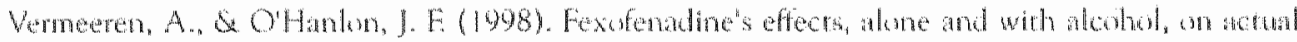

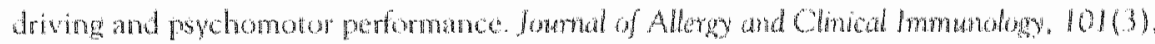
$306.3 \Perp 1$.

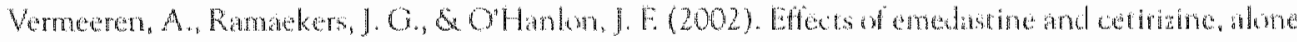

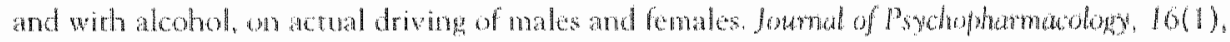
$57-64$

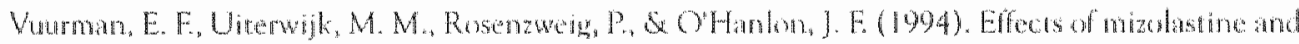

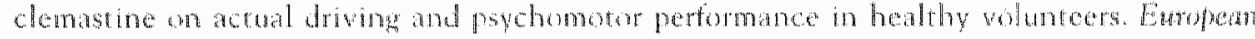
Joumal of Civical Phamacology, 47(3), 253-259

Vurman, E. F. P. M. Rikken, O.H. Muntgewerf, N. D. de Halleux, E. S Ramakers, I. G. (2004)

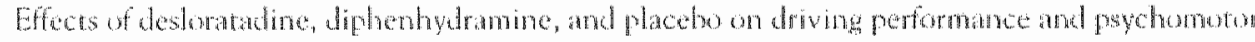

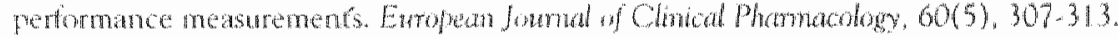

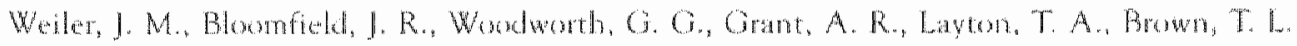
Mckenzic, D. R. Baker, T. W. \& Watson, G. S. (2000). Effects of forofonadine,

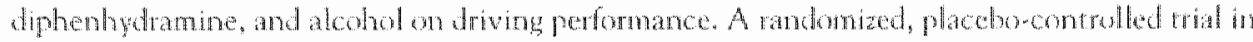
the low driving smulator. Amals of hemal Medine, 132(5), 354-363. 
Wickens, C. Krimer, A, Vanasse, L, Gonchin, E. (1983). Peaformance of concurrent tasks: a psycthophysological andysis of the reciprocity of infomation-processing resources Suence. $221(4615), 1080 \cdot 1082$.

Wickens; C. D., Istal, J. B., Dowhin, E. (1977). The event-retated cortical potental as an index of walk worklowd. In A. S. Neal B. R. F. Palased (Eds.). Procedings of the Homan Factors Sactery 21 st armual meeting. Santa Montea: Human Factors Society.

Withard, I. Johnon, M., \& Resenfeld, I. P. (1994). Interacton of oddlball probability and primary rask type on $\mathrm{P} 300$ in the dual-task paradign. Biofeedback and Self Regulanon, 19(1), 13-24. 



\section{Effects of a high dose of fexofenadine on cognitive function and motor impulsivity}

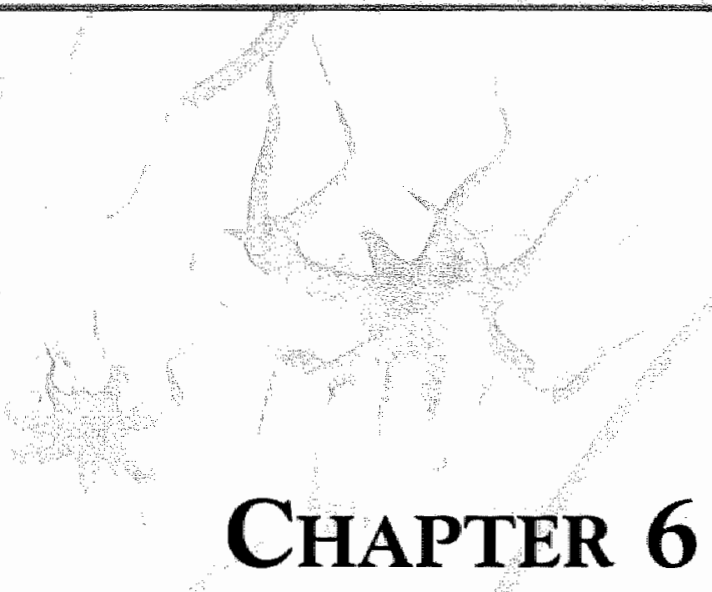

Based on:

Theunissen, E. L., van Kroonenburg, M. J., van Deursen, J.A., Blom-Coenjaerts, C. \& Ramaekers, J.G. Stimulating effects of fexofenadine: testing the dopamine transporter hypothesis. (Submitted). 
Chapter 6

\section{ABSTRACT}

Background: First and second generation antihistamines are known to produce different degrees of sedation. However, a few studies have shown that the $\mathrm{Hl}$-antagonist fexofenadine produces mild stimulant effects. These stimulant effects might be caused by fexofenadine's interaction with the dopamine system.

Aim: In the present study the effect of a high dose of fexofenadine on cognitive performance and motor impulsivity was investigated in a between subject study.

Methods: Forty healthy subjects received either fexofenadine $360 \mathrm{mg}$ or placebo. Cognitive performance was measured with the digit symbol substitution test (DSST) and motor impulsivity with a stop signal task (SST). In addition, subjective and physiological effects of fexofenadine were observed.

Results: The results demonstrate that fexofenadine improved performance on the DSST at $\mathrm{T}_{\max }$ of the drug. Fexofenadine did not affect motor impulsivity, subjective experience or physiological measures.

Conclusion: From these results it is concluded that fexofenadine has mild stimulant effects which are short-lived and not comparable to the effects of psychostimulants. 


\section{INTRODUCTION}

Histamine is an endogenous substance involved in allergic reactions. It is stored and released by mast cells in the periphery and its actions are mediated by three receptors; $\mathrm{HI}$, $\mathrm{H} 2$ and $\mathrm{H} 3$. In order to relief allergic symptoms, antihistamines or $\mathrm{H} 1$-antagonists block peripheral $\mathrm{Hl}$-receptors to prevent histamine from binding at these sites. However, histamine has also been found to act in the central nervous system. As a neurotransmitrer it is involved in the maintenance of arousal and the regulation of the sleep-wake cycle (Tashiro et al., 2002). Since antihistamines also block the central histamine receptors, they interfere with these processes of arousal and as a consequence produce sedation. First generation antihistamines in particular, have been demonstrated to seriously diminish cognitive, psychomotor and driving performance in healthy volunteers (Rombaut \& Hindmarch, 1994; Simons, 1994; O'Hanlon \& Ramaekers, 1995; Kay, 2000).

Besides binding at $\mathrm{Hl}$-receptors, anthistamines have also been reported to inhibit the neuronal uptake of dopamine in the neostriatum and nucleus accumbens of rats and mice (Oishi, Shishido, Yamori, \& Saeki, 1994; Matsunaga et al., 1998), resulting in increased dopamine levels (Dringenberg, de Souza-Silva, Schwarting, \& Huston, 1998). The dopaminergic system plays a major role in the processing of reward and reinforcement (Wise \& Rompre, 1989; Leshner \& Koob, 1999). At a behavioral level, dopamine stimulation can be expected to resemble the effects of psychostimulants like improved psychomotor function and attentional processes during task performance (Higgins et al., 1993; Lamers et al., 2003). Therefore, antihistamines which interact with the dopamine system and augment the dopamine levels can be expected to produce stimulant effects or at least counteract the sedative effect caused by the histamine blockade. Indeed, previous studies have indicated that stimulant effects can be found for certain antihistamines; i.e. terfenadine, ebastine desloratadine and fexofenadine (Theunissen, Vermeeren, Vuurman, \& Ramaekers, In Press). Acute doses of terfenadine ( $60 \mathrm{mg}$ ) were found to improve tracking and vigilance (Moskowitz \& Burns, 1988). Ebastine (10 and $20 \mathrm{mg}$ ) improved performance in an actual and simulated driving test (Mattila, Kuitunen, \& Pletan, 1992; O'Hanlon \& Ramaekers, 1995) while desloratadine $5 \mathrm{mg}$ decreased brake reaction time in a driving test (Vuurman, Rikken, Muntjewerf, de Halleux, \& Ramaekers, 2004). Fexofenadine (120 mg) treatment also resulted in improved performance in an actual driving test (Vermeeren \& O'Hanlon, 1998) and improved primary task performance in a divided attention task (Theunissen, Jonkman, Kuypers, \& Ramaekers, In press). In addition, neurophysiological ERP measurements also showed that fexofenadine decreased P300 latency, indicating improvement of information processing. Several other studies demonstrated a tendency of improved performance after trearment with these antihistamines, although the effect did not reach significance. Therefore, in combination with the few significant effects that were demonstrated, it can be concluded that the stimulant effect caused by these antihistamines is marginal, and not comparable to the effects of psychostimulants such as amphetamines.

Although stimulants can improve psychomotor and cognitive performance, they might also result in impulsivity and have negative effects on functions like inhibition behavior. Obviously in a lot of daily situations the ability to respond fast is essential, but in some instances the ability to inhibit responses is just as crucial. We were therefore also interested in the effect of fexofenadine on a motor impulsivity task. 
The goal of the present study was to investigate whether a high dose of fexofenadine has stimulant properties. First of all, we expect to demonstrate an improved performance in a cognitive task after treatment with fexofenadine, as shown in previous studies. Secondly, we are interested to see how fexofenadine influences motor impulsivity in a stop task. And finally, we were interested to see how subjects experience the effects of fexofenadine subjectively and how it affects physiological measures like heart rate and blood pressure.

\section{MATERIAL AND METHODS}

\section{Subjects}

Forty healthy volunteers ( 20 males and 20 females) aged between 19 and 47 were tecruited through local newspaper advertisements. Volunteers were screened using a medical history questionnaire and subjects with a history of major medical or psychiatric disorder, any noncorrected visual or psychomoror defect, unusual sensitivity to antihistamines, drug abuse and chronic use of medication or cigarettes, were excluded. Female subjects could not participate when pregnant or lactating, and were required to use an effective contraceptive during the study. Subjects were randomly assigned to a fexofenadine or placebo group. The groups were matched for age and sex. Mean (SD) age of the participants was 28.8 (8.3); the mean age of the placebo group was $28.95(8.6)$ and $28.65(8.2)$ for the fexofenadine group. Written informed consent was acquired from all participants prior to participation. The study was approved by the Ethics Committee of Maastricht University and conducted in accordance with the World Medical Associations Declaration of Helsinki (Edinburgh modification 2000).

\section{Drug treatment}

The study was conducted according to a double blind, placebo-controlled between subjects design. Treatments consisted of a single dose of fexofenadine $360 \mathrm{mg}$ or placebo. Fexofenadine is a potent and selective histamine Hl-antagonist. Absorption of fexofenadine occurs rapidly, with peak plasma levels reached in 1 to 2 hours. Elimination half-life of fexofenadine is 9 to 14 hours (Product Monograph). Treatments were given in the morning after arrival at our facilities and were administered as identical appearing capsules to ensure blinding.

\section{Procedure}

Subjects were individually trained in all tests in the week prior to their test day. The use of alcohol was prohibited from 24 hours prior to the test day and consumption of caffeine was not allowed on the test day. A baseline test battery was obtained when subjects arrived at our facilities. Subsequently they received their treatment. A second and third test battery was admintstrated $1 \mathrm{~h} 15 \mathrm{~min}$ and $3 \mathrm{~h} 15 \mathrm{~min}$ after drug intake. Subjects received a standard lunch 2 h45min post drug.

\section{Performance measures}

\section{- Digit symbol substitution task (DSST)}

A computerized version of the original DSST from the Wechsler Adult Intelligence Scale was used to measure information processing and psychomotor performance (Wechsler, 1981). 
The subject is shown an encoding scheme at the top of a computer screen consisting of a row of nine digits $(0-9)$ which are randonly associated with nine symbols. $A$ row of nine response buttons, representing the same symbols, is presented at the bottom of the screen. A randomization procedure makes sure that the symbols never appear at the same ordinal position within both rows. Single digits (0-9) are presented one by one in the centre of the screen. The subjects' task is to match each appearing digit with the corresponding symbol from the encoding list by clicking the correct response buttons. The number of digits correctly encoded within 3 minutes is the performance measure.

\section{- Stop Signal Task (SST)}

The stop signal task used in this study was an adapted version of the one described by Fillmore, Rush \& Hays (2002). The test was made up of 176 trials in which one letter $(A, B$, $C$ or D) was presented in the center of a computer screen. All four letters were presented equally often and were presented for $500 \mathrm{msec}$ with an inter stimulus interwal of $2500 \mathrm{msec}$. Subjects were required to react to these letters by pressing one of two buttons (one for $A$ and $C$, another for B and D). Occasionally however, the presentation of a stimulus was followed by the presentation of a stop signal. The stop signal consisted of an asterisk which appeared in one of the comers of the screen for $500 \mathrm{msec}$. The delay between the appearance of the stimulus and the stop signal varied; i.e. $50,150,250$ or $350 \mathrm{msec}$. A total of 48 stop signals were presented; equally divided over the different delay categories and different stimuli. Whenever a stop signal was presented, subjects had to withhold their response. Dependent variables in this test are the number of correct responses to the go signals (hits), the number of successfully inhibited responses (correct inhibitions) per delay, mean reaction time of the hits (Go-RT) and an estimated time required to inhibit responses (stop signal reaction time, SSRT). The SSRT was calculated based on the probability of inhibiting responses to stopsignals and the distribution of RT's to go-signals after excluding outliers (Logan, 1994).

\section{- Addiction research center inventory (ARCI)}

The Addiction Research Center Inventory is designed to be sensitive to the subjective effects of different classes of psychoactive drugs (Martin, Sloan, Sapira, \& Jasinski, 1971). It consists of 49 true/false questions and yields five different scales: the Benzedrine Group (BG) and Ampheramine (A) scales, sensitive to amphetamine-like stimulating effects; the Pentobarbital, Chlorpromazine, Alcohol Group (PCAG), sensitive for sedation; the Lysergic Acid Diethylamide (LSD) scale, a measure of dysphoria; and the Morphine-Benzedrine Group (MBG), sensitive to euphoric effects. The ARCI is administered at baseline and in the third test battery.

\section{Physiological measures}

Heart rate and blood pressure (systolic and diastolic pressure) were measured twice; once at baseline and once 3 h 45 minutes after drug intake. At borth rimes, subjects had to lie down for approximarely 5 minutes before physiological measures were determined.

\section{ANALYSIS}

To correct for baseline differences between groups, difference scores were calculated and analyzed. A repeated measure analysis of ANOVA with Treatment (2 levels) as a between factor and Time 


\section{Chapter 6}

\begin{tabular}{|c|c|c|c|c|c|c|}
\hline \multirow{2}{*}{ Perfornance test } & \multicolumn{3}{|c|}{ Placebo } & \multicolumn{3}{|c|}{ Fexofenadine } \\
\hline & Baseline & $1 \mathrm{~h} / \mathrm{smin}$ & $3 \mathrm{hlsmin}$ & Baseline & hls $\mathrm{sin}$ & $3 \mathrm{~h} / \mathrm{smin}$ \\
\hline \multicolumn{7}{|l|}{ DSST } \\
\hline Hits $(n)$ & $89.4 \pm 23$ & 897427 & $92,3 \pm 29$ & $842 \pm 23$ & $86.9 \pm 2.3$ & $86,6 \pm 2,5$ \\
\hline \multicolumn{7}{|l|}{ Stop Signal Task } \\
\hline Mits (n) & $125,7 \pm 0,4$ & $1259 \pm 0.4$ & $1254 \pm 0.6$ & $1248 \pm 08$ & $1255 \pm 06$ & $124,4 \pm 0.8$ \\
\hline Go $\mathrm{AT}(\mathrm{msec})$ & $547 \pm 17$ & $550+17$ & $548 \pm 20$ & $584 \pm 22$ & $588 \pm 23$ & $572 \pm 22$ \\
\hline SSRT (Insec) & $273+8$ & $265 \pm 6$ & $273 \pm 8$ & $261 \pm 10$ & $266+10$ & $272+8$ \\
\hline Correct inhibitons (n) & $88 \pm 05$ & $8.9 \pm 05$ & $8.6 \pm 0,6$ & $97 \pm 0.4$ & $96 \pm 0.4$ & $9: \pm 01$ \\
\hline ARCI & Baseline & & $3 \mathrm{hismin}$ & Baseline & & $3 \mathrm{~h} / \mathrm{smin}$ \\
\hline Mbs & $45 \pm 0.7$ & & $4.6 \pm 07$ & 5,1006 & & $5.2 \pm 0.7$ \\
\hline Lsd & $2.0 \pm 0.2$ & & $2,2 \pm 0,2$ & $211 \pm 02$ & & $1.7 \pm 0,4$ \\
\hline Pcag & $-8.5 \pm 0.5$ & & $5.5 \pm 0.6$ & $1,2+0,4$ & & $0.7 \pm 0.5$ \\
\hline Bg & 211004 & & $1,7 \pm 0,5$ & $20 \pm 03$ & & $1.4 \pm 0.4$ \\
\hline $\mathrm{Ag}$ & $23 \pm 0.4$ & & $22 \pm 0.5$ & $1,9 \pm 03$ & & $2,1 \pm 0.3$ \\
\hline Physiological measures & Baseline & & $3 \mathrm{~h} 4 \mathrm{smin}$ & Baseline & & $3 \mathrm{~h} 45 \mathrm{~min}$ \\
\hline Diastolic pressure (mmHG) & $752+2.0$ & & $74.3 \pm 2$ & $75.2 \pm 13$ & & $74.0 \pm 13$ \\
\hline Systolic pressure (mmHG) & 123,1427 & & $1225+31$ & $1204+30$ & & $1225+31$ \\
\hline Heart rate (bpri) & $68.8+21$ & & $640 \pm 20$ & $74.6 \pm 2.6$ & & $66.4 \pm 1.7$ \\
\hline
\end{tabular}

Table 1. Mean ( \pm SEM) absolute walues for both groups on the DSST, SST, ARCl and physiological measures at the different testing times.

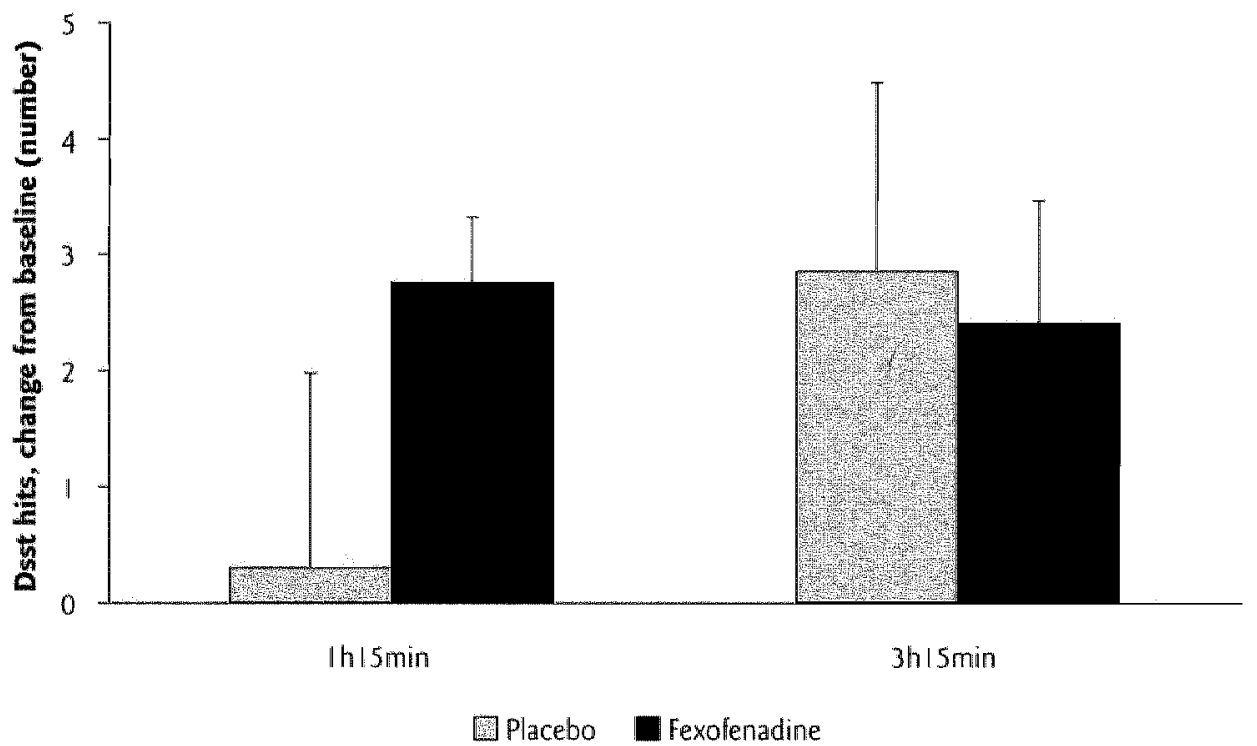

Figure 1. Digir syrubol substiturion rest: change from baseline in mean hirs at $1 \mathrm{~h} 15$ minures and $3 \mathrm{~h} 15$ minutes after druginatake. 
(2 levels) as a within factor was applied on all variables from the SST and DSST. Variables of the ARCI and physiological measures were tested using a t-test for independent satmples. All variables were tested 2-tailed, except for the DSST because of the one-sided nature of the prediction. A significance level of $\mathrm{p}<.05$ was used to detect differences between the treatment responses in the statistical tests. All statistical tests were conducted using SPSS (version 10.0).

\section{RESULTS}

A summary of the results of the psychomerric tasks and the physiological measures of both treatment groups is shown in Table 1. There was no significant overall effect of Treatment or Time on the number of hits in the DSST, however the interaction between Treatment and Time was significant $\left(F_{1,38}=3.74 ; p=.03\right)$. Whereas the number of hits after fexofenadine treatment was increased in test battery 2 and 3 compared to baseline, after placebo treatment only the third test battery showed increased hits compared to baseline (fig. 1).

In the stop signal task there were no significant overall effects of Treatment or Time on the number of hits, correct inhibitions, Go-RT or SSRT. A significant Treatment $x$ Time effect was found on the number of correct inhibitions after a $350 \mathrm{msec}$ delay $\left(\mathrm{F}_{1,38}=9.11\right.$; $\mathrm{p}<.025)$. Mean scores show that fexofenadine resulted in a decrease in correct inhibitions as compared to baseline in the third test battery, whereas placebo resulted in a slight increase in the $350 \mathrm{msec}$ delay condition (fig. 2).

Analysis of the ARCl indicated that there was no significant difference between the two treatment groups, on any of the scales. Also analysis of the physiological measures showed no significant difference between the two treatment groups at any measure.

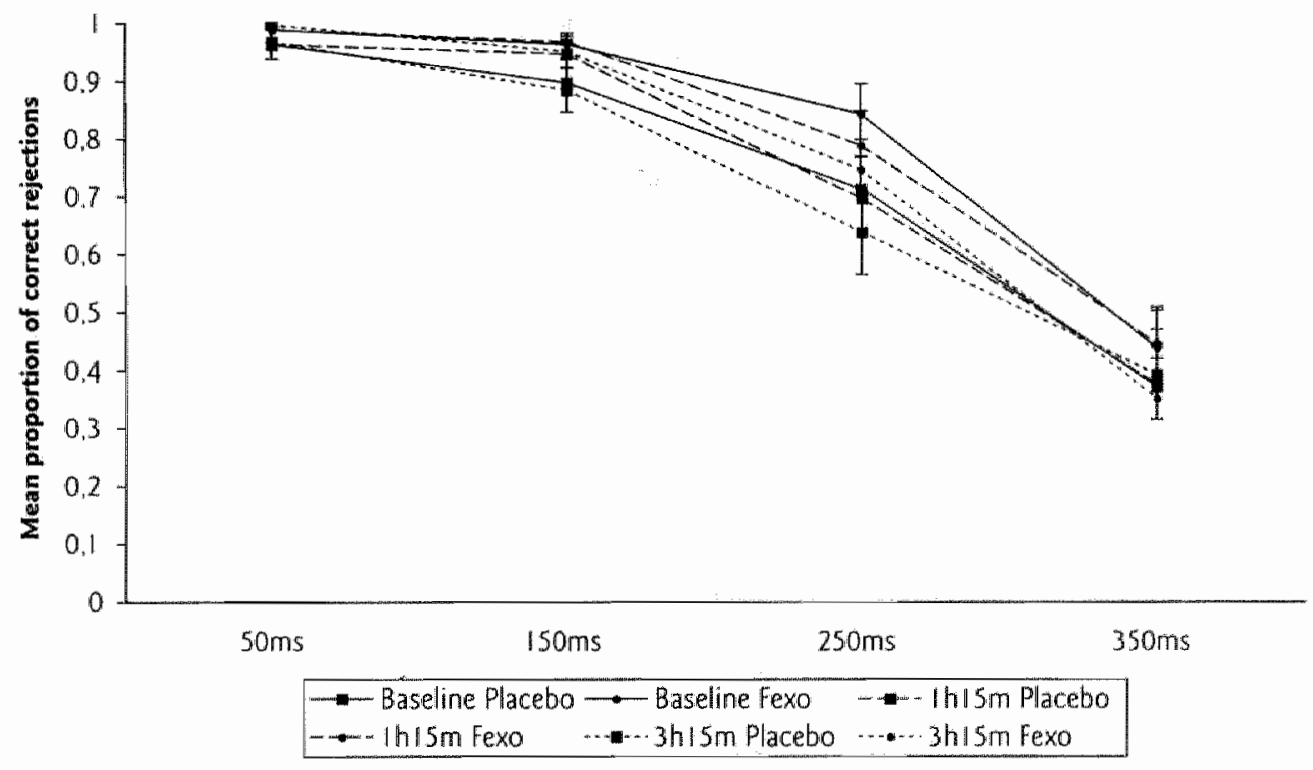

Figure 2. Stop signal test: Mean proportion of correct rejections at the four stimulus-stop signal delays, for ench trearment and at both measurement times. 


\section{DISCUSSION}

Previous studies have demonstrated that unlike other antihistamines, fexofenadine does not cause sedation, but might even slightly improve performance, especially after high doses (Vermeeren \& O'Hanlon, 1998; Theunissen et al., In press). In this study we investigated the stimulant effect of a high dose of fexofenadine on cognitive function and motor impulsivity.

Mild stimulant effects of high doses of fexofenadine have been demonstrated earlier on driving related performance, psychomotor performance and attention (Theunissen et al., In Press). In the present study, a high dose of fexofenadine resulted in a significant interaction between fexofenadine and time of measurement for the number of correct responses on the digit symbol substitution task. In the fexofenadine group, subjects produced more correct responses at both measurement times compared to baseline. However, only around one hour after drug intake did fexofenadine cause better performance than placebo. Around three hours after drug administration, both placebo and fexofenadine caused an increase in the number of correct responses compared to baseline, but the difference between the groups was no longer significant. It seems that fexofenadine mildly stimulated performance on a cognitive, psychomotor task, but only when peak plasma concentrations of the drug were maximal.

In this study, the effect of fexofenadine on a stop task was also investigated, in order to assess fexofenadine's effect on motor impulsivity. In previous studies, the effects of psychostimulants like cocaine and d-amphetamine on motor impulsivity have yielded contradictory results. De Wit, Enggasser and Richards (2002) found that d-amphetamine caused faster Stop RT but had no effect on Go RT in a stop signal task. D-amphetamine also decreased the number of commission errors in a Go-NoGo task. Fillmore, Rush, and Marcainski (2003), found a decrease in inhibitions in a cued Go-NoGo test in subjects with a history of substance abuse who were given d-amphetamine $(5,10$ and $20 \mathrm{mg})$. Also acute cocaine treatment resulted in a decreased inhibitory control in subjects with a history of cocaine abuse (Fillmore et al., 2002). Thus whereas the results of de Wit et al., (2002) indicated improved motor impulsivity, Fillmore et al., (2002 and 2003) showed impaired response control atter psychostimulant treatment. This difference might be explained by differences in prior stimulant use by the subjects (Fillmore, Kelly, \& Martin, 2005). Results in the present study showed that fexofenadine had no effect on the reaction time of the go or stop process in the stop signal task. Only one effect was found around three hours post drug; subjects treated with fexofenadine made less correct inhibitions when the delay between stimulus and stop signal was the longest. At the other intervals such an effect was not apparent. Since texofenadine had no effect on the go and stop reaction times, it can not be suggested that the decrease in inhibitions is due to a slowing of the stop process or acceleration of the go response. Therefore it is possible that this effect of fexofenadine on correct rejections is in fact a random result due to a type I error and consequently it is concluded that fexofenadine had no effect on motor impulsivity.

The ARCI questionnaite was administered to see how subjects subjectively experience the effect of fexofenadine. Previous studies using the ARCI have demonstrated that the Ascale in particular, is sensitive for the stimulant effects of d-amphetamine, MDMA and cocaine (Cami et al., 2000; Holdstock \& de Wit, 2001; de Wit et al, 2002; Haga, Baker, \& Rush, 2003). The present study showed that the stimulant effect of fexofenadine is probably too mild for subjects to be subjectively aware of the effect, since none of the scales 
demonstrated a significant effect of fexofenadine. In addition, fexofenadine did not produce differences in the physiological measures. This is in contrast with psychost mulant drugs like amphetamine or MDMA which have been demonstrated to increase both blood pressure and heart rate (Liechti \& Vollenweider, 2000; Makris; Rush, Frederich, \& Kelly, 2004). Together, this indicates that the stimulant effect of fexofenadine is not of the same magnitude as the stimulating effects of amphetamine-like drugs:

It should be mentioned, though, that the ARCl and physiological measures were only determined at baseline and 3 hours post-drug, and not at the time when stimulant effects were demonstrated in this study. Other studies were able however to demonstrate stimulant effects of fexofenadine after its $T_{\text {max }}$ (Vermeeren $\&$ OHanlon, 1998; Theunissen et al., In press). Nevertheless, from the present study it appears that the stimulant effects of fexofenadine are not long-lasting.

In conclusion, the results indicate that fexofenadine improved performance on a cognitive task. However, the stimulant effect is short-lived and not comparable to the degree of the stimulation found in psychostimulants, like amphetamine, MDMA or cocaine. This conclusion was also supported by the absence of an effect of fexofenadine on the motor impulsivity task, the drug experience questionnaire and the physiological measures. 
Chapter 6 


\section{REFERENCES}

Cami, J., Farre, M. Mas, M., Roset, P. N., Poudevida, S., Mas, A, San, L, L de lif Torre, R. 2000 . Haman pharmacology of 3.4-methylenedioxymerhampheramne ("ectusy"): pspchonotor performance and subjective effects. Jownal of dinical prychophamacolog, 20(4), 455466.

de Wir, H., Enggasser, J. L., \& Richards, 1. B. (2002). Acute adminstration of a-ampheramine decreases impulsivity in healchy wolunteers. Neuropsychophamacology official publication of the American College of Netroprychophamacology, $27(5), 813-825$.

Dringenberg, H. C., de Souza-Silva, M. A., Schwarting, R. K. \& Huston, J. R. (1998). Increased levels of extracellular dopamine in neostratum and nucleus accumbens after histamine $H 1$ receptor blockade. Naunym-Schmidebergs Archives of Phamacolngy, 358(4), 423-429.

Fillmore, M. T. Kelly, T. H., \& Martin, C. A. (2005). Effects of d-ampheramine in humara midels of information processing and inhibitory control. Drug and alcohol dependence, 77(2), 151-159.

Fillmore, M. T., Rush, C. R., \& Hays, L. (2002). Acute effects of oral cocane on inhibitory control of behavior in humans. Drug and alcohol dependence, 67(2), 157-167.

Fillmore, M. T. Kush, C. R., Marcinski, C. A. (2003). Effects of d-ampheramine on betravional control in stimulant abusers: the role of prepotent response tendencies. Drug and alcohol dependence, $71(2), 143-152$.

Haga, J. L., Baker, R. W., \& Rush, C. R. (2003). Behavional and physiological effects of cocanc in humans following triazolan. Phamacology, biochemisty, and behasior, $76(3-4), 383-392$.

Higgins, S. T., Rush, C. R., Bickel, W. K., Hughes, J. R., Lymn, M., S Capeles, M. A. (1993). Acurce behavional and cardiac effects of cocaine and alcohol combinations in humans. Psychophamacology. $111(3), 285-294$.

Holdstock. L., \& de Wit, H. (2001). Individual differences in responses to ethanol and damphetamine: a within-subject study. Alcholism, chinical and experimental research, 25(4), 540.548.

Kay, G. O. (2000). The effects of antihistamines on cognition and performance. Jowmal of Allergy and Clinical Immunology, 105(6 Pe 2), 5622-627.

Lamers, C. T., Ramaekers, J. G., Muntjewerff, N. D., Sikkema, K. L., Sampn, N., Read, N. L., Brookhuis, K. A., \& Riedel, W. J. (2003). Dissociable effects of a single dose of ecstasy (MDMA) on psychomotor skills and artenrional performance foumal of psychophamacology Oxjord, England, $17(4), 379.387$

Leshner, A. I. \& Koob, G. F (1999). Drugs of abuse and the brain. Procedtings of the Association of American Physicians, 11112$), 99-108$.

Liechri, M. E. \& Vollcrweider, F. X. (2000). Acute psychological and physiological effects of MDMA ("Ecsmsy") afer haloperidol pretreatment in healdhy humans. European Neumpychopharmacology, $10(4), 289-295$

Logan, G. D. (1994). On the ability to inhibit thotght and action. In D. Digenbach \& T. H. Carr

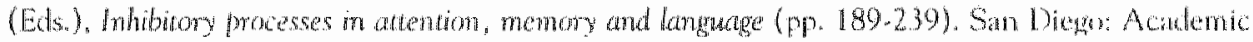
Press.

Makris, A. P. Rush, C. R., Frederich, R. C., \& Kelly, T. H. (2004). Wakepromong agents with different mechanisms of action: comparison of effects of modafinil and ampheranine an fund intake and cardiovascular activity, Appetine, $42(2), 185-195$.

Marcin, W. R., Sloan, J. W., Sapira, J. D. \& Jasinkki, D. R. (1971). Physiologic, subjectire and Whavioral effects of armp hetamine, methampletamine, ephedrine, phermetratine and methylphenidate in man. Chinal Pharmacolngy and Therapeatis, 12.245.258. 


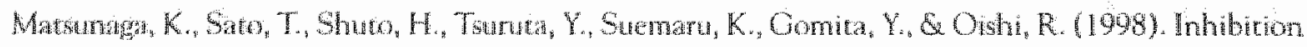
of neuronal dopumine uptake by some anciallegic drugs. Exropean Joumal of Pharmacobog, 3502 . $31,165 \cdot 169$.

Matria, M. J., Kuitunen, T, S Plewn, Y. (1992). Lack of phamacodynamic and phamacokineric

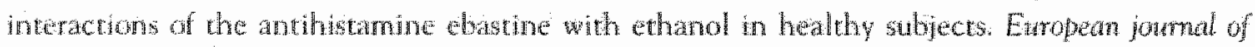
clincal pharmacilogy, 43(2), 179-184.

Moskowitz, H. \& Bums, M. B. (1988). Effects of terfenadine, diphenhydramine, and placebo on skills performance. Cuts; $42(4 \mathrm{~A}), 14-18$.

OHanton, J. F, E Ranaekers, J. G. (1995). Anthistamine effects on actual driving performance in a standard test: a summary of Dutch experience, 1989-94. Allergy, 50(3), 234-342.

Oishi, R., Shishido, S. Yamori, M. S Saeki, K. (1994). Comparison of the effects of eleven histamine Hi-receptor antagonists on monoamine turnover in the mouse brain. Namyn-Schmedebergs Archives of Pharmatology, 349(2), 140-144.

Rombaut, N. E. I., E. Hindmarch, I. (1994). Psychometric Aspects of Antihistamines: A Review. Human Psychophamacology, $9,157-169$.

Simons, F. E. (1.994). H1-receptor antagonists. Comparative tolerability and satery. Drug Safery, 1065), $350-380$.

Tashiru, M. Mochizuki, H., Iwabuchi, K. Sakurada, Y., ltoh, M., Watanabe, T, \& Yanai, K. (2002). Roles of histamine in regulation of arousal and cognition: functionat neuroimaging of histamine He receptors in human livain. Life Sciences, $72(4-5), 409-414$.

Theunissen, E. L., Jonkman, L. M., Kuypers, K. P. C., \& Ramaekers, J. C. (In press). Stimulating effects of fexofenadine under high workload condirions. A combined neurophwsiological and behavioral approach. Joumal of psychophamacology.

Theunissen, E. L., Vermeeren, A., Vuurman, E. E. P. M. Q Ramaekers, J. O. (In Press). Scimulating effects of $\mathrm{Hl}$-antagonisrs. Curent Phamacentical Design.

Vermeeren, A., \& O'Hanton, J. F. (1998). Fexofenadine's effects, alone and with alcohol, on actual driving and psychomotor performance. Jownal of Allergy and Clinical Immundogy, 101(3), 306-311.

Vuurman, E. F. P. M., Rikken, G. H., Muntjewerf, N. D., de Halleux, F, E Ramaekers, J. G. (2004). Effects of destoratadine, diphenhydramine, and placelwo on driving performance and psychomotor pertormance measurements. Emepean Joumal of Chniad Phamacology, 60(5), 307-313.

Wochaler, D. (1981). A mumal for the Wechler adule intelligence sede (revised). New York: Psychological Corporation.

Wise, R. A. S Rompre, P. P. (1989). Brain dopamine and reward. Annual reviaw of prychotogy, 40 , 191.225 



\section{Fexofenadine's potential to inhibit dopamine reuptake in healthy volunteers: a SPECT study}

\section{CHAPTER 7}

Based on:

Theunissen, E. L., van Kroonenburg, M. J., van Deursen, J.A., Blom-Coenjaerts, C. \& Ramaekers, J.G. Stimulating effects of fexofenadine: testing the dopamine transporter hypothesis. (Submitted). 
Chapter 7

\section{ABSTRACT}

Background: The H1-antagonist, fexofenadine, has repeatedly been shown to possess mild stimulating properties. However, the pharmacological mechanism underlying this stimulating effect is unknown. One hypothesis suggests that fexofenadine produces an increase in the dopamine levels by blocking the dopamine transporter.

Aim: In the present study, it was assessed whether fexofenadine blocks the dopamine transporter in the striatum.

Methods: Sixteen healthy volunteers were included in a between subject study. Half of the subjects received $360 \mathrm{mg}$ of fexofenadine while the other half received placebo. Subjects were subsequently injected with the radiotracer $\left[{ }^{123} \mathrm{I}\right] \mathrm{FP}-\mathrm{CIT}$, which has a high affinity for the dopamine transporter. The binding potential of FP-CIT was measured using singlephoton emission computed tomography (SPECT).

Results: The results of this study demonstrated that there was no difference in binding potential of FP-CIT at the dopamine transporter between the placebo and fexofenadine treated subjects in the striatum.

Conclusion: The present results do not provide evidence for the hypothesis that fexofenadine stimulates performance by blocking the dopamine transporter. 


\section{INTRODUCTION}

The most reported side effect of parients who use anthistamines is sedation. Anihistamines are classically divided into first and second generation anthwamines; wh the fres generation causing serious sedative effects, and second generation prodhoing les, but still measurable sedative effects (O'Hanlon \& Ramaekers, 1995; Hindnarch \& Shamsi, 1999).

In contrast to other antihistamines, fexofenadine was previously found not to cause sedation but to mildy stimulate performance on several performance and attention measures (Vermeeren \& O'Hanlon, 1998; Theunissen, Jonkman, Kuypers, \& Ramakers, In press; Theunissen, Vermeeren, Vuurman, \& Ramaekers, In Press). However, the phamacological mechanism responsible for the stimulating effects is still unclear.

Several studies have demonstrated that antihistamines influence endogenous dopamine Levels in animals. Oishi, Shishido, Yamori, and Saeki (1994) studied monoamine levels after administration of a carecholamine synthesis inhibitor $(\alpha-M T)$ and antihistamines in mice. Administration of $\alpha-M T$ resulted in a decrease in the dopamine level. Seven antihistamines (e.g. diphenhydramine, tripelennamine, promethazine and chlorpheniramine) were found to significantly increase extracellular levels of dopamine after $\alpha-M T$ dopamine depletion. Therefore, Oishi et al., (1994) concluded that dopamine reuptake is inhibited by most antihistamines. Matsunaga et al., (1998) examined the effects of 10 antihistamines (astemizole, azelastine, ebastine, emadastine, ketotifen, oxatomide, terfenadine, pemirolast and tranislast) on neuronal dopamine reuptake in the rat striatum (Matsunaga et al, 1998). The results showed that the degree of affinity for dopamine transporters varied considerably, and ebastine and terfenadine (i.e. the parent drug of fexofenadine) possessed the strongest inhibitory potencies for dopamine reuptake transporters. Chlorpheniramine and pyrilanine were atso found to increase extracellutar dopamine levels in the neostriatum and nucleus accumbens of rats (Dringenberg, de Souza-Silva, Schwarting, \& Huston, 1998). Recently, Lapa, Mathews, Harp, Budygin, and Jones (2005) demonstrated a dose-related increase in locomotor activity in mice after treatment with the HI-antagonist diphenylpyraline. In addition, diphenylpyraline was found to inhibit dopamine reuptake and to increase extracellular dopamine levels in the nucleus accumbens.

The evidence from animal studies above, suggests that changes in dopamine availability mighr mediate the mild stimulating effects of the $H 1$-antagonists such as fexofenadine (Vermeeren, 2003). The increased level of endogenous dopamine is thought to be a consequence of a blocking of the dopamine transporter (DAT). This suggested mechanism still needs to be tested in humans and in order to do so ligand binding assessment by PET or SPECT appears to be the best method. The current study therefore investigates the affinity of fexofenadine for the dopamine transporter in humans, using SPECT. As far as we know, this is the furst attempt to explore the binding potential of an antihistamine on the dopamine transporter in humans.

\section{METHODS}

\section{Subjects}

Sixteen volunteers ( 8 males and 8 females) aged between 32 and 47 were recruited through local newspaper advertisements. Volunteers were screened using a medical history questionnaire and subjects with a history of major medical or psychiatric disorder, any non-corrected visual or 
psychomotor defect, unusual sensitivity to anthistamines, drug abuse and chronic use of medication, were excluded. Female subjects could not participate when pregnant or lactating, and were required to use an effective contraceptive during the study. All participants were nonsmokers. Subjects were randomly assigned to an experimental and control group. The groups were matched for age and sex. Mean (SD) age of the participants was 37.6 (4.3); the mean age of the placebo group was $37.9(5.0)$ and $37.4(3.9)$ for the fexofenadine group. Written informed consent was acquired from all participants prior to participation. The study was approved by the Ethics Committee of Maastricht University Hospital and conducted in accordance with the World Medical Associations Declaration of Helsinki (Edinburgh modification 2000).

\section{Design and drug treatment}

The study was conducted according to a double blind, placebo-controlled between group design. Treatments consisted of a single dose of fexofenadine $360 \mathrm{mg}$ or placebo. Treatments were administered as identical appearing capsules to ensure blinding.

\section{Procedure}

Subjects were not allowed to use alcohol from 24 hours prior to the test day and consumption of caffeine was not allowed on the test day. After arrival at our facilities, subjects' physiological measures (heart rate and blood pressure) were determined after a five minute horizontal rest. Subsequently they received the treatment (fexofenadine $360 \mathrm{mg}$ or placebo). One hour after drug intake, subjects were injected with the $\left[{ }^{123}\right.$ I] FP-CIT tracer. Two hours and forty-five minutes post-drug, subjects received a standard lunch and physiological measures were determined a second time three hours and forty-five minutes post-drug. Four hours after drug intake the SPECT scan was taken.

\section{- Radioligand}

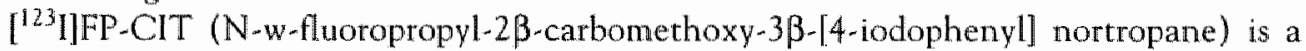
tracer for SPECT imaging the dopamine transporter (DaTSCAN, Nycomed, Amersham, UK). An average dose of $185 \mathrm{MBq}$ of the radioligand was injected as a slow bolus, followed by $10 \mathrm{ml}$ saline to flush the i.v. line.

\section{- SPECT procedure}

SPECT imaging was performed at the department of Nuclear Medicine (University Hospital Maastricht) using a Siemens Multispect triple-headed gamma camera, equipped with parallel-hole low energy collimators. SPECT acquisition was performed 3 hours afrer the injection of the tracer ( 4 hours post drug). Data was collected from 64 angular values over $360^{\circ}$ in a $128 \times 128$ matrix, with a total acquisition time of 32 minutes (30s/projection).

\section{- Data Processinus}

Filtered back-projection was performed using a Butterworth filter with a cut-off value of 0.5 and an order of 0.4 . For analysing the striatal $\llbracket^{123}$ I]FP.CIT binding, a semi-automatic template model programme was used to calculate the ratios between left and right striatal and occipital regions, respectively (figure 1). Also a separation was made between the caudate nucleus and putamen. The ratios were corrected using Alderson's brain phantom (putamen/occipital cortex and caudate nucleus/occipital cortex). 

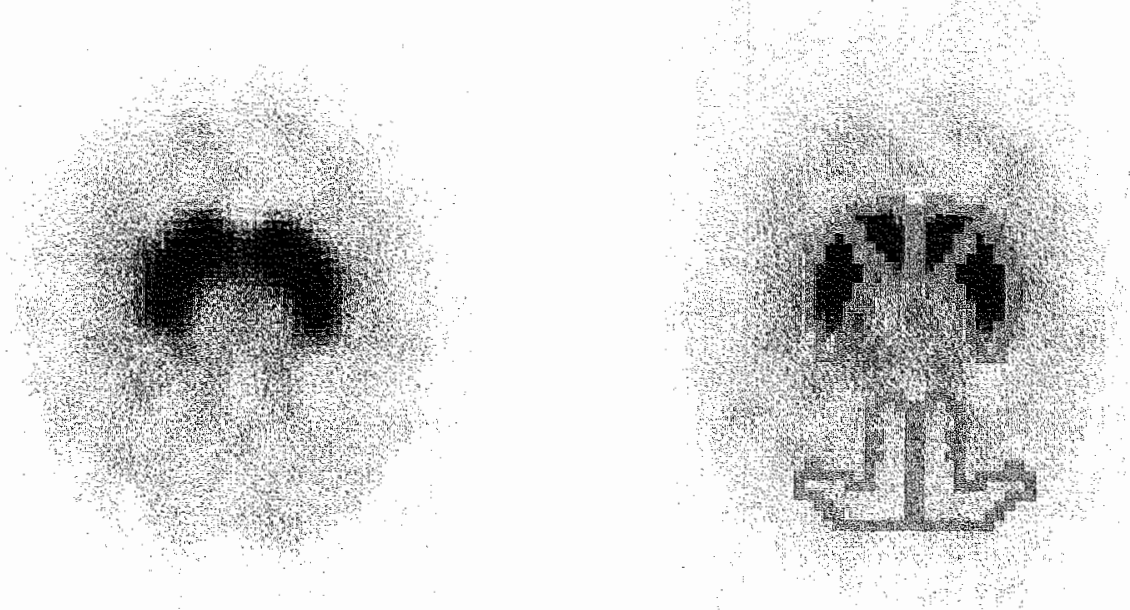

Figure 1. [123]]FP.CIT SPECT images of one subject. On the lef, a transverse slice with dhe stratum showing a high level of radioactivity is shown. On the right, the remplate is put on the caudate nucleas, putamen and on the occipital regions, in order to calculate the binding ratio of FP.CIT.

Another method to compare $\left.\left[{ }^{123}\right]\right]$ FP-CIT binding in the two groups involved SPM2 (Statistical Parametric Mapping; Wellcome Department of Cognitive Neurology, Londen, UK). To obtain consonant orientation between the data sets, realignment of the data was performed. The realigned data were co-registered and normalized to a standard, NMI SPECT template, of normal dopamine uptake. As regions of interest, the basal ganglia, were used to study between group differences. Between group differences were tested using one way ANOVA for independent samples. The results were analyzed using a threshold of $p<$ 0.01 uncorrected. Results were reported when a cluster was significant at $p<0.05$ corrected.

\section{STATISTICS}

Physiological measures were first corrected for baseline differences by calculating the difference score. The difference in physiological measures and binding potential between the groups was tested with a t-rest for independent samples. A significance level of $p<0.05$ was used. All analyses were carried out with SPSS 10.0 for W/indows.

\section{RESULTS}

\section{Physiological measures}

Mean scores on the heart rate and blood pressure difference scores are shown in table 1. No difference on the physiological measures appeared to be significantly different between the two groups.

\section{$\left[{ }^{123}\right.$ I]FP-CIT SPECT imaging}

Mean differences scores in the binding potential of FP-CIT in the caudate nucleus and putamen for both groups are shown in table 2 . There were no significant differences in 


\begin{tabular}{|c|c|c|c|c|c|}
\hline & Placebo & fexolenadine & of & $t$ & Sig \\
\hline Systolic pressure (minc) & $40 \pm 52$ & $213 \pm 3,8$ & 4 & 3.09 & NS \\
\hline Diastolic pressure (minHG) & $163+29$ & $138 \pm 29$ & 14 & 0,61 & NS \\
\hline Heart ate (bpm) & 5042.4 & $763 \times 37$ & 14 & 0.597 & NS \\
\hline
\end{tabular}

Table 1. Mean change from baseline (4SEM) in the physiologicat measures n the placebo and fexofenadine group Bpm beats per nainute; NS: nor significant; df: degrees of freedon.

\begin{tabular}{|c|c|c|c|c|c|}
\hline & Placebo & Fexofenadine & Df & $t$ & Sig. \\
\hline Cauda te nucleus left & $1180 \pm 09$ & $10.89 \pm 14$ & 14 & 0,562 & NS \\
\hline Caudate nucleus right & $10.38 \pm 0.6$ & $10,45 \pm 0.8$ & 14 & 0,071 & NS \\
\hline Putamen left & 115340.6 & $10.75 \pm 12$ & 14 & 0,567 & NS \\
\hline Putamen olght & $1032 \pm 0.6$ & $1053 \pm 06$ & 14 & 0,257 & NS \\
\hline
\end{tabular}

Table 2. Mean [123]|FP-CIT SPECT binding ratios ( \pm SEM) in the placebo and fexofenadine group. NS: not significant; df: degrees of freedom.

binding potential between the two groups. Also the SPM analysis did not result in significant differences between the two treatment groups.

\section{DISCUSSION}

The dopamine transporter is an important presynaptic receptor, which recollects dopamine when released into the synaptic cleft. Subsequently when the dopamine transporter is blocked, the avallability of dopamine in the synaptic cleft increases (Chen \& Reith, 2000).

Animal studies have previously demonstrated that several antihistamines inhibit dopamine reuptake and thereby affect the level of dopamine (Oishi et al., 1994; Marsunaga et al., 1998; Lapa et al., 2005). The present study was set up to test wherher fexofenadine blocks the DAT. This was done in order to find support for the hypothesis that this DAT blockage is responsible for the stimulating effects that were previously demonstrated after fexofenadine treatment. Therefore, the binding competition between $360 \mathrm{mg}$ of fexofenadine and the radiotracer FP.CIT for the dopamine transporter was studied in the striatum. The results showed, however, that there was no difference in binding potential of FP-CIT between the placebo and fexofenadine group.

Previous studies which demonstrated inhibition of dopamine reuptake by antihistamines have been performed in animals in vitro (Oishi et al., 1994; Matsunaga et al., 1998; Lapa et al., 2005) and in vivo (Dringenberg et al., 1998). Although these studies investigated several antihistamines, fexofenadine was not among these. Studies to determine the binding affinity of fexofenadine for the DAT in humans are currently nonexistent. In this study we presumed that the binding affinity of FP-CIT and fexofenadine would be about equal and that the co-administration of these ligands would lead to a competition for the DAT. It cannot be excluded, however, that the binding affinity of FP-CIT is much higher compared to fexofenadine. In such a scenario, it is thinkable that fexofenadine would be fully displaced from the transporter in the presence of FP.CIT. 
The results from the present scudy do however not allow us to draw any firm conclusion on this notion.

The timing of the SPECT-scan is probably not a reason why a decreased binding of FPCIT after fexofenadine treatment could not found. Since we demonstrated a stimulating effect of fexofenadine around $T_{\max }$ (i.e. 1 hour after treatment) but not three hours after drug intake in the previous chapter of this dissertation, one could suggest that the blocking of the DAT by fexofenadine had already disappeared at the time of scanning (i.e, 4 hours post-drug). However, in other recent studies, the stimulating effects of fexofenadine were shown to persist for 2-4 hours (Vermeeren \& O'Hanlon, 1998; Theunissen et al., In press). Therefore, it can safely be concluded that the SPECT measurement was conducted within a relevant time window.

The present study was set up to find evidence for the hypothesis that fexofenadine's stimulating properties come about by its potential to block the dopamine transporter and subsequently increase dopamine levels. The results of the ${ }^{123}$ IIFP-CIT SPECT binding ratio's, demonstrated no difference between the placebo and fexofenadine group. Thus so far, there is no evidence for the suggestion that the stimulating effect of fexofenadine in humans is caused by a blocking of the dopamine transporter. There are two other hypotheses which try to explain how fexofenadine causes stimulating effects (Vermeeten, 2003; Theunissen et al., In Press). One assumption is based on the finding of Korotkova, Haas and Brown (2002), who demonstrated that histamine stimulates GABA-neurons and that this excitation was blocked by the antihistamine mepyramine. GABA has an inhibiting effect on dopamine release, so when GABA is inhibited this leads to excitation of the dopamine cells due to disinhibition. Another suggestion is that the histamine autoreceptor $(\mathrm{H} 3)$ is blocked by fexofenadine, leading to an increase in histamine, which causes an increased level of arousal. Several H1-antagonists have been demonstrated to bind with different affinities to the central H3-receptors in rodents (Sharif, Su, \& Yanni, 1994). Furrher research is needed to investigate whether any of these hypotheses can explain the pharmacological mechanism responsible for the stimulating effect of fexofenadine. 
Chapter 7 


\section{REFERENCES}

Chen, N. S Reith, M. E. (2000). Structure and functon of the dopamine tramoponte: Eturopean Joumal of Pharmacology, 405(1-3), 329-339.

Dringenberg, H. C. de Souza-Silva, M. A, Schwarting, R. K. \& Hustom, J. . (1998). Increased levels of extracellular dopamine in neostriatum and nucles accumbens after histambe $\mathrm{H}$ receptor blockade. Nanyn-Schmiedebergs Archites of Phannacolagy, 358(4), $423-429$.

Hindmatch, L., \& Shamsi, Z. (1999). Anthistamines models to assess sedative properties, whsesment of sedation, safery and other side-effects. Chical and Expermenal Alery. 29(Supp 3), 133-142.

Korotkova, T. M. Haas, H. L., \& Brown, R. E. (2002). Histamine excits GA BAergic cells in the tat substantia nigra and venmal tegmental area in viro. Netroscience Letters, 320(3), 133-136.

Lapa, G. B., Marhews, T. A. Harp. J., Budygin, E. A. \& Jones, S. R. (2005). Diphenylpyraline, a listamine HI receptor antagonise, has psychostimulant properties. Emopean joutsnal of thamenolog, $506(3)$, 237.240 .

Matsunaga, K., Sato, T., Shuro, H., Tsuruta, Y, Suemaru, K., Oomita, Y. \& Oshi, R. (1998). Inhibition of neuronal dopamine uptake by some antial lergic drugs. Europeon foumal of Phomacolong, $350(2-3), 165-169$

O'Hanlon, J. F, \& Ramakers, J. O. (1995). Anthistamine effects on acual driving performance in a standard test: a summaty of Dutch experience, 1989-94. Allergy, 50(3), 234.342.

Oishi, R., Shishido, S., Yamori, M. \& Saeli, K. (1994). Comparison of the effects of eleven histanine H1-receptor antagonists on monomine turnover in rhe mouse brain. Nawny-Schmedebergys Archives of Phamacology, 349(2), 140.144.

Sharif, N. A., Su, S. X., \& Yanni, 1. M. (1994). Emedastine: a potent, high aftinity histamine HI. receptor-selective antagonist for ocular use: receptor binding and second messenger studies. Joumal of ocular phamacology, $10(4), 653-664$.

Theunissen, E. L., Jonkman, L. M., Kuypers, K. . C., B Ramaekers, J. G. (In press). Stimularing effecs of fexofenadine under high workload conditions. A combined neurophysiological and behavional approach. Journal of pyychopharnacology

Theunissen, E. L., Vermeeren, A., Vuuman, E. F. P. M. S Ramakers, J. O. (In Press). Stimulating effects of $\mathrm{Hl}$-antagonists. Cunrent Pharmacentical Desiyn.

Vermeren, A. (2003). Hypotics and anthistamines. Effects on cognitive functions and driving perfomance. Matsrricht Universiny, Matantricht.

Vermeeren, A. S OHambn, J. F. (1998). Fexofunadines effects, alone and with alcohol, on acrual

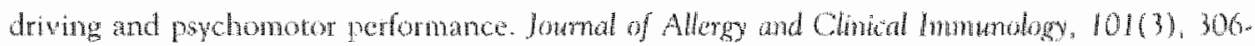
311. 
General discussion

\section{Chapter 8}


Chapter 8 
In this thesis, old problems and new insights about antihistamines were assessed and discussed. Old problems refer to the well established fact that many antihistamines produce drowsiness which may in turn cause severe performance impairment. Over the years, antihistamine research has produced an extensive classification of the sedative potential of almost every $1^{\text {st }}$ and $2^{\text {nd }}$ generation antihistamine (O'Hanlon \& Ramaekers, 1995; Simons, Fraser, Reggin, \& Simons, 1996; Hindmarch \& Shamsi, 1999; Shamsi \& Hindmarch, 2000). This line of research has had a positive influence on the prescription routines of physicians who have started to select drugs not only on the basis of their therapeutic potential but also on the presence or absence of side effects. The first part of the present thesis builds on this traditional line of research by investigating the sedative potential of one of the few $2^{\text {nd }}$ generation antihistamines of which the sedative potential has not yet been fully determined, i.e mequitazine.

New insights refer to the phenomenon that some antihistamines were shown to slightly improve performance in certain laboratory tasks. These activating effects cannot be explained by blockade of the $\mathrm{HI}$-receptor in the brain which is the main cause of the sedating effect of antihistamines. There's a growing body of evidence that the activating effects of certain antihistamines are not anomalous findings but represent a real pharmacodynamic effect. The second part of this thesis further explored the true nature of these so called stimulating effects. Event related brain potentials were used to investigate the subtle stimulating effects of the drug on cognitive processes. In addition, receptor binding after antihistamine treatment was studied using ligand binding SPECT-scans, in order to discover the mechanism leading to the stimulating effect.

In this final chapter, the findings which emerged from the previous chapters are discussed in a broader perspective, in addition to some general issues.

\section{OBJECTIVE VERSUS SUBJECTIVE MEASUREMENT OF SEDATION}

In order to be able to advice patients abour the safety of drugs, methods for measuring the sedaring effects are needed. A reliable way to derermine the sedating potential of psychoactive drugs is to measure the drowsiness caused by these drugs, using objective performance tests and/or subjective questionnaires. By using subjective measures of drowsiness, sedation caused by second generation antihistamines often goes unnoticed (Seidel, Cohen, Bliwise, \& Dement, 1987; Simons, Fraser, Reggin, \& Simons, 1995). Using objective tests of impairment, it was found that differences exist in sedation between the first and second generation antihistamines, but also within the group of second generation antihistamines (O'Hanlon \& Ramaekers, 1995; Hindmarch \& Shamsi, 1999). In addition, many researchers found that although subjects do experience drowsiness, they are often not aware of the amount of performance impairment a drug is causing. In chapter 2 and 3 of this dissertation, it was again demonstrated that although the objective tests indicated impairment, it did not show from subjective measures of sedation. This unawareness of the impairment could put the patients in considerable danger, since they may take part in high risk activities, such as controlling machines or driving. It can thus be concluded that objective tests are essential to assess the antihistamine-related impairment. 


\section{EFFECT OF PSYCHOACTIVE DRUGS ON DRIVING PERFORMANCE}

Driving is a skill which incorpotates many different functions such as cognitive processes, sensory perceptions and motor skills. In today's society, driving has almost become indispensable and the roads have become crowded with cars and other road users. So, when someone"s driving skils ate impaired, this does not only affect the driver's safety, but also endangers the safery of others. For these reasons, governments apply strict laws to driving under the influence of alcohol which is known to impair driving performance (Zador, Kuwchuk, \& Vaas, 2000\%. Applying such laws for medicinal drugs is however not that simple, because of various reasons. This would mean, for example, that a large proporrion of the population would be excluded from taking part in traffic. In addition, relatively simple and reliable breath analyzer tests are avallable for estimating the amount of alcohol in the blood circulation, but such easy tests do not exist for measuring circulating levels of psychoactive substances. Therefore, it is essential that drugs are screened thoroughly on their potential to affect patients" driving performance and that research into the development of safe medicines continues.

Over the years, many studies have confrmed that the standard highway driving test is highly sensitive to impairment caused by psychoactive drugs. This test was developed in the $1980^{\circ}$ s in The Netherlands, and this method has since been used to test the effects of several psychoactive substances on driving performance (OHanlon, Haak, Blaauw, \& Riemersma, 1982). The primary outcome is the standard deviation of lateral position (SDLP), which is an index of road tracking or weaving. The SDLP is a reliable measure, with test-retest reliability coefficients higher than $\mathrm{r}=0.85$ (Ramaekers, Ansseau, Muntjewerff, Sweens, \& O'Hanlon, 1997).

In chapter 2 and 3 , the sedative effects of mequitazine, cetirizine and dexchlorpheniramine were compared using objective tests as well as subjective questionnaires. Results from the experimental studies described in chapter 2 and 3 demonstrated the acute sedating effect of a first generation antihistamine, dexchlorpheniramine, and of a second generation antihistamine, mequitazine. These antihistamines only had an effect on the highway driving test and not on the cognitive tests or subjective measures, though. Chapter 3 demonstrated that this sedation diminished when treatment was continued over several days. In neither study did cetirizine demonstrate sedating effects on driving or cognitive performance, probably because cetirizine's sedative effects are limited to a certain time window and to highly sensitive persons.

Drugs which have typically shown large effects on the highway driving tests include tricyclic antidepressants, anxiolytics and hypnotics (O'Hanlon, Vermeeren, Uiterwijk, van Veggel, \& Swijgman, 1995; Vermeeren et al., 2002; Verster, Volkerts, \& Verbaten, 2002; Ramakers, 2003). The level of impairment differs for different drugs, depending on the drug, dose and time of measurement, but some drugs reach SDLP increases up to $10 \mathrm{~cm}$. Therefore, the effects of antihistamines on driving performance that were demonstrated in this thesis, seem rather minor. However, when compared with the effects of alcohol, it appeared that the impairing effect of dexchlorpheniramine and mequitazine are clinically significant. A previous study demonstrated that a blood alcohol concentration (BAC) of 0.5 mg/ml (the legal limit in most European countries) produced an increase of about $2.2 \mathrm{~cm}$ on the SDLP, the primary variable of the highway driving test (Louwerens, Gloerich, de Vries, Brookhuis, \& OHanlon, 1987). Since a BAC of $0.5 \mathrm{mg} / \mathrm{ml}$ is associated with a significantly 
higher risk in traffic accidents (Zador et al, 2000), an SDLP increase of about $2.2 \mathrm{~cm}$ is considered clinically relevant. In chapter 2 , it was shown that mequitazine $10 \mathrm{mg}$ caused an SDLP increase of $1.0 \mathrm{~cm}$ and dexchlorpheniramine an increase of $2.4 \mathrm{~cm}$, while in chapter 3 mequitazine $10 \mathrm{mg}$ increased SDLP with $2.5 \mathrm{~cm}$ and dexchlorpheniramine with $2.0 \mathrm{~cm}$ on the first day of treatment. While these results seem conflicting about the level of impairment caused by mequitazine and dexchlorpheniramine, it indicates that some individuals are sensitive for the sedating effects of these antihistamines and will show clinically significant impairment in driving, comparable to that of an alcohol-intoxicated driver with an approximate $B A C$ of $0.5 \mathrm{mg} / \mathrm{m}$ l.

When compared with other antihistamines, it seems that the driving impairment caused by mequitazine and dexchlorpheniramine is smaller than that produced by first generation antihistamines, which demonstrated increases in SDLP between 2 and $5 \mathrm{~cm}$ (Riedel, Ramaekers, Uiterwijk, \& O' Hanlon, 1990; Volkerts, Van Willigenburg, Van Laar, \& Maes, 1992; Ramaekers \& O'Hanlon, 1994; Vuurman, Uiterwijk, Rosenzweig, \& O'Hanlon, 1994; Verster et al., 2003). The effect of dexchlorpheniramine, a first generation antihistamine, on SDLP was unexpectedly low. This finding can be explained by the formulation of the drug; i.e. dexchlorpheniramine was administered as a slow release formulation, so that the substance is gradually and slowly released. Consequently, it appears that a slow release formulation seems a good way to overcome the strong sedating effect of first generation antihistamines. Other studies, with the first generation antihistamine triprolidine, also support this suggestion (Riedel, Schoenmakers, \& O' Hanlon, 1989; Riedel et al., 1990).

Together with many others studies, the driving studies described in this thesis demonstrated that second generation antihistamines can impair performance because of the sedating effects they produce. It should therefore be clear that the term "non-sedating" antihistamines which is also often used to discriminate this class of drugs, is an inappropriate term. The distinction with the first generation is that those antihistamines clearly produce sedation after the recommended dose, while nearly all second generation antihistamines only produce sedation after higher than therapeutic doses.

\section{STIMULATING EFFECTS OF ANTIHISTAMINES}

The product marketing of fexofenadine focuses on the claim that this antihistamine dloes not enter the CNS and therefore does not cause sedative effects. Several clinical trials have indeed demonstrated that the use of fexofenadine is not associated with feelings of drowsiness and sleepiness (Bernstein et al., 1997; Howarth, Stern, Roi, Reynolds, \& Bousquet, 1999; Mann, Pearce, Dunn, \& Shakir, 2000). In chapter 5 and 6 it was even demonstrated that fexofenadine mildly stimulates performance of healthy subjects in tasks with a high workload. From chapter 4 it became evident that this stimulating effect is not only specific for fexofenadine, but that orher studies have also sporadically reported stimulating effects of terfenadine, desloratadine and ebastine. As most subjects were not aware of the stimulating effect, the clinical significance of these findings is unclear, and it is unlikely that these drugs will be abused as stimulants. In chapter 6 it was concluded that the effects of fexofenadine on psychomotor tasks is not comparable to the effect of stimulant drugs such as amphetamines that was found in previous studies. In addition, if we compare the results of fexofenadine and psychostimulants on performance in the standard highway driving test, we see that 


\section{Chapter 8}

psychostimulants like MDMA and methylphenidate produce a decrease in SDLP of about 2 $\mathrm{cm}$ (Ramackers \& Kuypers, 2004b, 2004a) whereas fexofenadine (120 mg) produced a decrease of around $1.5 \mathrm{~cm}$ after repeated doses. It would be interesting to compare the effects of fexofenadine with a stimulant directly in a future experimental study.

The mild stimulating effects of fexofenadine and some other antihistamines indicate that these drugs do cross the blood brain barrier and interact with central arousal processes. Thus it can not be claimed that fexofenadine does not enter the central nervous system. Several ideas about the mechanism leading to the increased arousal have been postulated in chapter 4. It is suggested that fexofenadine causes an increase in dopamine by blocking the dopamine transporter or by blocking $\mathrm{GABA}$. Another suggestion is that an increase in histamine due to a blocking of the histamine autoreceptor is the cause of the increased arousal. For all hypotheses, some inclirect evidence is available mainly from animal studies (Oishi, Shishido, Yamori, \& Saeki, 1994; Monti, Jantos, Ponzoni, \& Monti, 1996; Korotkova, Haas, \& Brown, 2002). In chaptew 7, the dopamine transporter blocking hypothesis was directly rested in healthy humans, but could not be confirmed. Future research is needed to find the process responsible for the heightened arousal in humans, e.g. the involvement of dopamine in this process could be tested by assessing the extracellular dopamine levels after fexofenadine treatment in humans.

By causing mild stimulating effects instead of sedative effects, fexofenadine and a few other antihistamines clearly discriminate from the first and second generation antihistamines. Although the exact mechanism whereby these drugs induce stimulation tather than sedation, remains unclear, it is advisable to group these antihistamines in a different drug class. Frevious researchers have already suggested that these antihistamines should be called the third generation, and probably this term is more appropriate than stimulating antihistamines, since the stimulating effects seem somewhat minor.

\section{HISTAMINE AND AROUSAL}

The knowledge that histamine plays an important role in arousal is mainly based on the observation that blocking histamine neurotransmission by $\mathrm{H} 1$-antagonists causes a decrease in arousal levels. Many first generation antihistamines were also found to affect other neurotransmitters systems involved in arousal, including acetylcholine, serotonin, noradrenaline, dopamine and GABA (Speeg, Wang, Avant, Parker, \& Schenker, 1981; Oishi et all. 1994; Sangalli, 1997; Dringenberg, De Souza Silva, Rossmulter, Huston, \& Schwarting, 1998). Binding at these receptors seems to be dependent of the given antihistamine and the given dose. A complicating factor is that these neurotransmitter systems do not act independently but rather interact with each other (Saper, Chou, \& Scammell, 2001). Therefore the sedating effects of these antihistamines can not be completely explained by blockade of the histamine neurotransmission.

Findings that second generation antihistamines bind to a much lesser extent at the central Hl-receptors, has often led to the conclusion that they do not enter the central nervous system. However these studies do not exclude that second generation antihistamines bind at other neurotransmitter receptors. In addition, several studies have since demonstrated that most second generation antihistamines, especially in high doses, bind at central H1-receptors, although to a lesser extent than first generation antihistamines (Tashiro et al., 2004). The variation in binding at Hl-receptors and other neurotransmitter 
receptors might account for the variation in sedating potential of these second generation antihistamines.

The studies with fexofenadine described in this thesis, clearly demonstrate that this antihistamine also has psychoactive effects, and thus acts centrally. In chopter 7, it could not be demonstrated that fexofenadine binds at the dopamine transporter, however. Future studies with stimulating antihistamines should include receptor binding studies, so that it can be elucidared which neurotransmitter system(s) is/are responsible for the arousalpromoting effects in these drugs. A particularly interesting target for further research is the histamine $\mathrm{H} 3$-receptor, since $\mathrm{H} 3$-antagonists have repeatedly demonstrated to enhance cognition and wakefulness in animals (Leurs, Blandina, Tedford, \& Timmerman, 1998; Vohora, 2004).

\section{CONSEQUENCE FOR PATIENTS}

Although the studies described in this dissertation were performed in healthy subjects, some generalization for the patient population is possible. It is well documented that the allergic condition in itself has impairing effects on the functioning of the patient. Patients report diminished quality of life and experience difficulties in their working situation (Meltzer, Nathan, Selner, \& Storms, 1997; Blaiss, 2000). Studies have also demonstrated a diminished working productivity in allergic patients (Burton, Conti, Chen, Schultz, \& Edington, 2001). Therefore, the ideal antihistamine should also result in improved daily functioning. First generation antihistamines were effective in relieving the allergic symptoms, and thereby do affect the patients' quality of life. But because these drugs caused sedative effects, patients were again limited in their daily functions. So depending on the severity of the complaints and on the drugs taken, the patient had to choose between the lesser of two evils, and treatment was often discontinued. Second generation antihistamines are as effective as the first generation and in clinical trials, these antihistamines are mostly preferred over first generation antihistamines, because they produce less sedation (Harvey et al, 1996; Nolen, 1997). A few antihistamines were even found to improve patients' quality of life compared to placebo (Melzzer \& Grant, 1999). Fexofenadine treatment, for example, was found to improve patient's quality of life and to reduce the performance impairment due to the allergic condition (Meltzer, Casale, Nathan, \& Thompson, 1999).

Physicians should provide correct information to patients about the different antihistamines available, and although there are still inexpensive first generation antihistamines on the market, the first choice of treatment should be a second generation or preferably a third generation antihistamine.

\section{CONCLUSION}

For quite some time antihistamines have been divided into first and second generation antihistamines. Numerous studies have however demonstrated that the distinction between these two categories is small. The previous chapters have contributed to the notion that there is a considerable amount of variation in sedation among the second generation antihistamines, and that although they bind less to central Hl-receptors, they are not free of impairing effects. Probably other neurotransmitter systems are also involved in generating the sedation in these antihistamines. Therefore, the most appropriate way to determine the 


\section{Chapter 8}

sedating effect of antihistamines is to test them extensively using objective tests, including the highway driving test. Subsequently these results should be used to inform patients reliably about the safery of the drug and the risk they are taking when participating in traffic.

Only a few recently developed antihistamines were found to be free of sedative effects, and were even reported to mildly stimulate performance. It might be a good idea to group these antihistamines in a different class, in order to clearly discriminate them from the sedating first and second generation antihistamines. At present, it remains unclear how these antihistamines cause their stimulating effect.

Taken together, the information provided in this dissertation has contributed to the knowledge about the sedating and stimulating effects of antihistamines. This information should be taken into account when choosing the appropriate treatment for an allergic condition, so that the choice of treatment is not only based on efficacy and costs, but also on safery and effect on quality of life. In addition, further research should concentrate on possible other neurotransmitter systems involved in arousal which might further explain the sedating and stimulating effects of antihistamines. 


\section{General discussion}

\section{REFERENCES}

Bernstem, D. L., Schoenwerter, W. F, Nathan, R. A. Stoms, W. Ahlmand, R. \& Mason, I. (1997)

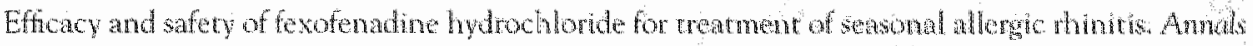

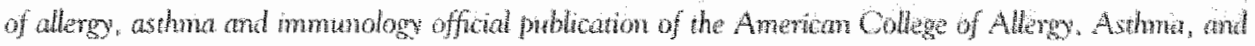
Immunotogy, 79(5), 443-448.

Blaiss, M. S. (2000). Cognive social, and economic costs of allergic thiniris. Allergy and astha proceedings the offucial joumal of regronal and state allergy societtes, 2(1), 7.13 .

Burton, W. N., Conti, D. J., Chen, C. Y, Schuls, A. B. E Edingron, D. W. (2001). The impact of

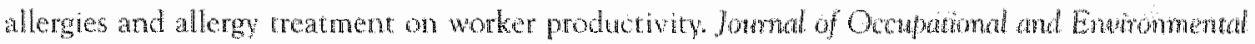
Medicine, 43(1),6471.

Dringenberg, H. C. De Souza Siwa, M. A. Rosmulles, I. Huston, J. P., S Sohwaring, R. K. (1998). Histamine $H 1$ receptor antagonists produce increases in extracelluar acevldohine in rat fomtal cortex and himpocampus. Jom of nemochemsery, $70(4), 1750.1758$.

Harvey, R. P., Comer, C., Sanders, B., Westley, R., Marsh, W., Shapiro, H., Wiener, M. (1996). Model for outcomes assesment of anchistamine use for seasonal allewgic rhinitis. Joumal of allergy and dinical mmenolgery. 97(6), 1233-1241.

Hindmarch, 1., \& Shamsi, Z. (1999). Antihistamines: models to assess sedative propertes, absersment of sedation, safery and other sidereffects. Clinical and Expermental Allogy, 29(Supp) 3), 133.142.

Howarh, P. H., Stern, M. A.. Roi, L., Reynolds, R., \& Bourquet, ]. (1999\%. Douhle-blind, placebocontrolled study companing the effocy and safery of fexofenadine hydrochloride (120 and $180 \mathrm{mg}$

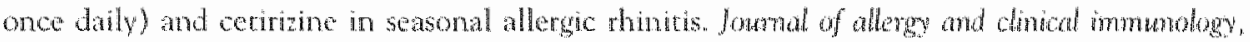
$104(5), 927.933$.

Korotkova, T. M., Hars, H. L. \& Brown, R. E. (2002). Histamine excites OABAergic cells in the rat substantla nigra and ventral regmental area in vitro. Neurascience Lutters, 320(3), 133-136.

Letirs, R. Blandina, P., Tedford, C., \& Timmerman, H. (1998). Therapeutic potential of thiscamme H3 receptor agonists and antagonuss. Trends in phamnocologicat sciences, 19(5), 177-183,

Lonwerens, J. W. Gloerich, A. B. M., Ae Wries, G., Brookhuis, K. A., S. Othanlon, J. F (1987). The relationship between drvers blod alohot concentation (BAC) and actual driting performano daring high speed trawel. Paper presented at the International Congres on Alcohol, Drugs and "Traftic Sitery: T86, Amsterdam.

Mann, R. D. Pearce, G. L., Dum, N. S Shakir, S. (2000). Sedation with "fon-seduing" antihistamines: four prescriprofu-event monitoring stukles in gencral practice. Brish Modical Joumal, $320(7243), 1184.1186$.

Melcer, E. O. Casale, T. B., Nathan, R. A. \& Thompson, A. K. (1999). Oncedaly fexofenadine HCl improves quality of life and reduces work and activity impaiment in pariants with seasonal allergic rhinitis. Anmals of allergy, asthma and mmanalogy official puthication of the American College of Alleygy, Asthona, and hinmwnologes, 83(4), 311-317.

Meltzer. E. O. \& Grant, J. A. (1999). Impact of cetinitne on the therden of alleryic thinitis. Amals of Allergy. Asthroa, and Immunology, 83(5), 455-463.

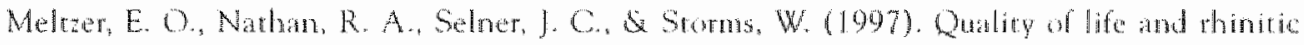
symptoms: Resulds of a nationwide surrey with the SF-36 and RQLQ questionmares. Jenomal of Allergy and Clinical Immónolegy, $99(6), 5815-5819$.

Monti, J. M., Janros, H., Ponzoni. A., \& Monti, D. (1996). Sleep and waking during acure histamme $\mathrm{H} 3$ agonst BP 2.94 or $\mathrm{H} 3$ antagonist carboperamide (MR 16155 ) administration in rats.

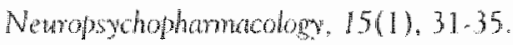




\section{Chapter 8}

Nolen, T. M. (1997). Sedarive effect of anthistamines: safer, performance, learming and qualing of life. Clrical Therapetatcs, $19(1), 39.55$.

OHanlon, J. F, Hark, T. W., Blatuw, G. J. S Remersma, J. B. (1982). Diazepan impairs lateral posing control in thighway drimes science, $217(4554), 79.81$

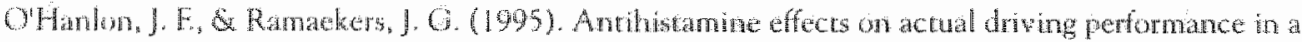
standard test as summary of Ditch experience, 1989-94. Allergs, 50 3), 234-342.

OHanlon, J. F, Vermeteren, A. Uiterwijk, M. M., vin Veggel, L. M. \& Swigman, H. E. (1995). Anxiglytics ffect on the actual driving performance of patients and healthy volunteers in a standardized test. An integration of three studies. Newropsychobiology, 31(2),81-88.

Oishi, R. Shishido, S. Yamoni, M. \& Sreki, K. (1994). Comparison of the effects of eleven histamine Hl-receptor antagonists on monomine curnower in the mouse brain. Naunyn Schmiedeberga Ardives af Pharmacology, 349(2), 140144.

Ramaekers, J. O. (2003). Antdepressants and driwer impaiment: empirical eqdence from a standard onetheroad test. Joumal of Clinical Psychatry, 64(1), 20-29.

Ranackers, J. G. Ansseau, M., Muntiewerf, N. D. Sweens, J. P, \& OHanlon, J. E (1997). Considering the P450 cytochrome system as dermining combined effects of antidepressants and benzadiazepnes on actual drwing performance of depressed ouparients. International clinical psychupharmucolog, $12(3), 159.169$.

Ramackers, J. O., \& Kuypers, K. P. C. (2004a). Interdwon effects of 3,4-methylenedioxymethamphetwime (MDMA) and atcohol on actual drining, psychomotor perfomance and risk takings behwer. Marastricht: Experimenal Psychopharmacology Unit.

Ramaekers, 1. G. \& kuypers, K. P. C. (2004b). A placebo controlled sudy on the effects of 3,4. methylenedioxymethamphetamine (MDMA) $75 \mathrm{mg}$ and merhylphenidare $20 \mathrm{mg}$ on actual driving performance, wisuospatial attention and memory during invoxication and withdrawal. Maatricht: Expermental Psychothamacology Unir.

Ramakers, J. O., \& OHanlon, J. E. (1944). Acrivastine, terfenatine and diphenhydramine effects on driving performance as a function of dose and lime after dosing. European Joumal of Chincal Phamacology, 47(3), 261-266.

Ricald, W. J., Ramackers, G., Uirewijk, M. M., \& O Hanlon, J. F. (1990). Higher doses of terfenadine

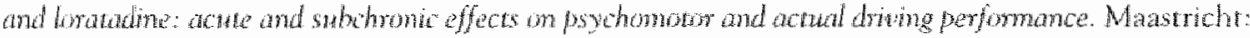
Institute for Druge, Siffety and Beliavior, University of Limburg.

Rictel, W. J., Schuenmakers, E. A. J. M., \& O'Hankn, J. F. (1989). Sodation and performance imparment wirly anthistamines. In M. A. Kalinger (Ed.), Mamagement of allergy in the $1990 \mathrm{x} 6 \mathrm{po}$. 3:48-49). Torounv: Hans Huber.

Sangalli, B.C. (1997). Rule w the central histaminergic neuronal system in the CNS wosicy of the

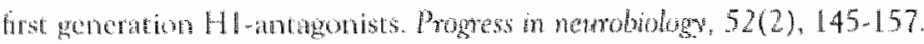

Saper, C. B. Chot, T. C. \& Scammel, T. E. (2001). The atee swith: hypothaliamic control of steep and wakefulness. Trends in nedrostencer; 24012$), 726-731$.

Seide, W.E, Cohen, S., Bliwise, N. G., \& Dement, W. C. (1987). Cenrizine effects on objectiwe mexsures of divtime sleepiness and performane. Annats of allergy $59(6 \mathrm{Pr} 2), 58.62$.

Shanki, Z. \& Hindmarch, 0. (2000). Sedation and anthistamines: A review of intertrug differences using proportonal impairment ratios. Human Psychopharmacology Clinical and Experimental, $15(5$ uppl 1$), 83-530$.

Simons, F. E., Frater, T. O., Reggin, J. D., \& Simons, K.J. (1995). Indiqual differences in central

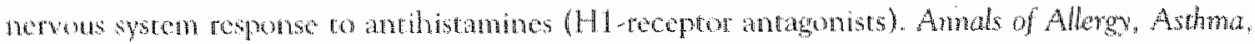
and immunology. $7566 \mathrm{Pt} 1) .507 .514$ 


\section{General discussion}

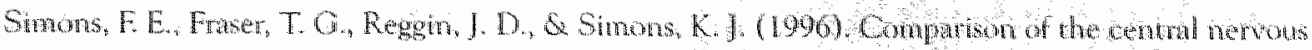

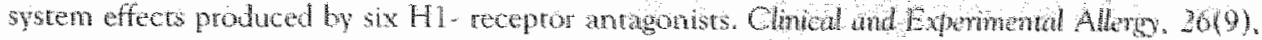
$1092-1097$.

Speeg, K. V. J., Wang, S, Avant, G. R., Parker, R, S Schenken, S. (1981). Jn vitro anmgonim of

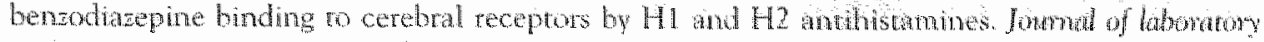
and dinical medicne, $97(1), 112,112$.

Tashiro, M., Sakurada, Y., lwabuchi, K., Mochizaki, H. Kato, M., Adk, M. Funaki, Y, Iroh, M. Iwata, R., Wong, D. F, S Yanai, K. (2004). Central Effect of Fexofenathe and Cetirine: Measurement of Psychomotor Perfomance, Subjective Sleppiness, and Brain Hivamine H1. Receptor Occupancy Using $11 \mathrm{C}$-Doxepin Positron Emission Tomagraphy. Jowmal of chimal phamacology, 44(8), 890,900

Vermeeren, A., Riedel. W. J, wan Boxtel, M. P., Darwish, M., Fary, I. \& Patat, A. (2002), Difterental residual effects of aldeplon and zopiclone on actual driving: a comparison with a low dowe of alcohol Slev, 25(2), $224-231$.

Verster, I. C, de Weert, A. M, Bijes, S. I., Aarab, M., wan Oosterwijck, A. W., Bijken, E. J., Verthaten, M. N. \& Volkerts, E. R. (2003). Driving ability afrer acute and subehromic administration of levoctirine and diphenhydramine: a randomized, double-blind, placebocontrolled trial. Psychophamacolog, $169(1), 8400$.

Verster, J. C., Volkers, E. R. \& Verbaten, M. N. (2002). Effeces of alprazalam on driving athiliny, memory functioning and psychomotor perfomance: a randomized, placeborentiofled study. Newropsychopharmacology official publicaton of the American College of Newapsychopharmacolagy. $27(2), 260-269$.

Whora, D. (2004). Histamine-selective $\mathrm{H} 3$ recepter ligands and cognitre funchons: an owervew, Dhags the investigational drugs jomant, 7(7),667-673.

Volkerts, E. R., Van Willigenburg, A. P. Van Lat, M. W., S Maes, R. A. (1902). Does certinine belong to the new generation of ancihistamines? An investigation into its acute and subchonic effects on highway driving psychometric test performance and daytime sleppiness. Humm Psychophamacology Clinical and Expermenal, $7(4), 227-238$.

Vutman, E. F, Uiterwijk, M. M. Rosenzweig, P. \& O'Hanlon, ). Fe (1994). Elfects of mizolasine and clemastine on actual driving and psychomowor pertormance in healthy voluntees. European Jomol of Climical Phomacolugy, 476), 253.259.

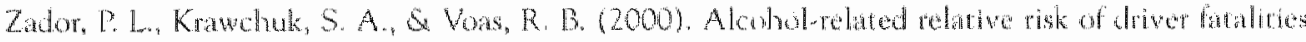

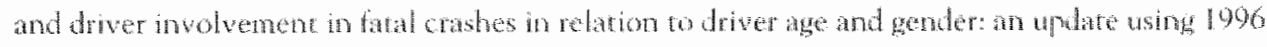
dinta. Jownd of Studies on Akohol, $61(3), 387-395$. 


\section{Summary}


A large proportion of the population suffers from allergies, and consequently use antihistamines to relief the symptoms. It is relatively well known that psychoactive drugs like hypnotics, antidepressants and illicit drugs can influence people's performance, however fewer people are aware of the effects antihistamines have on daily functions such as driving.

The first antihistamines developed to treat allergic patients produced considerable sedation, which forced the pharmaceutical industry to develop better drugs with fewer side effects. In the eighties, new antihistamines were introduced, hence called the second generation antihistamines. The assumption that all second generation antihistamines are non-sedlating, however, does not hold. Previous studies have demonstrated that almost all second generation antihistamines have the potential to produce sedation, although generally to a lesser extent than the first generation. The sedating effects are largely dependent on the given dose and in most cases disappear when treatment is continued over a longer period. When compared with the effects of alcohol on the standard highway driving test, the impairing effect of first generation antihistamines is larger than that of the legal limit of alcohol (BAC $0.5 \mathrm{mg} / \mathrm{ml}$ ). The driving impairment caused by second generation antihistamines, is of a comparable magnitude as that of the legal limit of alcohol. It is however disturbing that most patients are not aware of the influence these drugs have on their daily functioning. In questionnaires measuring subjective sedation or subjective performance, the effects of second antihistamines are most often not found. Therefore it should be advised that all antihistamines are tested using objective tests, sensitive for small sedating effects.

Sporadically, some antihistamines have shown to be able to stimulate performance in some tests. However, it is not clear how these $\mathrm{HI}$-antagonist are able to stimulate performance. Nevertheless, it is obvious that stimulating antihistamines will be preferred by patients over the sedating ones. At present, the stimulating effects of these antihistamines appear to be mild and are mostly not even noted by patients. Future drug research should elaborate on these stimulating antihistamines, so that patients, who already experience sedating effects of the allergic condition itself, can continue functioning at an optimal level.

In chapter 1, some background information is given related to the topics discussed in this dissertation. The subjects of this chapter include the function of histamine in allergic reactions and its function in the central nervous system, and the therapeutic action of antihistamines in the periphery as well as the central action of antihistamines. Subsequently, the traditional classification of antihistamines into first and second generation antihistamines is outlined. Antihistamines which do not fit in this classification system are discussed afterwards. This chapter ends with the aim and outline of this dissertation.

Chapter 2 presents the results of a study into the effects of different doses of mequitazine ( 5 , 10 and $15 \mathrm{mg}$ ). Mequitazine has been considered to be a second generation antihistamine even though it was never firmly established that this drug's sedative porential actually differs from the first generation antihistamines. Eighteen healthy volunteers were treated with three doses of mequitazine in a cross-over study. The sedative effects of mequitazine on actual driving, psychomoror performance and memory were compared with those of a first and a second generation antihistamine; dexchlorpheniramine and cetirizine, respectively. The results of the highway driving test revealed that dexchlorpheniramine impaired driving performance as indicated by a significant rise in the Standard Deviation of Lateral Position (SDLP). Mequitazine significantly increased SDLP in a dose related manner, but the 
separate dose effects failed to reach statistical stgnificance. Mequitazine caused a dose related increase in reaction time in a divided attention task and the high dose was significantly different from placebo. Subjects reported to be less alert after treatment with dexchlorpheniramine. Cetirizine did not affect performance in any of the tasks. It was concluded that mequitazine is mildly sedating. The effects of mequitazine are comparable to those of other second generation antihistamines, in that it causes mild driving impairment, particularly at higher doses.

In chapter 3 the effects of repeared doses of mequitazine $10 \mathrm{mg}$ are investigated on driving and psychomotor performance of healthy subjects. In chapter 2 it was demonstrated that mequitazine produces mild sedation after single doses. It is not known, however, whether the acute sedation persists after repeated dosing. The effect of repeated doses of mequitazine was studied in sixteen healthy volunteers and compared to the effects of cetirizine, dexchlorpheniramine and placebo. Treatments were conrinued for 8 days and drug effects were assessed on day 1 and day 8 using two on the road driving tests, psychomotor tests and a subjective questionnaire. Driving performance in the highway driving test was significantly impaired after dexchlorpheniramine and mequitazine treatment on day 1 . After 8 days of treatment, these effects on driving performance disappeared. There were no effects of treatment on any of the other measures, including car following, tracking and divided attention. Although subjective ratings confirmed that subjects knew their driving had been impaired in the mequitazine and dexchlorpheniramine condition after completion of the highway driving test on day 1 , they did not expect their driving to be affected before the start of the test. It was concluded that single doses of mequitazine $10 \mathrm{mg}$ and dexchlorpheniramine cause mild driving impaiment. However, when taken over several days, the impairing effect wears off, possibly as a result of tolerance.

Chapter 4. First and second generation antihistamines are associated with different degrees of sedation. Sporadically however, evidence of stimulating effects of antihistamines appeared in the literature. This chapter reviews the studies that demonstrated stimulating effects of antihistamines and postulates several hypotheses trying to explain the mechanism by which antihistamines cause these stimulating effects. The reports of antihistamines with mild stimulating properties concentrate around four Hl-antagonists: terfenadine, ebastine, fexofenadine and desloratadine. The stimulating effects were mostly demonstrated in rasks involving high levels of attention, e.g. divided atrention tasks, vigilance tasks and driving tasks. The stimulating effects of these antihistamines were also often dependent of the given dose; however the relation was not always linear. The mechanism responsible for the stimulating effects of these four antihistamines is still unclear. Two hypotheses suggest that it is caused by increased levels of dopamine either through blocking the dopamine transporter or through GABA inhibition. A third hypothesis suggests that the stimulating effect is caused by increased levels of histamine, due to blocking of the $\mathrm{H} 3$ histamine receptor. Further research is needed to clarify the ambiguous role of histamine in processes of arousal.

In chapter 5 , a study into the stimulating effects of fexofenadine is presented. Previously, some studies reported mild stimulant effects of fexofenadine. In this study, the stimulating effects of high doses of fexofenadine $(180$ and $360 \mathrm{mg}$ ) were studied and it was detemined 
whether such effects are related to workload. The effects of fexofenadine were studying in 16 healthy volunteers and compared with placebo. A divided attention task (DAT), continuous performance task (CPT) and motor choice reaction time test (MCRT), all with increasing levels of workload were used to determine drug effects. The underlying neurophysiological processes in the DAT and CPT were measured using Event Related brain Potentials (ERP's). Results demonstrated that performance on the DAT was less affected by increments in workload after fexofenadine treatment. The results of the event related potentials indicated faster attentional and information processing latencies following fexofenadine treatment. Treatment did not influence performance in the CPT task or in the ERP's measured during this task. The MCRT demonstrated faster movement times following fexofenadine treatment. Together, these results suggest that although the neurophysiological data indicate CNS activation after fexofenadine treatment, the magnitude of the centrally activating effecrs is too small to produce relevant performance improvement at the behavioral level.

Chapter 6 - Previous studies demonstrated mild stimulating effects of fexofenadine, probably due to its interaction with the dopamine system. The study described in chapter 6 investigates the effects of a high dose of fexofenadine on cognitive performance, motor impulsivity, physiological measures and subjective experience. Forty subjects were included in this between subject study. Half of the participants received fexofenadine $360 \mathrm{mg}$ while the other half received placebo. Cognitive performance and motor impulsivity were measured using the digit symbol substiturion test (DSST) and a stop signal task (SST), respectively. One hour after drug intake, performance on the DSST was improved in the fexofenadine group. Fexofenadine did not affect motor impulsivity, subjective experience or physiological measures. From these results it was concluded that fexofenadine has mild stimulant effects which are short-lived and not comparable to the effects of psychostimulants.

Chapter 7 - In the previous chapters, the mild stimulating effect of fexofenadine has been demonstrated. In the present chapter the hypothesis that this stimulating effect is caused by a blocking of the dopamine transporter (DAT), is investigated. Sixteen healthy volunteers participated in this between subject study. Subjects received either fexofenadine $360 \mathrm{mg}$ or placebo, and were subsequently injected with the radiorracer [123I]FP-CIT. FP-CIT has a high affinity for the dopamine transporter. The binding potential of FP.CIT was measured using SPECT-scan. Results of this study demonstrated that there was no difference in binding potential of FP-CIT at the dopamine transporter between the placebo and fexofenadine group. Therefore we could not conlirm our hypothesis. It could however be that fexofenadine's binding at the DAT was broken by the strong binding of FP-CIT at this receptor.

Chapter 8 - In this chapter the most important findings of this dissertation are discussed in a broader perspective: objective and subjective measures for assessing the sedating effects of antihistamines are evaluated; attention is given to the use of the standardized test for measuring impairment caused by antihistamines and other psychoactive drugs; the significance of the stimulating effects of antihistamines is discussed; the role of histamine in arousal as well as the role of other neurotransmitters involved in the psychoactive effects of 
antihistamines are dealr with in addition to the practical relevance of the findings for allergy patients. From this chapter it becomes clear that future research should in addition to the histamine system concentrate on other neurotransmitrer systems that might explain the variation in the sedating effects of antihistamines and the stimulating effects of a few antihistamines. 
Een groot deel van de bevolking heeft last van allergieèn, en gebruikt bijgevolg antihistamines om de symptomen tegen te gaan. Het feit dat psychoactieve drugs zoals slaapmiddelen, antidepressiva en illegale drugs de prestaties van de gebruiker kunnen beinvloeden is algemeen bekend. Minder mensen zijn zich bewust van het effect dat antihistanines kunnen hebben op alledaagse activiteiten zoals autorijden.

De eerste antihistamines die ontwikkeld werden voor de bestrijding van allergieèn produceerden behoorlijke sedatie, hetgeen de farmaceutische industrie ertoe verplichtte on betere geneesmiddelen met minder bijwerkingen te ontwikkelen. In de jaren tachtig werden nieuwe antihistamines geinntroduceerd die men vervolgens de tweede generatie antihistamines noemde. De veronderstelling dat alle tweede generatie antihistamines niet-sederend zijn, klopt echter niet. Voorafgaande studies hebben aangetoond dar bijna alle rweede generarie antihistamines sedatie kunnen veroorzaken, hoewel doorgaans in mindere mate dan de eerste generatie. De sederende effecten zijn in grote mate afhankelijk van de toegediende dosis en verdwijnen in de meeste gevallen wanneer de behandeling over langere tijd wordt voortgezet. Wanneer de effecten van antihistamines op een standaard rijtest op de snelweg vergeleken worden met de effecten wan alcohol, blijkt dat de verslechtering die veroorzaakt wordt door de eerste generatie antihistamines groter is dan de verslechtering als gevolg van de wertelijke alcohol limiet (BAC $0.5 \mathrm{mg} / \mathrm{ml}$ ). De rijverslechtering veroorzaakt door tweede generatie antihistamines is van een vergelijkbare omvang als de wettelijke alcohol limiet. Het is echter verontrustend dat de meeste patiënten zich niet bewust zijn van de invloed die deze geneesmiddelen hebben op hun dagelijks functioneren. Vragenlijstonderzoeken naar de subjectieve sedatie of subjectieve prestatie, kunnen meestal de effecten van tweede generatie antihistamines niet aantonen. Het is daarom aan te raden dat alle antihistamines getest worden met objectieve tests die gevoelig zijn voor kleine sedatieve effecten.

Incidenteel is aangetoond dat bepaalde antihistamines in staat zijn om de prestatie op sommige tests te stimuleren. Het is evenwel niet duidelijk door welk mechanisme de H1antagonisten deze prestaties bevorderen. Niettegenstaande is het duidelijk dat stimulerende antihistamines door patiënten verkozen worden boven de sederende. Op dit ogenblik lijken de stimulerende effecten van deze antihistamines mild en bijna niet merkbaar voor de patiënten. Het is aan te raden dat toekomstig geneesmiddelonderzoek doorgaat met het onderzoeken van deze stimulerende antihistamines, zodat patienten die reeds sederende effecten ervaren van de allergische aandoening op zich, kunnen blijven functioneren op een optimaal niveau.

In hoofdstuk 1 wordt achtergrondinformatie gegeven gerelateerd aan de onderwerpen die in dit proefschrift besproken worden. De onderwerpen van dit hoofdstukken omvatten de functie van histamine in allergische reacties en in het centrale zenuwstelsel, de therapeutische werking van antihistamines in de periferie en de centrale werking van antihistamines. Vervolgens wordt de traditionele classificatie van antihistamines in eerste en tweede generatie antihistamines uirgelegd. Antihistamines die niet in dit classificatiesysteem passen worden naderhand besproken. Het hoofdstuk eindigt mer de doelstelling en opbouw van dit proefschrift.

In hoofdstuk 2 worden de resultaten van een studie naar de effecten van verschillende doses mequitazine $(5,10$ en $15 \mathrm{mg})$ gepresenteerd. Hoewel nooit voldoende onderhouwd werd vastgesteld dat de sedatieve effecten van mequitazine feitelijk verschillen van de eerste 
generatie antihistamines, werd het geneesmiddel bij de rweede generatie anthistamines gerekend. Aan dit cross-over onderzoek namen achttien gezonde vrijwilligers deel. De deelnemers kregen drie verschillende doses mequitazine toegediend. De sedatieve effecten van mequitazine op rijvaardigheid, psychomotorische prestatie en geheugen werden vergeleken met die van een eerste en een tweede generatie anthistamine, respectievelijk dexchlorpheniramine en cetirizine. De resultaten van de rijtest op de snelweg toonder aan dat dexchlorpheniramine een significante toename in Standaatd Deviatie van de Laterale Positie (SDLP) veroorzaakte, hetgeen duidt op een verslechtering in de rijvardigheid. Mequitazine verhoogde de SDLP op cen dosis-afhankelijke manier, zonder dat de afzonderlijke doses statistisch significant waren. Mequitazine veroorzaakte een dosis gerelateerde toename in reactietijd in de verdeelde aandachtstaak en de hoogste dosis was significant verschillend van placebo. Proefpersonen rapporteerden minder alert te zijn na toediening van dexchlorpheniramine. Cetirizine beïnvloedde de prestatie in geen van de taken. Er werd geconcludeerd dat mequitazine mild sederend is. Mequitazine veroorzaakt lichte verslechtering van de rijwatrdigheid met name na hoge doses en is daardoor vergelijkbaar met andere tweede generatie antihistamines.

In hoofdstuk 3 worden de effecten van herhaalde doses mequitazine $10 \mathrm{mg}$ op de rijvaardigheid en psychomotorische prestatie van gezonde vrijwilligers onderzocht. In hoofdstuk 2 was aangetoond dat mequitazine milde sedacie produceert na een enkele dosis. Her is echter nog onbekend of de acute sedatie standhoudt bij herhaalde toediening. De effecten van een herhaalde dosis mequitazine werden bestudeerd bij zestien gezonde vrijwilligers en vergeleken met de effecten van cetirizine, dexchlorpheniramine en placebo. De geneesmiddelen werden gedurende acht dagen toegediend, en de effecten werden gemeten op dag 1 en dag 8 door middel van twee rijtesten, psychomotorische testen en een subjectieve vragenlijst. Op dag 1 was de rijvaardigheid op de snelweg significant slechter na dexchlorpheniramine en mequitazine toediening. Na 8 dagen toediening waren deze effecten op rijvaardigheid niet langer aanwezig. Er waren geen effecten van de geneesmiddelen op een van de andere maten. Uit de subjectieve wragenlijst bleek dat proefpersonen op dag 1 zich na het uitwoeren van de rijrest bewust waren van hun slechtere rijprestarie in de mequitazine en dexchlorpheniramine conditie, mar dat ze dit voorafgaand aan de rijtest niet vootspeld hadden. Er werd geconcludeerd dat een enkele dosis mequitazine $10 \mathrm{mg}$ en dexchlorpheniramine een milde rijverslechtering veroorzaken. Echter, wanneer de geneesmiddelen gedurende verschillende dagen toegediend werden, nam de verslechtering af, mogelijk als gevolg van tolerantie.

Hoofdstuk 4 - Eerste en tweede generatie antihistamines worden geassocieerd met verschillende mate van sedatie. Sporadisch zijn er bewijzen voor stimulerende effecten van antihistamines in de literatuur verschenen. Dit hoofdstuk beschrifft studies die stimulerende effecten van antihistamines hebben aangetoond en postuleert verschillende hyporheses omtrent het mechanisme verantwoordelijk woor de stimulerende effecten van antihistamines. De meldingen van antihistamines met milde stimulerende eigenschappen concentreren zich rond vier $\mathrm{H} 1$-antagonisten: terfenadine, ebastine, fexofenadine en desloratadine. De stimulerende effecten werden veelal aangetoond in taken waarbij een hoge mate van aandacht noodzakelijk is, bijvoorbeeld verdeelde aandacht, volgehouden aandacht en rijvaardigheid. De stimulerende effecten van deze antihistamines waren meestal ook afhankelijk van de gegeven dosering, hoewel de relatie niet altijd lineair was. Het is nog onduidelijk 
welk mechanisme verantwoordelijk is voor de stimulerende effecten van deze vier antihistamines. Twee hypotheses suggereren dat het effect veroorzaakt wordt door een verhoogd dopamineniveau, als gevolg van blokkade van de dopamine transporter ofwel door inhibitie van GABA. Een derde hypothese stelt dat het effect veroorzaakt wordt door een verhoogd histamineniveau als gevolg van een blokkade van de histamine $\mathrm{H} 3$-receptor. Verder onderzoek is noodzakelijk om de ambigue rol van histamine in arousal processen te verklaren.

In hoofdstuk 5 wordt een onderzoek naar de stimulerende effecten van fexofenadine gepresenteerd. Voorheen hebben enkele studies mild stimulerende effecten wan fexofenadine aangetoond. In dit onderzoek werden de stimulerende effecten van een hoge dosis fexofenadine (180 en $360 \mathrm{mg}$ ) onderzocht en er werd bepaald of zulke effecten gerelateerd zijn aan de werklast. De effecten van fexofenadine werden bestudeerd bij 16 gezonde vrijwilligers en vergeleken mer placebo. Er werd gebruik gemaakt van de 'divided attention taak' (DAT), 'continuous performance taak' (CPT) en 'motor choice reaction time test' (MCRT), allen met een toenemende werklast, om de effecten van het geneesmiddel te bepalen. De onderliggende neurofysiologische processen werden tijden de DAT en CPT gemeten met behulp van Event Related brain Potentials (ERP's). De resultaten coonden aan dat de prestatie op de DAT minder beïnloed werd door toename in werklast na fexofenadine behandeling. De resultaten van de event related potentials duiden op snellere aandachts- en informatieverwerkingsprocessen na fexofenadine toediening. Fexofenadine had geen invloed op de prestatie op de CPT of op de ERP's die gemeten werden tijdens deze taak. De MCRT toonde snellere bewegingstijden aan na fexofenadine toediening. Samengevat suggereten deze resultaten dat hoewel de neurofysiologische data wijzen op een activatie van het centrale zenuwsrelsel als gevolg van fexofenadine toediening, de omvang van de centraal activerende effecten te klein zijn om relevante prestatie verbeteringen te produceren.

Hoofdstuk 6 -Voorgaande onderzoeken hebben mild stimulerende effecten van fexofenadine aangetoond, waarschijnlijk als gevolg van een interacrie met het dopamine systeem. Het in hoofdstuk 6 beschreven onderzoek bestudeert de effecten van een hoge dosis fexofenadine op cognitief functioneren, motor impulsiviteit, fysiologische maten en subjectieve beleving. Veertig proefpersonen namen deel aan dit 'between subjects' onderzoek. De helft van de deelnemers kreeg fexofenadine $360 \mathrm{mg}$ toegediend, terwijl de andere helft placebo kreeg toegediend. Cognitief functioneren en motorische impulsiviteit werden respectievelijk gemeten met behulp van de 'digit symbol substitution test' (DSST) en een 'stop signal taak' (SST). Eén uur na inname was de prestatie op de DSST verbeterd in de fexofenadine groep. Fexofenadine had geen invloed op motor impulsiviteit, subjectieve beleving of op de fysiologische maten. Aan de hand van deze resultaten werd geconcludeerd dat fexofenadine milde en kortdurende stimulerende effecten heeft die niet vergelijkbaar zijn met de effecten van psychostimulanten.

Hoofdstuk 7 - In de vorige hoofdstukken werden mild stimulerende effecten van fexofenadine aangetoond. In dit hoofdstuk wordr de hypothese getest dat dit stimulerend effect veroorzaakt wordt door een blokkade van de dopamine transporter (DAT). Zestien gezonde vrijwilligers namen deel aan dit 'between subjects' onderzoek. Proefpersonen kregen ofwel fexofenadine 
$360 \mathrm{mg}$ of placebo toegediend, en kregen vervolgens de radiotracer [1231]FP-CIT genjecteerd. FP.CIT heeft een hoge affiniteit voor de dopamine transporter. De binding wan FP-CIT werd gemeten met behulp van SPECT-scans. De resultaten van dit onderzoek lieten zien dat er geen verschil was tussen de placebo en fexofenadine groep in binding van FP-CIT aan de dopamine transporter. Daardoor konden we de gestelde hypothese niet bevestigen. Het is echter niet uit te sluiten dat de binding van fexofenadine aan de dopamine transporter verbroken werd door een sterke binding van FP-CIT aan deze receptor.

Hoofdstuk 8 - In dit hoofdstuk worden de belangrijkste bevindingen van dit proefschrift in een perspectief geplaatst: objectieve en subjectieve maten voor het bepalen van sederende effecten van antihistamines werden geëvalueerd; gestandaardiseerde testen voor het meten van prestatieachteruitgang door antihistamines en andere psychoactieve drugs werd belicht; de significantie van de stimulerende effecten van antihistamines werd besproken; zowel de rol van histamine in arousal processen als de rol van andere neurotransmitters betrokken in de psychoactieve effecten van antihistamines werden behandeld alsook de praktische relevantie van de bevindingen voor allergiepatiënten. Dit hoofdstuk maakt duidelijk dat onderzoek in de toekomst zich naast het histamine systeem moet concentreren op andere neurotransmittersystemen zodat de variatie in sederende effecten van antihistamines en de stimulerende effecten van enkele antihistamines verklaard kan worden. 


\section{Dankwoord}

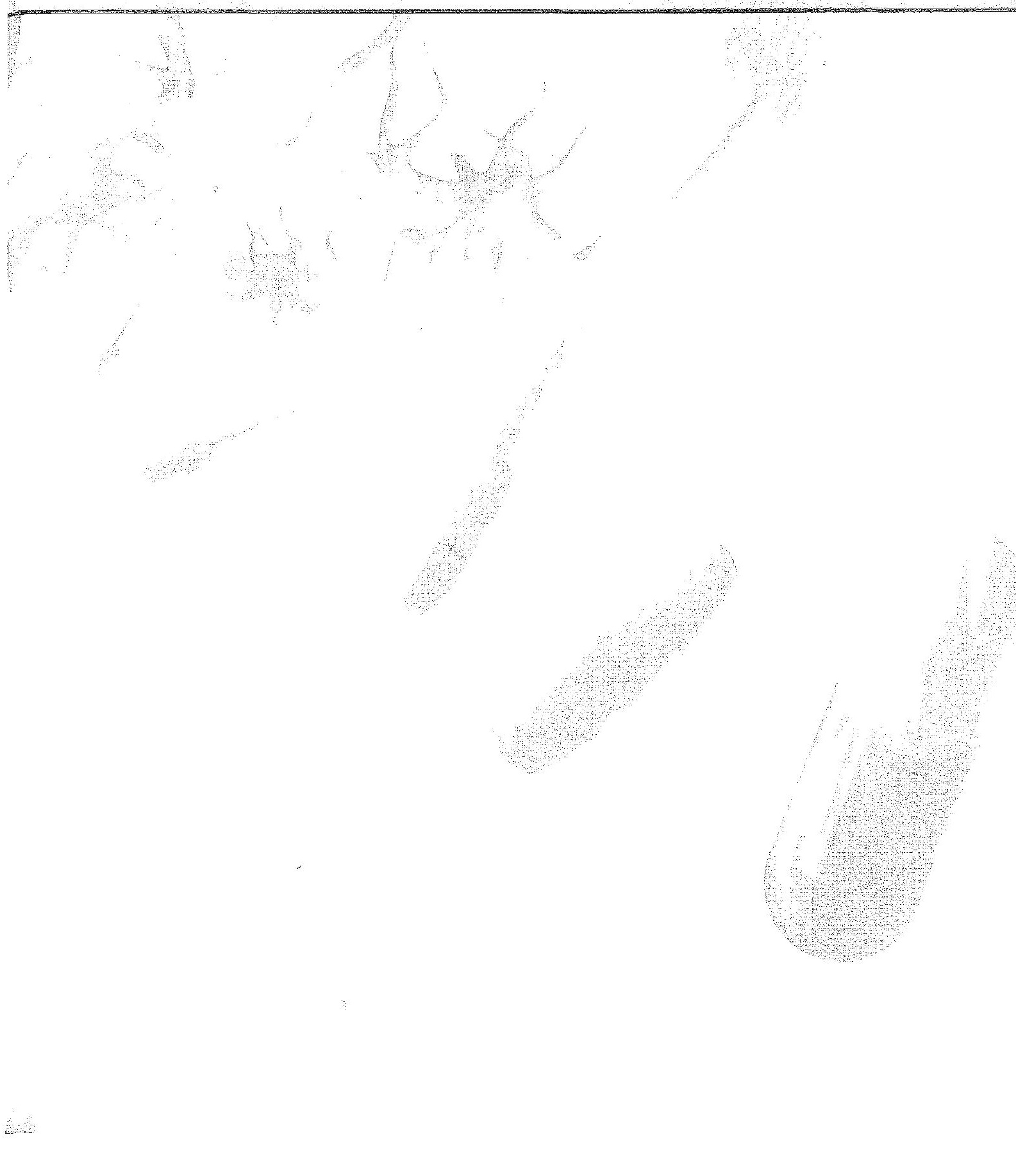


Bedankt! Bij het voltooien van mijn proefschrift, lijkt her mij meer dan gepast on een aantal mensen nadrukkelijk te bedanken voor hun medewerking, hulp en vriendschap.

Uiteraard te beginnen met de mensen die direct betrokken zijn geweest bij het tot stand komen van dit boekje. Allereerst mijn copromotor Jan Ramaekers. Jan, bedanki dat ik de onderzoeken onder jouw supervisie mocht opzetten en uitvoeren. Je deur staat altijd open, en door de vrijheid die je me gaf lier je je vertrouwen in mij blijken. En over éen ding had die "astrologe" dan toch ongeveer gelijk; we hebben samen een boek geschreven..

Mijn promotor Wim Riedel, je werd ongeveer twee jaar geleden mijn promotor, en ik was heel verheugd dar je dit wilde doen. En al waren toen de meeste onderzoeken afgerond of in uitvoering, ik heb je steun en advies enorm gewaardeerd. Je was oprecht geinteresseerd in de voortgang van de projecten en artikelen, en ook je ervaring en advies bij de laatste fases van het boekje kwamen erg goed van pas.

Co-auteur van een aantal van de voorgaande hoofdstukken, Annemiek Vermeeren. Annemiek, ik was altijd even stil en onder de indruk van de commentaar die je op een paper gaf maar uiteindelijk heb ik heel veel van je geleerd, en je kritische blik heel erg geapprecieerd. En hoewel Jan en jij soms een heel andere kijk hadden op een artikel, besef ik maar al te goed dat ik veel baat heb gehad aan deze verschillende visies.

En tot slot Jelle Jolles, bedankt om mij de kans te geven te promoveren en dat je tijdens de eerste twee jaar de rol van promotor op je nam.

Daarnaast wil ik nog een aantal andere mensen in het bijzonder bedanken die betrokken waren bij diverse hoofdstukken: Lisa Jonkman voor haar expertise op het gebied van ERP. Dr. van Kroonenburgh, Ciska Coenjaerts en de medewerkers van de afdeling Nucleaire Geneeskunde voor hun hulp bij het opzetten en uitvoeren van het SPECT-onderzoek en Jeroen van Deursen voor zijn hulp bij de verwerking van de SPECT-data. Nienke Muntjewerff en Cees van Leeuwen voor de medische ondersteuning. Henk, Willy, en Irma, voor de coördinatie en uitvoering van de rijtesten. Ilse, Marieke, Ellen, Kim en Desiree voor hun zeer gewaardeerde assistentie tijdens het onderzoek en, zeer belangrijk, de goede ambiance. En tot slot Anita voor haar ondersteuning bij de protocollen, proefpersoonwerving en uitvoering van de studies. Het uitvoeren van de onderzoeken was natuurlijk onmogelijk geweest zonder de bereidwilligheid van alle proefpersonen, waarvoor mijn oprechte dank.

Ook wil ik al mijn collega's van psychologie en neuropsychologie bedanken voor de leuke werksfeer, en dan vooral alle collega's van EPU en biopsy: Caroline, Kim, Marleen, Anita, Tim, Peter, Jeroen, Petra, Sven, Arjan, Jan, Annemiek, Eric, Wim en Pascal. Bedankt voor de gezellige lunches, zonnige terrasbezoeken en avontuurlijke dagjes-uit.

Evenzeer speciale dank aan de collega's die instaan voor de secretariële, logistieke en technische ondersteuning.

Vanzelfsprekend mijn paranimfen Lotte en Caroline. Bedankt woor jullie steun, vriendschap en fine organisarie van alles rondom deze dag. Ik ben ontzettend blij dat jullie naast me willen staan tijdens mijn promotie. Lotte, hoewel je het de laatste tijd heel erg druk hebt hoop ik dat we toch nog geregeld samen kunnen gaan shoppen of een relaxdagje kunnen organiseren. Caroline, je was een super toffe kamergenote! En ook al werk je nu ergens anders, we blijven goede vriendinnen, en ik ben er zeker van dat we elkaar regelmatig blijven zien, voor een gezellige babbel of één van je lekkere erentjes. 
Heel speciale dank aan Theo woor het ontwerpen van een essentieel onderdeel van dit proefschrift: de moote kaft. Ik had in het begin niet zo'n duidelijk beeld wan hoe het er moest gaan uitzien, maar jouw creativiteit en harde werk heeft tor dit mooie resultaat geleid.

Zelfs all is het al een tijd geleden, toch denk itk nog aan de mensen die me overtuigd hebben om verder te gaan in het onderzoek; Margot, Roxane, Fernanda, Guillaume et Magali: merci pour le temps exeptionelle que j'ai pu passer à Toulouse; c'est grace à votre passion pour la recherche que jai aussi choisi pour la recherche. Merci aussi pour les amitiés qui continue encore toujours.

Natuurlijk niet te vergeten: mijn familie, en dan in het bijzonder mama en Peter, Lotte en Sven, en Sanne; merci voor jullie onvoorwaardelijke steun, woor alle goede zorgen en dat ik altijd bij jullie terecht kan. Tante Lut; dank je voor de vele huisruil vakanties de plezierige kaartavonden en slappe-lachbuien. Ook de families Beulen en Könings, ontzettend bedankt voor jullie aanmoedigingen en gezelligheid.

En als allerlaatste, mijn steun en toeverlaat, Bas, al tien jaar blijf je me verbazen. Bedankt dat je er altijd voot me bent en voor je woor sommige niet te volgen humor. 


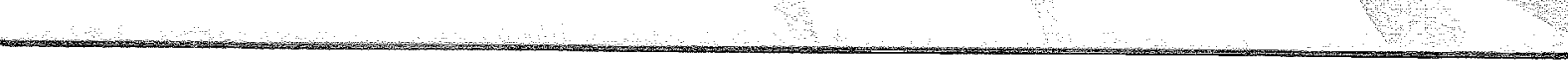




\section{Curriculum Vitae}

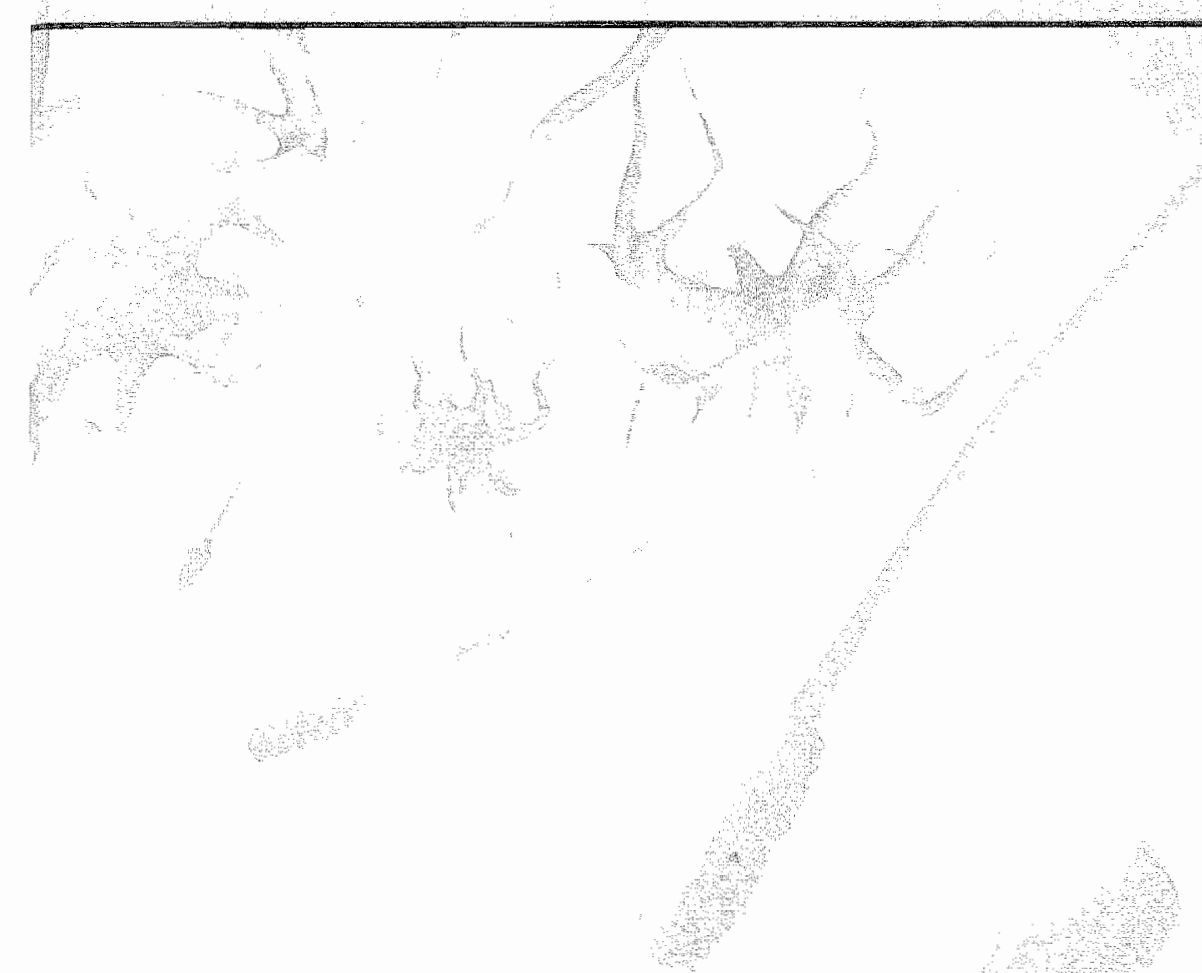


Eef Theunissen werd op 1 mei 1977 geboren. In 1995 behaalde zij het diploma moderne talen - menswetenschappen aan het KSO te Borgloon. Aansluitend begon zij met de studie Psychologie aan de Universiteit Maastricht, waarbij ze koos voor de afstudeerrichting ontwikkelingspsychologie. Ze beèindigde de opleiding met een extra stage aan het Centre de Recherche Cerveaux et Cognition in Toulouse. Het doctoraal diploma psychologie behaalde ze in januari 2001. In april van hetzelfde jaar startte ze als assistent in opleiding bij het instituut Hersenen en Gedrag binnen de vakgroep Neurocognitie. Daar heeft zij onderzoek verricht naar de effecten van antihistaminica op cognitieve en psychomotorische functies, onder leiding van dr. J. Ramaekers en Prof. dr. W. Riedel. Momenteel is zij werkzaam als post-doc bij de vakgroep Neurocognitie, faculteit Psychologie aan de Universiteit Maastricht. 


\section{Publications}

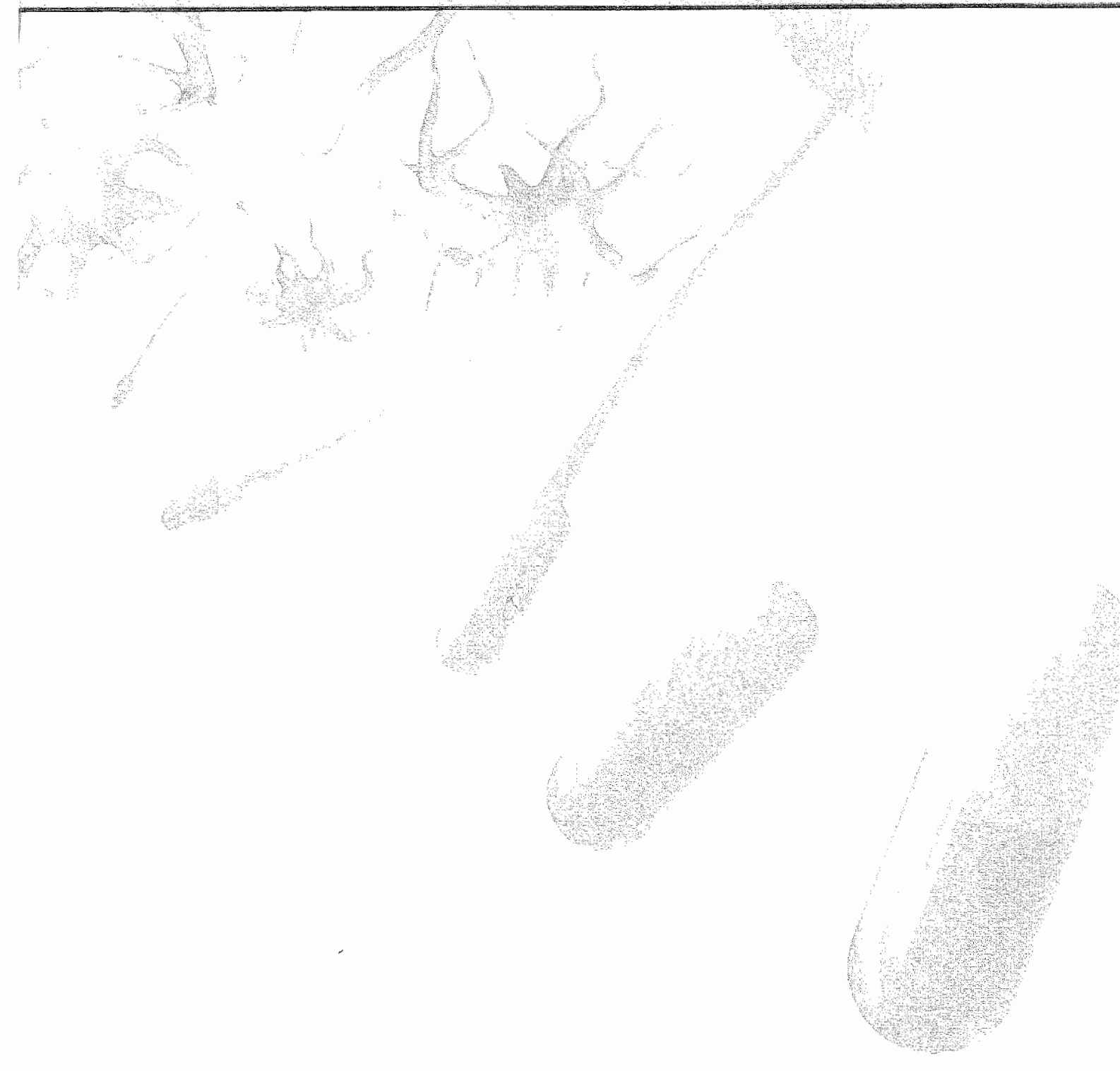


Theunissen, E. L., Alain, C. Chevalier, H., Ge Taylor, M. J. (2001). Binding occurs ar atly stuges of processing in children and adults. Nemowpors, $1291,104941954$.

Theurissen, E. L, Vermeeren, A., Oers, A. C. M., van Maris, I. S Ranatker, O. (2003) Acureand subchronic effecs of mequitaze on actual drivig memory and psychomotor performance as compared to dexchlorpheniramine, cetricine and placebo. Alergy, $58($ Suppl), 283.

Themissen, E. L., Vermeeren, A., van Ders, A. C. M, van Maris, L. \& Ramelker, ). G. (2003). Acute and subchonic effects of mequitazine on actual driving memory and prychomotow peromance as compared to dexchlorpheniramine, cetirizine and placebo. Jound of Psychohamacolagi, 17 (Supp), A63.

Theunissen, E. L., Jonkman, L. M., Kuypers, K. P. C., \& Ramakers, J. G. 2004). Fexofenatine's eflect

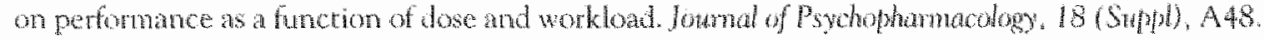

Theunissen, E. L., Vemeeren, A., \& Ramakers, J. G. (2004). Effects of the antihisumines mequitizine on actual ariving and cogritive performance. Procedings af the 17 th International Conference on Alcohol, Dhugs and Traffe Safety. 099

Theunissen, E. L., Vermeeren, A., van Oers, A. C. M., van Maris, I. S Rameken, J. G. (2004). A dose ranging study of the effects of mequitazine on actual driving, memory and pspehumotor perfonmance as compared to dexchlorpheniranine, cetirine and placeho. Clinical and Expremental Allerg, $34(2), 250-258$

Theunissen, E. L., Jonkman, L. M., Kuppers, K. P. C. Q Ramakers, ]. O. (In puess). Stimularing effects of fexofenadine under bigh workloat condirions. A combined ncurophysiological and behavioral approach Joumal of psychophumacoligy.

Theunissen. E. L. Vermeeren, A., S Ramackers, J. G. (In press). Repeated-obe eftects of nequitume, cerizume and dexchlorpheniramine on driving and pychomotor performance. British Jestmal of Chancal Phamaiology.

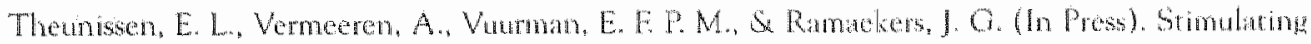
effects of HI antagonists. Cment Phannivetutical Design.

Theunisen, E. L., van Kronenburgh, M. J., wan Doursen, J. A. Blom Conjaerts, C., B Ramekers,

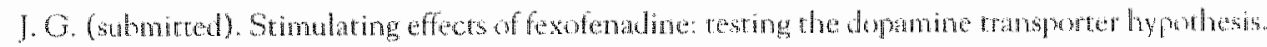

Alain, C., Theursen, E. L. Chevalier, H. Batty, M. \& Taytor, M. J. (2003). Developmental changes

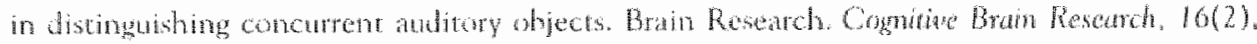
210.218. 

Notes 